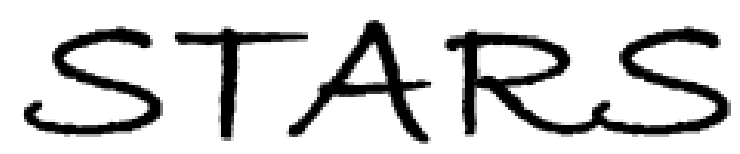

University of Central Florida

STARS

Electronic Theses and Dissertations, 2004-2019

2005

\title{
A Dialectical Methodology For Decision Support Systems Design
}

Wafa Elgarah

University of Central Florida

Part of the Management Information Systems Commons

Find similar works at: https://stars.library.ucf.edu/etd

University of Central Florida Libraries http://library.ucf.edu

This Doctoral Dissertation (Open Access) is brought to you for free and open access by STARS. It has been accepted for inclusion in Electronic Theses and Dissertations, 2004-2019 by an authorized administrator of STARS. For more information, please contact STARS@ucf.edu.

\section{STARS Citation}

Elgarah, Wafa, "A Dialectical Methodology For Decision Support Systems Design" (2005). Electronic Theses and Dissertations, 2004-2019. 549.

https://stars.library.ucf.edu/etd/549

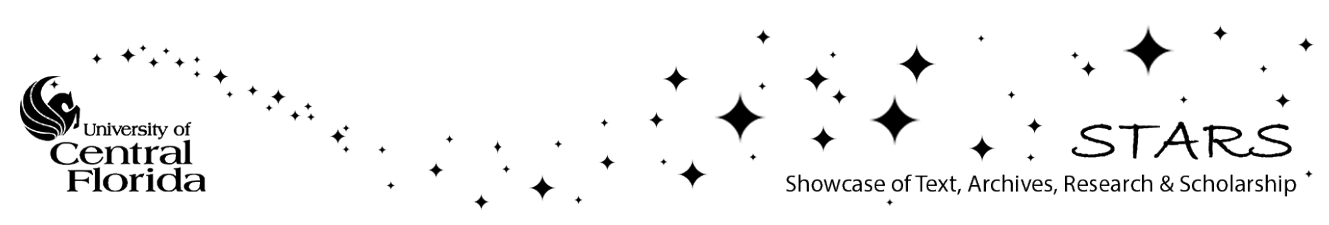




\section{A DIALECTICAL METHODOLOGY FOR DECISION SUPPORT SYSTEMS DESIGN}

by

\section{OUAFAA ELGARAH}

Ph.D. University of Central Florida, 2005

A dissertation submitted in partial fulfillment of the requirements for the degree of Doctor of Philosophy

in the Department of Management Information Systems

in the College of Business Administration

at the University of Central Florida

Orlando, Florida

Fall Term

2005

Major Professor: James F. Courtney 
(C) 2005 Ouafaa Elgarah 


\begin{abstract}
As organizations continue to grow in size, reaching global proportions, they have ever increasing impacts on their environments. Some believe that a much broader array of concerns should be brought into organizational decision-making processes, including greater consideration of social, political, ethical and aesthetic factors (Mitroff and Linstone, 1993; Courtney, 2001). Decision environments such as these are decidedly “wicked” (Rittel and Webber, 1973). Designing decision support systems in such environments where there is a high level of interconnectedness, issues are overlapping and a multiplicity of stakeholders is involved, is a very complex task. In this dissertation a methodology for the development of a DSS for wicked situations is proposed using the design theory building process suggested by Walls et al. (1992). This proposed theory is based on dialectic theory and the multiple perspective approach suggested by Linstone and Mitroff (1993). The design process consists of identifying relevant stakeholders, their respective worldviews, and conflicts in these worldviews. A design (thesis) and “counter design” (antithesis) are created, and a prototype systems based on these designs are developed. These prototypes are then presented to the different stakeholder groups who engage in a dialogue which leads to the development of a synthesized design. The process is repeated until all conflicts are resolved or resources are exhausted, and a final system is produced.

Using action research and system development research methodologies, the proposed design theory was applied to zoning decision process in Orange County, Florida. The results of this study led to the following:
\end{abstract}

1. It is feasible to implement the MPDP methodology proposed in this dissertation. 
2. The MPDP methodology resulted in a synthesized design that accommodates the different views of the stakeholders.

3. The MPDP methodology is suitable for contentious situations and may not be feasible for structured decisions.

4. Most of the subjects did achieve a more understanding of the decision process.

These results suggest that the MPDP design theory can be effective in developing decision support systems in contentious situations. 
To my parents, Naima and Mokhtar. I am very blessed for having you as parents.

In memory of my cousin Tahar Fahmi, your life has touched the lives of many of your family and friends in such a positive way. 


\section{ACKNOWLEDGMENTS}

This dissertation would not have been possible without the dedication and numerous contributions of a large number of people over the past two years. I would like to thank and acknowledge their contributions.

First, I would like to express my gratitude to my Chair, advisor and mentor Dr. James Courtney for his continuous support, patience and encouragement throughout my doctoral studies. Thank you Dr. Courtney for listening and for the valuable advice and enlightenment you provided me during this journey.

My special thanks go to my committee members, Dr. Craig Vanslyke for his support and for providing valuable comments that improved the quality of this study, Dr. Ross Hightower, Dr. Parikh Mihir for their suggestions, Dr. John Haynes for his support and feedback, Dr. Scott Poole for his constructive feedback.

Much credit should go to several individuals who played significant roles in this dissertation. I am very grateful to Mr. Richard Van Slyke for introducing me to the Orange County Planning Department staff and for providing me with valuable information about the whole zoning decision making process. I am thankful to Mr. Chris Testerman, Director of the OC planning department and Mr. John Smogor, for allowing me to conduct my study in the Planning department. Special thanks to Mr. Sargent, for his availability, his patience, and the valuable information he continuously provided me during this whole process. I also would like to express my thankfulness to Rhonda Payne for her time and support.

I am also very grateful to all the elected officials and their staff who took part of this study. Thanks also to all subjects of my study who have all dedicated part of their valuable time to answer my endless questions. 
Thanks also to all my friends and colleagues at the Department of MIS for providing me with great working conditions and support. Special thanks to Dr. Paul Cheney, the Chair of department, for his understanding and his support.

Last but not least, I would like to thank Nidal Bazzi for his continuous support and for his encouraging words when most needed. My deepest gratitude and love for my parents for their unconditional love, dedication and the many years of support during my studies. 


\section{TABLE OF CONTENTS}

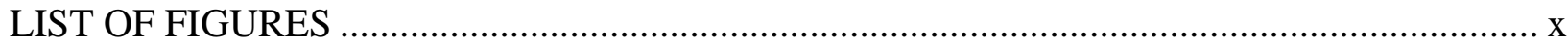

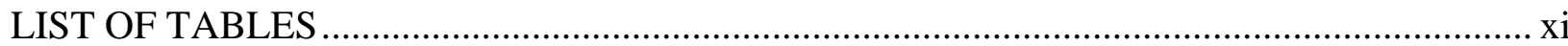

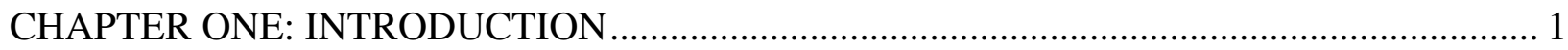

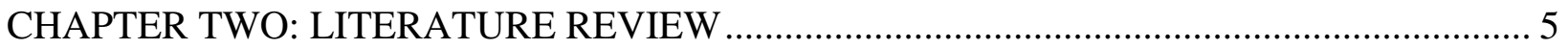

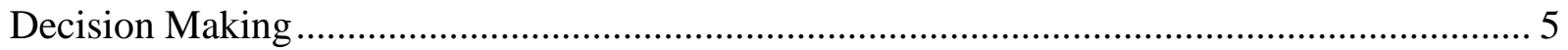

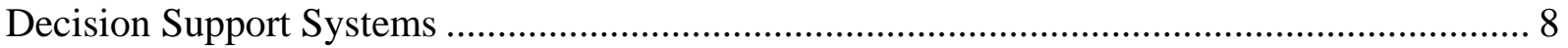

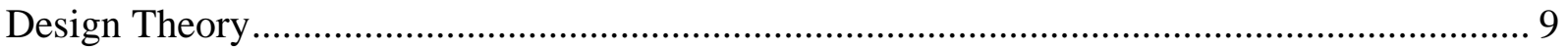

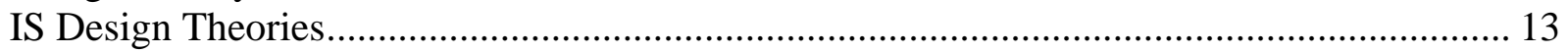

System Development Life Cycle (SDLC) …………........................................................ 13

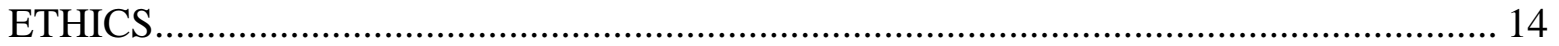

Soft Systems Methodology (SSM) …………………........................................................ 15

The Multiview Approach........................................................................................... 17

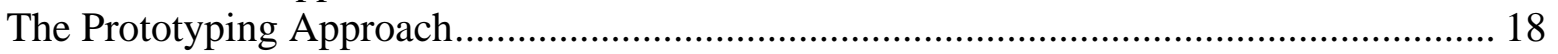

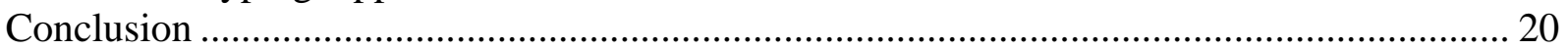

CHAPTER THREE: THE MULTIPLE PERSPECTIVE DIALECTIC PROCESS (MPDP)

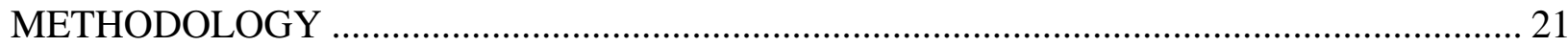

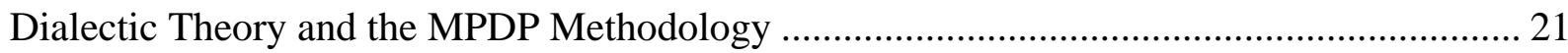

The Multiple Perspectives Approach.................................................................................... 22

DSS Framework for Wicked Situations............................................................................ 24

Multiple Perspective Dialectic Process (MPDP) Methodology .................................................. 26

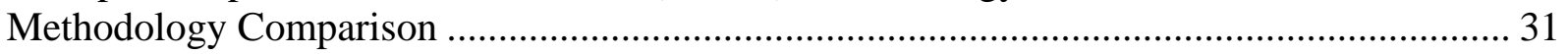

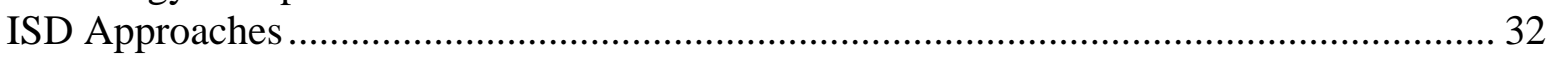

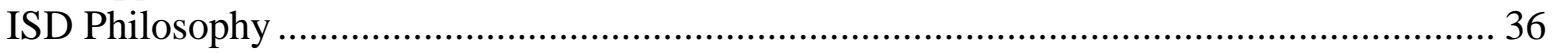

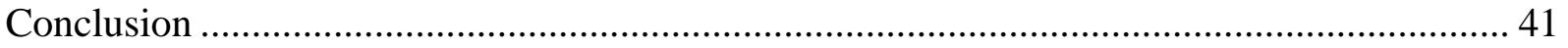

CHAPTER FOUR: RESEARCH METHODOLOGY …………............................................... 43

Research Approach …………………………………................................................... 43

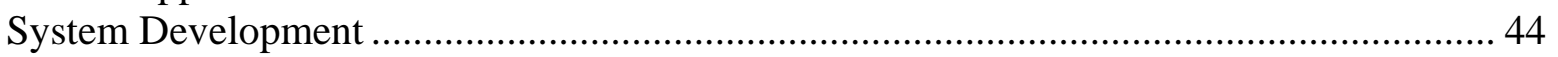

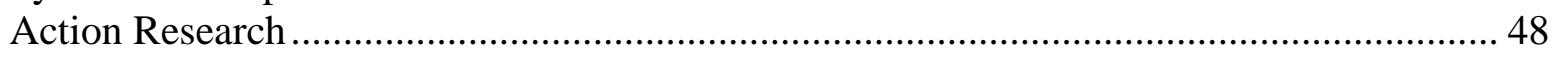

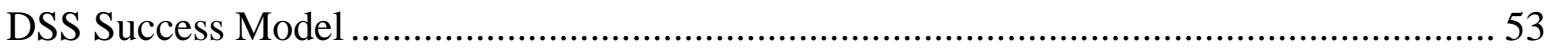

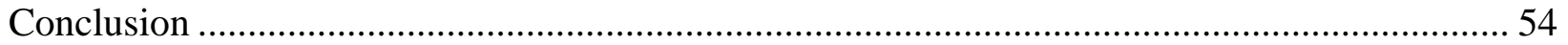

CHAPTER FIVE: THE MPDP METHODOLOGY FIELDWORK - PART I ………................. 55

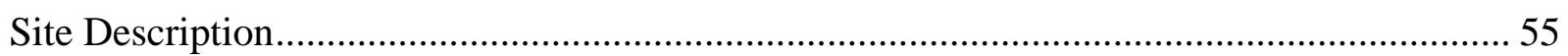

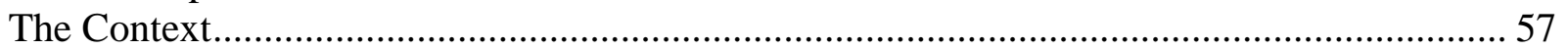

The Orange County re-Zoning Decision Process ………................................................... 57

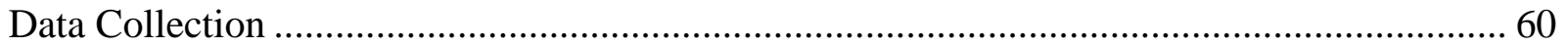

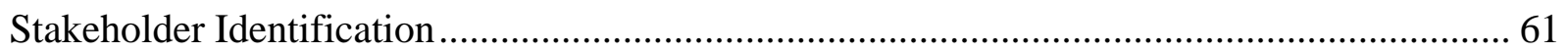

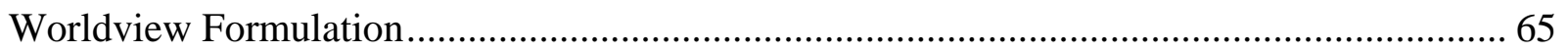

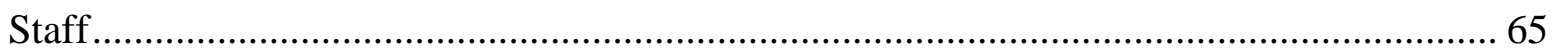

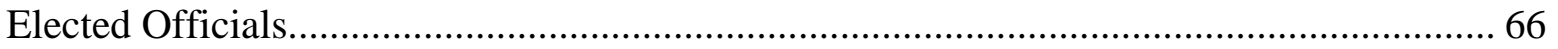

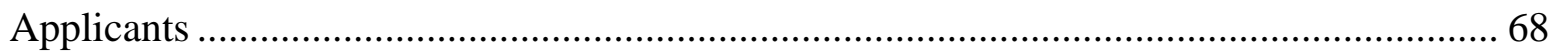

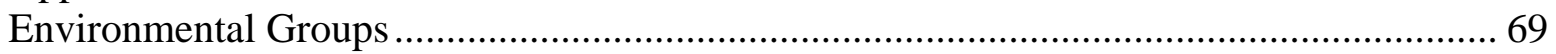

Neighborhood Associations ............................................................................................. 70 
Multiple Perspectives Identification ................................................................................ 71

Decision Factors Determination ..................................................................................... 74

Conflict Identification - Thesis and Anti-thesis..................................................................... 78

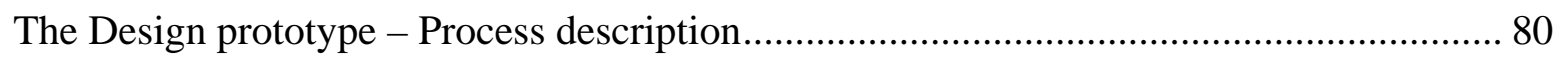

The Counter-design Prototype - Process Description ........................................................ 84

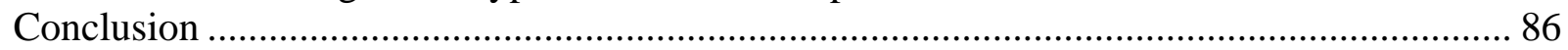

CHAPTER SIX: THE MPDP METHODOLOGY FIELDWORK - PART II ……………….......... 87

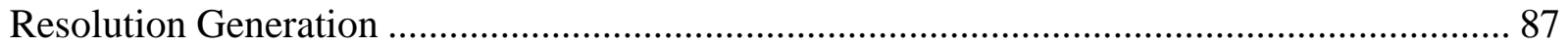

Stakeholder Information Satisfaction and Information Quality......................................... 88

Scenario Development............................................................................................ 98

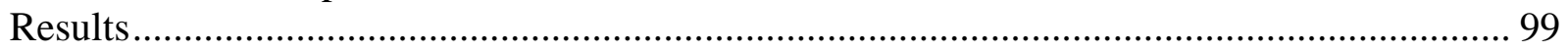

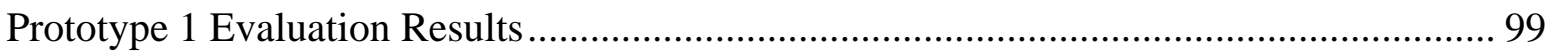

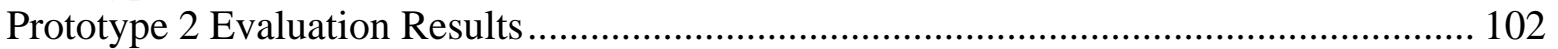

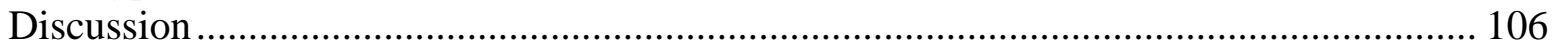

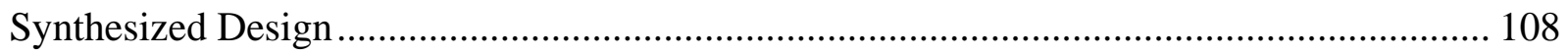

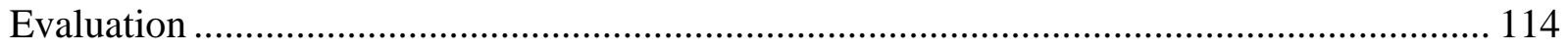

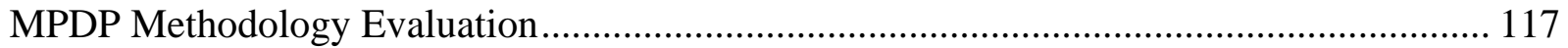

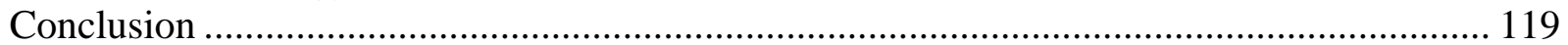

CHAPTER SEVEN: SUMMARY, CONTRIBUTIONS, AND SUGGESTIONS FOR FUTURE

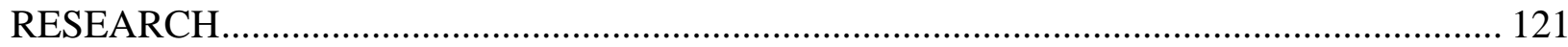

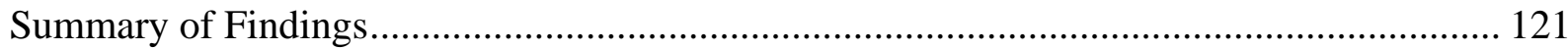

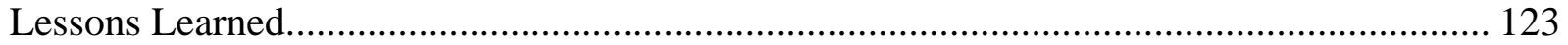

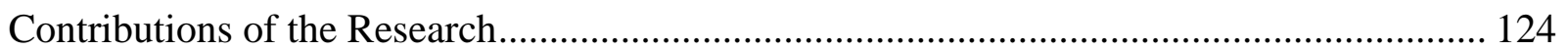

Limitations and Suggestions for Future Research ....................................................... 127

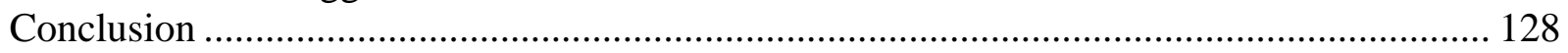

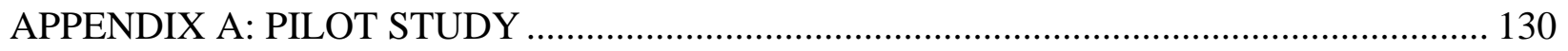

APPENDIX B: STAKEHOLDER GROUPS INTERVIEW GUIDES …………………............ 133

APPENDIX C: STAKEHOLDER GROUPS COGNITIVE MAPS ……................................ 138

APPENDIX D: EXAMPLE OF DISTANCE RATIO CALCULATIONS …............................. 142

APPENDIX E: STAKEHOLDER GROUPS ASSOCIATION MATRICES ………................... 146

APPENDIX F: PROTOTYPE EVALUATION INTERVIEW GUIDE ...................................... 150

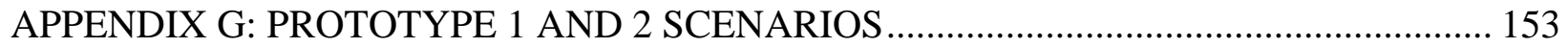

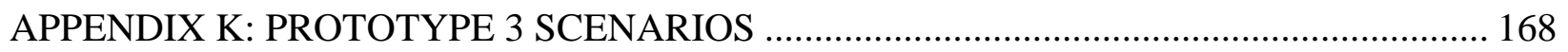

APPENDIX L: PROCESS EVALUATION INTERVIEW QUESTIONS …….......................... 187

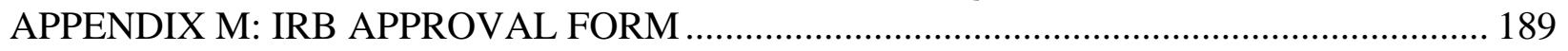

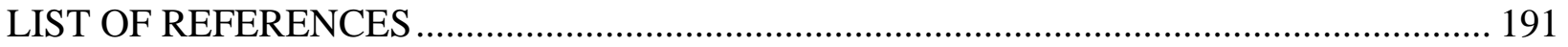




\section{LIST OF FIGURES}

Figure 1. Courtney's Model of the Multi-Perspective Decision Process ...................................... 2

Figure 2. Multiple perspectives and dialectic framework to decision-making .......................... 26

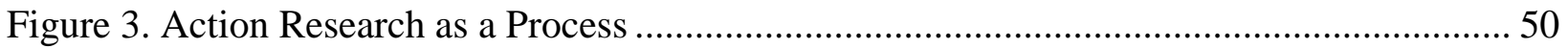

Figure 4. Research Strategy Using Susman and Evered's Cyclical Approach.......................... 53

Figure 5. Interviews stages in the MPDP methodology ...................................................... 61

Figure 6. Stakeholder Relationship Diagram Note: Shaded boxes are stakeholders and non-

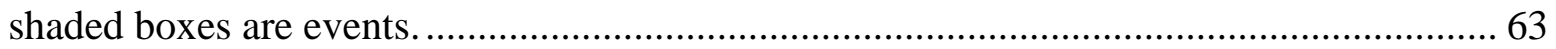

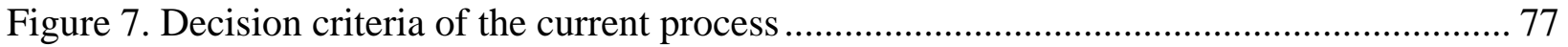

Figure 8. Distance ratio formula by Markoczy and Goldberg (1995) ..................................... 79

Figure 9. Design prototype Use Case diagram .............................................................. 81

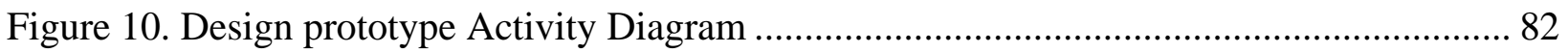

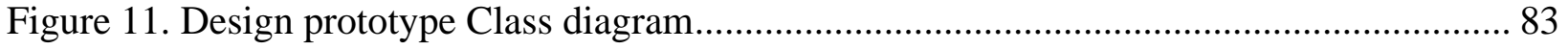

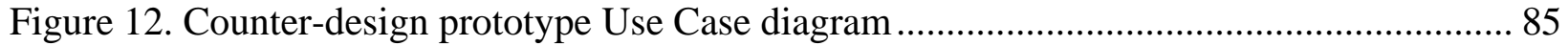

Figure 13. Counter-design prototype Activity Diagram .................................................... 85

Figure 14. Counter-design prototype Use Case diagram ....................................................... 86

Figure 15. Synthesized Design Prototype Use Case diagram............................................... 112

Figure 16. Synthesized Design Prototype Activity Diagram.............................................. 112

Figure 17. Synthesized Design Prototype Class diagram ..................................................... 113 


\section{LIST OF TABLES}

Table 1. Components of an Information Systems Design Theory........................................ 11

Table 2. Illustration of the MPDP methodology stages using the pilot study as an example....... 28

Table 3. Summaries of the Four IS Development Approaches .............................................. 35

Table 4. Summary of the Six Methodology Comparison ...................................................... 41

Table 5. Evaluation criteria for system development research methodology ........................... 48

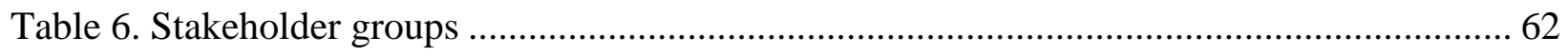

Table 7. Stakeholders perspectives and their views on the current process decision factors ....... 74

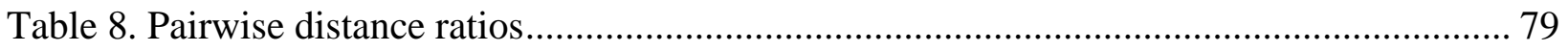

Table 9. Information quality measures (adopted from Delone and Mclean 1992).................... 89

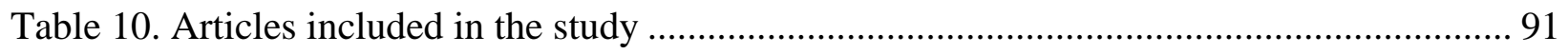

Table 11. Dimensions’ definitions and their equivalent constructs ........................................ 92

Table 12. Information quality dimensions used in the studies sample ................................... 94

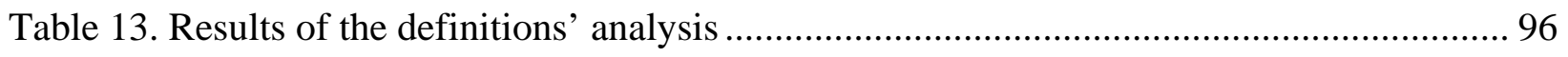

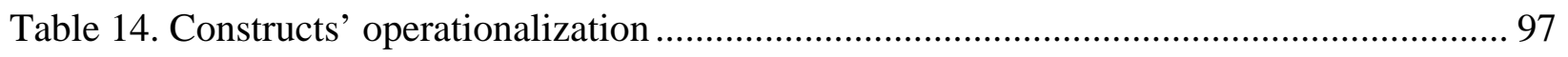

Table 15. Decisions of the three scenarios by each prototype ............................................... 98

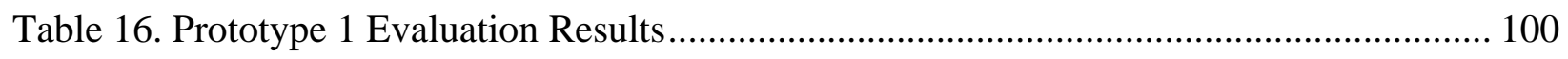

Table 17. Missing data from prototype 1 report grouped by stakeholders groups .................... 102

Table 18. Prototype 2 Evaluation Results.......................................................................... 104

Table 19. Missing data from prototype 2 report grouped by stakeholders groups .................... 105

Table 20. Information used in the decision of the design vs. the counter-design..................... 108 
Table 21. Portion of the information presented in each prototype that is considered essential for or instrumental in completing a zoning decision .................................................... 110

Table 22. Information used in the synthesized design decision......................................... 111

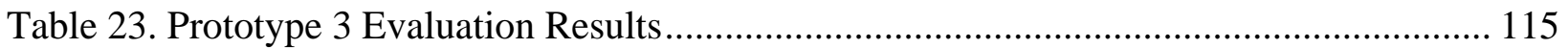

Table 24. Quotes from some respondents concerning the type of situations the MPDP methodology would be useful for 118 


\section{CHAPTER ONE: INTRODUCTION}

Organizational environments are becoming increasingly complex, changing radically and discontinuously (Kelly, 1998; Malhotra, 1997). In today's environment, corporations must consider a vast array of increasingly vocal stakeholders, ranging from consumer groups to environmental activists, governmental agencies, the media and even terrorists. Public agencies are no exception and also find themselves in more challenging managerial environments. It is essential that organizational decision-making processes include greater consideration of social, political, environmental, ethical, and other factors (Mitroff and Linstone, 1993; Courtney, 2001).

Decision environments such as the ones mentioned above are decidedly "wicked” (Rittel and Webber, 1973), in that they have no definitive problem formulation, in fact, formulating the problem is the problem. Further, the answers to wicked problems are not true or false, but good or bad; hence, wicked problems involve ethical issues. And they have no stopping rule, the problem solver quits when resources are exhausted or a "satisfactory" solution has been found. In addition, wicked problems are highly interrelated, and each wicked problem is to be found in every other wicked problem.

It has been argued that Churchman's (1971) Hegelian and Singerian inquiring systems provide frameworks for dealing with wicked problems (Mitroff and Linstone, 1993; Chae and Courtney, 2000; Courtney, 2001; Haynes, 2001). Wicked problems require a pluralistic approach in which the problem is viewed from the many and varied perspectives of the numerous stakeholders involved, and, because they are so highly interconnected, require a holistic view of the problem situation (Mitroff and Linstone, 1993). Courtney (2001) has proposed a decisionmaking paradigm for decision support systems based on the Singerian model and the Mitroff and 
Linstone multiple perspective approach (Technical (T), Organizational (O) and Personal (P)) (Figure 1). Courtney illustrated some of the holistic aspects of the model in decisions related to urban planning and infrastructure management.

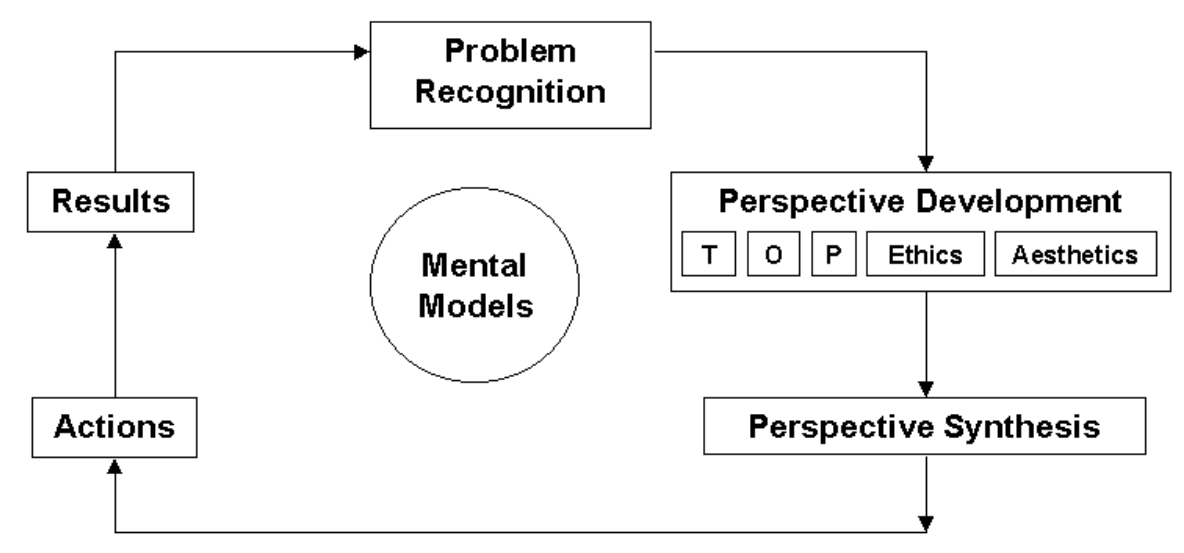

Figure 1. Courtney's Model of the Multi-Perspective Decision Process

The design of a DSS for wicked decision environments is complicated by the multiplicity of the stakeholders involved and the pervasive nature of conflicts among their perspectives. The work herein is predicated on the assumption that, for the results of a DSS to be acceptable to decision makers in this environment, attempts must be made to accommodate conflicting views into the design process itself. Currently, no DSS design methodology suitable for use in such a complex, conflict-filled situation as this has been developed. Thus, the main purpose of this study has been to develop a methodology for DSS design that identifies the nature of conflicting perspectives, so that they can at least be acknowledged, if not actually accommodated by the designers.

The proposed approach arose from a US National Science Foundation project to develop a DSS for infrastructure decision making in the city of Houston. This turned out to be a highly 
complex process, involving stakeholders ranging from the mayor and city council to the planning, public works and finance departments of the city, contractors, the media and ordinary citizens and taxpayers. Problems of this sort are legion in governments of all types, and the research team responsible for the whole project could not find a suitable design methodology for such an environment. Thus the proposed methodology presented in this study is intended to fill this gap. The approach to developing this methodology is based on dialectic theory and a multiple perspective approach. By using dialectic theory, potential barriers to DSS implementation will be isolated and ways to overcome those barriers will be provided. The multiple perspective approach is used to avoid the pitfalls and the limitations of the technical perspective (Mitroff and Linstone, 1993) currently used in most DSS.

The proposed design methodology may not be suited for clear-cut problems. For clearcut problems, conflict may be a time-consuming nuisance (Mason and Mitroff, 1973). The methodology is best suited for ill-defined problems that are characterized by the following : (1) The number of stakeholders is large, (2) each stakeholder group has different vested interest in the decision or problem to be solved, (3) there is disparity of power and or resources among the stakeholder groups, (4) the stakeholder groups have different levels of expertise about the problem domain, (5) there is a high degree of conflict among and between the stakeholder groups, (6) technical solutions to the problem are never satisfactory, (7) there are many factors and variables to consider that are interconnected in such a way that it is difficult to fully comprehend the problem, (8) the problem domain is dynamic meaning that as you learn about the environment and the problem domain and as time goes by new variables and/or constraints may appear thus changing the problem definition. 
Examples of problems with these characteristics include city planning decisions, infrastructure decisions, zoning decisions, fighting terrorism, etc. Most social problems and public sector decisions can be candidates to which the proposed methodology can be applied. As societies, businesses, nations and cities grow and become more interconnected, the number of problems grows exponentially making the domain of application of the proposed methodology a vast one.

This proposed work consists of three major phases: (1) develop a DSS design methodology for wicked decisions based on dialectic theory and multiple perspectives using the design theory process proposed by Walls, et al. (1992), and exemplified by Markus, et al. (2002) (2) apply the methodology to an actual project using an action research approach and (3) formally evaluate the system developed and the design methodology using appropriate dimensions of DSS success measures. 


\section{CHAPTER TWO: LITERATURE REVIEW}

In this chapter, I review relevant literature in decision making, decision support systems and design theories. In particular this review focuses on identifying and describing different design theories. I argue that the current design theories are not feasible for developing DSS for contentious decisions. Finally, I conclude this chapter with an argument for the need for a new design theory for developing DSS for wicked situations.

\section{Decision Making}

Before diving into the discussion about DSS and the proposed design theory, I feel that it is necessary to discuss the decision making process and present some approaches to decision making from the literature. Such discussion is relevant to the present study as decisions are the output of Decision Support Systems.

Decision making is the process by which an individual or a group evaluates and selects among various alternatives. Simon (1969) described the decision-making process as consisting of three phases: (1) Intelligence - used in the military sense - searching for the problem, the need to make a decision, (2) Design - developing alternative ways of solving the problem, (3) Choice - analyzing the alternative and choosing the one as solution for implementation.

There are different types of decisions, Simon (1969) distinguished between two polar types: programmed decisions and nonprogrammed decisions. Programmed decisions are those that are repetitive and routine. They have a predefined set rules that decision-makers can follow to reach the final decision. Programmed decisions are those found in well-structured situations. 
Nonprogrammed decisions on the other hand are novel, unstructured and sequential (Simon, 1969, p.7). There are no predetermined decision rules and procedures for handling these types of decisions. The situations in which these types of decisions occur are by nature complex, ill structured and characterized by the multiplicity of stakeholders. These different types of decisions call for different approaches to decision making.

One of the most challenging areas in non programmed decisions is reaching group consensus on objectives, decision factors and priorities. There are many techniques and approaches that have been developed for organizing information involved in making such decisions. These include techniques such as Dialectic inquiry, devil's advocacy, and Analytic Hierarchy Process.

Analytic Hierarchy Process (AHP) is an approach to decision making. It is based on three principles (Saaty, 1995, p. 17): (1) the principle of constructing hierarchies, (2) the principle of establishing priorities, and (3) the principle of logical consistency. AHP provides an effective structure for group decision making by imposing a discipline on the group's thought processes (Saaty, 1995). The fundamental concept of AHP is that it works by developing priorities for alternatives and criteria used to judge alternatives. Basically, AHP works by breaking down a complex, unstructured situation into its components parts; arranging these parts, or variables, into hierarchic order; assigning numerical values to subjective judgments on the relative importance of each variable; and synthesizing the judgments to determine which variables have the highest priority and should be acted upon to influence the outcome of the situation (Saaty, 1995, p. 5). The problem with the AHP is that it is largely quantitative, it is often criticized for the way the criteria weights are elicited (Karsak, 2002). Additionally, the AHP adopt a reductionist approach rather than a systems approach. When one breaks a complex 
system into more manageable parts, information is lost even if we tried to aggregate and/or synthesis the parts later in the process. In fact, Aristotle noted that "the whole is greater than the sum of its parts.” Therefore, when one breaks the whole into parts and then aggregates them to form the whole, the result may not necessarily form the whole again. Concomitantly, Avison and Fitzgerald (1995) warned against the reductionist approach and noted that "something is lost when the whole system is broken up in the 'reductionist' approach of scientific analysis” (Avison and Fitzgerald, 1995 p. 365). Thus, AHP does not support the systems approach, which suggests that we must try to develop decisions for the whole system rather than for functions in isolation.

Dialectic inquiry and devil advocacy are both based on the use of constructive group conflict (Cosier, 1982, Mason, 1969). Some researchers have argued that the conflict approach in both methods produces higher quality decision than other approaches that do not promote conflict and debate (Mason and Mitroff, 1981, Mitroff et al., 1979). The difference between Dialectic inquiry and devil advocacy is that the later relies on critique of single sets of recommendations and assumptions whereas dialectic inquiry uses debates between diametric sets of recommendations and assumptions (Schweiger et al., 1986). Devil advocacy is less effective in developing quality alternative assumptions as opposed to dialectic inquiry, hence dialectic inquiry leads to better quality solutions than devil’s advocacy (Mason, 1969, Schweiger et al., 1986). Opponents to these conflict driven approaches argue that the inherent debate and argumentation may lead to damaged feelings among member of the group and therefore individuals may not be willing to work the same members in the future (Schweiger et al., 1986). However, if properly managed and controlled, conflict can be very beneficial to the decision making process. In this study, dialectic inquiry is used in the design process of developing decision support systems in wicked situations. 


\section{$\underline{\text { Decision Support Systems }}$}

Decision support systems research is relatively young field compared to other disciplines such as economics, psychology, and organizational behavior. DSS technologies and applications have evolved significantly since the early 1970s. DSS research has evolved from two main research streams: the theoretical studies of organizational decision making conducted at what was then the Carnegie Institute of Technology (now Carnegie Mellon University) during the late 1950s and early 1960s and the technical work carried out at Massachusetts Institute of Technology in the 1960s (Shim et al. 2002, p. 111). The term decision support systems was coined in the early 1970's (Eom, 2002). DSS was then referred to by terms such as computerbased decision system, computer-aided decision systems and management support systems. Several definitions have been suggested for DSS (Little, 1970, Sprague, 1980, Gorry and Morton, 1978, Alter, 1980, Keen, 1980). In this study, I will adopt the definition suggested by Keen and Morton (1971) because it seems to be a complete one. According to Keen and Morton (1978) Decision Support Systems imply use of computers to assist managers in their decision processes in semi-structured tasks, support, rather replace, managerial judgment and improve the effectiveness of decision-making rather than its efficiency.

There are several research streams within the study of DSS. Since its inception DSS had a strong focus on decision makers and decision processes (Keen, 1997). However, with the introduction of PCs, spreadsheets, and graphical user interfaces, the focus has shifted and the system not the decision and support has become the focus. As Keen (1997) noted "we lost the 'D' in DSS.” Eom (2002, p.15) identified three groups of research areas in DSS (1) developing a specific DSS; (2) Developing DSS theory by either developing theory on decision makers, data, 
model and interface or developing theory on design, implementation and evaluation; (3) Study of contributing disciplines. The current study focuses on the development of theory about design, implementation and evaluation of a DSS in a wicked situation. DSS information needs and models differ from the information needs of most organizational information systems (Gorry and Morton, 1971), hence the need for new design theories that address the specific needs of a DSS.

\section{Design Theory}

To develop a design theory for DSS in wicked situations, the design theory building process proposed by Walls, et al. (1992) will be adopted. A design theory is a prescriptive theory based on theoretical underpinnings which state how a design process can be carried out in a way that is both effective and feasible (Walls, et al. 1992). Design is central to the information systems discipline. Design is defined as "the use of scientific principles, technical information and imagination in the definition of a structure, machine or system to perform pre-specified functions with the maximum economy and efficiency” (Fielden 1975, cf. Walls, et al. 1992). Much of the research in information systems deals with design-related issues. Given that theory development is an important pursuit in any discipline, the IS discipline needs to articulate and develop a class of “design theories” (Walls, et al. 1992). Walls, et al. argued that design theories have several characteristics. They are prescriptive and must deal with goals as contingencies. They can never involve pure explanation or prediction. They are composite theories which encompass kernel theories from natural science, social science and mathematics. Additionally, while explanatory theories tell "what is," predictive theories tell "what will be,” and normative theories tell "what should be," design theories tell "how to/because.” Furthermore, they show how explanatory, 
predictive, or normative theories can be put to practical use. Design theories are theories of procedural rationality (Walls, et al. 1992, p. 41).

Design theory according to Walls et al. has two main components: Design product and design process. Design product is "plan of something to be done or produced." It consists of defining the meta-requirements, meta-design, kernel theories and testable hypotheses (Walls, et al. 1992, p. 42). Meta requirements describe the class of goals to which the theory applies. Metadesign describes a class of artifacts hypothesized to meet meta-requirements. Kernel theories are theories from natural and social science governing design requirements. Testable hypotheses are design process hypotheses, which can be used to verify whether is a set to test whether metadesign satisfies meta-requirements. The design process is "to plan and proportion the parts of a machine or structure so that all requirements will be satisfied.” It consists of design method, kernel theories and testable hypotheses (Walls, et al. 1992, p. 43). A design method describes procedures for artifact construction. Kernel theories are theories from natural and social science governing the design process itself. These theories may be different from those identified in the design product. Testable hypotheses are design process hypotheses which can be used to verify whether or not the design method results in an artifact which is consistent with the meta-design. The components of an IS design theory and its application to DSS design in wicked situations are summarized in Table 1. 
Table 1. Components of an Information Systems Design Theory

\begin{tabular}{|c|c|c|}
\hline \multicolumn{3}{|c|}{ Design Product } \\
\hline $\begin{array}{l}\text { 1. Meta- } \\
\text { requirements }\end{array}$ & $\begin{array}{l}\text { Describe the class of } \\
\text { goals to which the theory } \\
\text { applies }\end{array}$ & $\begin{array}{l}\text { Include perspectives of all stakeholder groups } \\
\text { Isolate conflicts among stakeholder groups } \\
\text { Accommodate those perspectives in the final DSS } \\
\text { design and implementation }\end{array}$ \\
\hline 2. Meta-design & $\begin{array}{l}\text { Describes a class of } \\
\text { artifacts hypothesized to } \\
\text { meet the meta- } \\
\text { requirements }\end{array}$ & $\begin{array}{l}>\text { Models to address the decision in its context } \\
>\text { Tools that promote open dialogue and facilitate } \\
\text { debate } \\
>\text { Data necessary for the decision }\end{array}$ \\
\hline 3. Kernel Theories & $\begin{array}{l}\text { Theories from natural or } \\
\text { social sciences governing } \\
\text { design requirements }\end{array}$ & $\begin{array}{l}>\text { Dialectic Theory (Hegel) } \\
>\text { Multiple Perspectives (Mitroff and Linstone, 1993) }\end{array}$ \\
\hline $\begin{array}{l}\text { 4. Testable } \\
\text { hypotheses }\end{array}$ & $\begin{array}{l}\text { Used to test whether the } \\
\text { meta-design satisfies the } \\
\text { meta-requirements }\end{array}$ & $\begin{array}{l}\text { Building and testing the prototype } \\
\text { Measuring DSS success using adapted IS success } \\
\text { instruments }\end{array}$ \\
\hline \multicolumn{3}{|c|}{ Design Process } \\
\hline 1. Design method & $\begin{array}{l}\text { Procedure(s) for artifact } \\
\text { construction }\end{array}$ & $>$ MPDP methodology \\
\hline 2. Kernel theories & $\begin{array}{l}\text { Theories from natural or } \\
\text { social sciences governing } \\
\text { design process itself }\end{array}$ & $\begin{array}{ll}> & \text { Dialectic Theory (Hegel) } \\
> & \text { Multiple Perspectives (Mitroff and Linstone, 1993) }\end{array}$ \\
\hline $\begin{array}{l}\text { 3. Testable } \\
\text { hypotheses }\end{array}$ & $\begin{array}{l}\text { Test whether the design } \\
\text { method results in an } \\
\text { artifact which is } \\
\text { consistent with the meta- } \\
\text { design }\end{array}$ & $\begin{array}{l}\text { Building and testing the prototype } \\
\text { Measuring stakeholder groups satisfaction with the } \\
\text { design process (methodology) and the prototype. }\end{array}$ \\
\hline
\end{tabular}

Design theory is much related to design science. Both concepts of design theory and design science were introduced by Simon (1969) in his book, The Sciences of the Artificial. Research using design science as a methodology often results in the building of new systems and evaluating their feasibility in solving the problem under investigation. Design science is recognized as a research methodology in IS (Ball, 2001) and is widely accepted and adopted in the engineering and computer science disciplines. The IS discipline in general has also focused 
on the natural science paradigm since its inception. Nunamaker et al. (1991) classified design science as an applied research methodology, or research that applies knowledge to solve practical problems. Design science results in the creation of artifacts. March and Smith (1995) define design science as those activities that a researcher participates in to "create things that serve human purposes.”

March and Smith (1995, pp. 253-258) argue that design science leads to four types of outputs: constructs, models, methods, and implementations. The constructs constitute the vocabulary of a domain and conceptualizations used to describe problems within the domain. Models are a set of propositions expressing relationships among constructs. A model can be viewed as a description or a representation of how things are. Both constructs and models serve as ways to describe the relationship between the artifact and its environments. Methods are sets of steps used to perform a task. They are based on the construct and the models of the solution space. Implementation is simply the realization of the artifact in its environment.

Example of IS design theories and design science projects include the System Development Life Cycle (SDLC), the prototyping approach used in most DSS projects, the socio-technical ETHICS method (Mumford, 1983), the Multiview framework (Avison and Wood-Harper, 1990), and the soft systems methodology (Checkland, 1989). None of these design methods were developed specifically for wicked situations characterized by the multiplicity of the stakeholders involved and the pervasive nature of conflicts among their perspectives. Additionally, the design process for effective DSS is generally different and necessarily more complex than that of information systems (Moore and Chang, 1980). 


\section{$\underline{\text { IS Design Theories }}$}

There are number of design approaches and methodologies that can be applied to the process of IS design and development. Recent studies have identified more than 100 different approaches to the design and construction of IS technologies (Hirschheim et al., 1997, Avison and Fitzgerald, 1995). In this section, I will explore five different design theories, namely the SDLC, Soft System Methodology (SSM), ETHICS, Multiview, and Prototyping. These five design theories were selected based on different IS development approaches (Iivari, Hirschhiem and Klein, 1998, 2000/2001): Structured approach (SDLC and Prototyping), Socio-technical approach (EHTICS) and Soft Systems approach (SSM). Multiview is considered a hybrid of both the socio-technical and soft systems approaches.

\section{System Development Life Cycle (SDLC)}

SDLC has evolved over the past several decades and is widely accepted structured approach to the analysis and design of information systems. It was designed in the late 1960s by the National Computing Center (NCC) in the United Kingdom (Avison and Fitzgerald, 1995). SDLC is often referred to as a waterfall model. It is composed of a common set of phases and activities that serve as a guide to the development process. These include preliminary investigation, analysis phase, logical design, physical design, and implementation.

This traditional systems analysis and design method has a number of strengths. It is well accepted and has been tested many times. The sequential nature of the SDLC makes it easy to monitor and review progress. By dividing the development of a system into phases, each sub-

divided into more manageable tasks, along with the improved training and the techniques of 
communication offered gives greater control over the development process (Avison and Fitzgerald, 1995).

Although the SDLC is a widely accepted and adopted system methodology, it did not escape criticisms. One criticism is the fact that the time necessary to go through all the phases of the development has become prohibitive in today's fast paced world (Marakas, 2001). This lengthened development comes with increased cost of development. Other weaknesses of the SDLC include (Avison and Fitzgerald, 1995): instability, inflexibility, user dissatisfaction and lack of control. Additionally, SDLC has been criticized for failing to meet the needs of management. Management information needs, such as that required when making decisions as where to locate a new factory, which product to stop selling are neglected. The SDLC is not feasible for ill-structured problems especially the ones that are hard to define.

\section{ETHICS}

The ETHICS (Effective Technical and Human Implementation of Computer-Based Systems) methodology was developed by Enid Mumford to successfully integrate the objectives

of an organization and at the same time optimize human gain. It is presently being widely used in firms in the UK and its use is starting to spread in the USA. It is based on the participative design and socio-technical approach. Mumford (1983) defines the socio-technical approach as being: 'one which recognizes the interaction of technology and people and produces work systems which are both technically efficient and have social characteristics which lead to high job satisfaction.' ETHICS main purpose is to improve the efficiency of a system and enhance job satisfaction for the user. This design methodology enables the user to play an active role in the 
design process. Ethics is made up of 15 steps which come together to make the whole system (Avison and Fitzgerald, 1995). They consist of (1) establish the need for change, (2) defining system boundaries, (3) describing the existing system, (4-6) defining key objectives and tasks, (7) diagnosing efficiency needs, (8) diagnosing job satisfaction needs, (9) conducting future analysis, (10) specifying and weighing efficiency and job satisfaction needs and objectives, (11) organizational design of the new system, (12) determining technical options, (13) preparing a detailed work design, (14) implementation, (15) evaluation.

The strength of ETHICS is in its context sensitivity and intensive user participation. The participatory approach of the methodology helps improve job satisfaction and create a sense of ownership in the users which is intended to lead to successful implementation. A weakness of the method is in the lack of formality and dynamics. Unlike structured methods, ETHICS does not clearly indicate when to move on to the next step. Additionally, it provides no support for testing and maintenance.

\section{Soft Systems Methodology (SSM)}

SSM was developed by Peter Checkland in late 70's and early 80's. Soft Systems Methodology is a learning system (Checkland, 1989). It explicitly focuses on problem formulation by helping identify the "relevant" systems from the perceptions of different stakeholders (Hisrchheim et al., 1997). Von Bulow (1989) summarized the overall purpose of SSM as follows:

"SSM is a methodology that aims to bring about the improvement in areas of social concern by activating in the people involved in the situation a learning cycle which is ideally neverending. The learning takes place through the iterative process of using systems concepts to reflect upon and debate perceptions of the real world, taking action in the real world, and 
again reflecting on the happenings using the systems concepts. The reflection and debate is structured by a number of systemic models. These are conceived as holistic ideal types of certain aspects of the problem situation rather than accounts of it. It is taken as given that no objective and complete account of a problem situation can be perceived."

SSM has several assumptions and characteristics:

1. SSM is a process for managing. Managing is interpreted very broadly as a process of achieving organized action. It assumes that managers are reacting and trying to cope with an ever-changing flux of interacting events and ideas. Therefore, managing means reacting to this flux: meaning perceiving, evaluating the flux, deciding upon action, taking action which itself becomes part of the flux, and leading to new perceptions and evaluation and further actions.

2. SSM assumes that different individuals and groups will make different evaluations leading to different actions.

3. SSM stems from the experience of developing it. It takes into account the Weltanschauung (worldview).

4. SSM is an inquiring process. It learns by comparing pure models of purposeful activity with perceptions of what is going on in a real world problem situation.

5. SSM is an articulation of a complex social process in which assumptions about the world are teased out, challenged and tested. It is a participative process because it can only proceed via debate.

SSM consists of seven stages (Checkland, 1989) (1-2) finding out, (3) formulating root definitions, (4) building conceptual models (similar to logical modeling), (5) comparing models and 'reality', (6) defining changes, (7) taking action. It is important to realize that these seven steps, and the relationships between them, are not sequential but iterative. SSM treats both what to do as well as how to do it as part of the problem. SSM is a learning, not an optimizing system. SSM has a number of strengths. Its main strength lies in the fact that the designer tries to create an ideal system and then compares the current situation to the ideal one. SSM's main focus is on behaviors and change. It does not focus on the structure of the system but the purpose of the 
system. SSM promotes the understanding of multiple worldviews. It takes into consideration to social and political views of the organization. It is well suited for messy, changing, ill-defined problem situations (Checkland, 1998).

SSM major weakness from the standpoint of IS development is that its role in IS development is not particularly well articulated (Hirschhiem et al. 1997). Additionally, SSM has been criticized of being very complex and the learning curve is very high, thus making it time consuming. An another important issue with SSM is that it does not involve the user as much as other methodologies such as ETHICS.

\section{The Multiview Approach}

Multiview is an approach that looks at the human and technical aspects of software development and combines some aspects of ETHICS and SSM. Multiview is a contingency approach. The approach adopted is always contingent on the particular situation depending on its complexity and levels of user and analysts competence (Avison, Wood-Harper, 1990). There are five stages to the Multiview development method: analysis of human activity systems, information modeling, analysis and design of the socio-technical system, design of the human computer interface and design of the technical sub-systems. These five stages move from the general to the specific, from the conceptual to hard fact and from issue to task (Avison and Wood-Harper, 1990, p. xiv). Outputs of each stage either serve as inputs of subsequent stages or major outputs of the methodology. These stages consist of (1) analysis of human activity, (2) analysis of information, (3) analysis and design of socio-technical aspects, (4) design of the Human-Computer Interface, (5) design of the technical aspects. 
The main strength of Multiview is that it is a flexible approach to systems development. Its contingent nature makes it feasible for a wide range of problems ranging from complex to small more specific situations. It places a great deal of attention on both the human and the technical views of the problem. A major criticism of the Multiview methodology is that it is time consuming. Additionally, it requires special skills in the designer team to be able to fully take advantage of its approach.

\section{The Prototyping Approach}

In the prototyping approach, designers prototype the system as a way of determining the system requirements. A prototype is a facsimile system that simulates the user interface as well as the data and modeling activities of the system. After the designers meet with the users and decision-makers to determine their basic needs and preferences, they produce a prototype that they believe meets those needs. Next the users are presented with the prototype which they operate as they intend to use the ultimate system. The user experiences all the features of the system including interfaces. The user then provides their feedback to the designers. Armed with this feedback the designers adjust the prototype quickly to respond to the user's needs. This allows the designers to better meet the user's specific needs.

The prototype is a great way to enable designers to communicate concretely and easily with the users. It also reduces the chances of miscommunication and increases the system's adoption success after completion. Concomitantly, it gives the user a great sense of ownership. Prototypes are often developed in fourth generation languages to allow for easy changes and 
updates. Once the user and the decision maker are satisfied with the prototype, the designers then proceed to translate the code into more efficient code that would be easier to maintain.

Prototyping is usually carried out within a systematic framework. This framework consists of four steps (Turban and Aronson, 1998) which include (1) establishing prototype objectives, (2) selecting function to be included in the prototype, (3) constructing the prototype, (4) evaluating the prototype. After each evaluation session, the designers update the prototype based on the feedback received from the user and then subjects it to further evaluation. The process is repeated several times until a fairly stable and comprehensive system evolves. The process continues until the end-user is satisfied with the system. This process is necessary because in complex decisions, the users often do not know exactly what they want, and the system builder does not understand what end-users need or will accept. The iterative process permits mutual learning to occur.

The prototyping approach has many benefits. The most significant benefit is the reduction in development time and generally lower cost compared to other traditional approaches such as the SDLC. Additionally, the iterative nature of prototyping and the immediate user response and feedback regarding the systems features and functionality results in a greater degree of support from the users and the decision maker because it gives them a sense of ownership and makes them part of the design process.

One of the main limitations that is often attributed to the prototyping approach is that it increases the likelihood that the system maintenance will be more difficult than in other approaches such as SDLC. This is caused by the fact that the focus of both the designer and the user in a prototype design is on the immediate functionality and usability of the system rather then on other issues such as ease of maintenance, documentation and adherence to design 
standards. These limitations can be easily overcome by effectively promoting attention to detail and constant reminder of the designer for diligent attention to documentation and its importance.

\section{$\underline{\text { Conclusion }}$}

In this chapter, I have described five design theories and discussed their strengths and weaknesses. A general remark about the above design theories is that they are all user focused. None of the design theories explicitly addresses conflicts and emphasizes the involvement of stakeholders beyond users. That is why I propose a design methodology to address these limitations. The proposed methodology is described in the next chapter and compared to the design theories presented in this chapter. 


\section{CHAPTER THREE: THE MULTIPLE PERSPECTIVE DIALECTIC PROCESS (MPDP) METHODOLOGY}

In this chapter, I describe the proposed design theory and its theoretical underpinnings. I also illustrate the different steps using a pilot study conducted to test the feasibility of the methodology. Then I compare the proposed methodology to the five design theories described in chapter 2. Finally, I conclude the chapter with a presentation of the limitations addressed by the MPDP design theory.

\section{Dialectic Theory and the MPDP Methodology}

The proposed new design methodology is based on dialectic theory. The notion of dialectic has its origin in the medieval art of disputation which in turn, is a product of Platonic and Aristotelian dialectic (McKinney, 1983). The word dialectic is derived from the Geek word

for discourse: dialegein. The modern notion of dialectics is found in Hegel's newer conception of the nature of the development of ideas and reality (McKinney, 1983). For Hegel, dialectic is not only a methodology for understanding, but also an ontology that reveals an evolving world as well (McKinney, 1983). This new notion of dialectic theory by Hegel is built over the assumption that organizational entities exist in a pluralistic world of colliding events, forces or contradictory values that compete with each other for domination or control (Van de Ven and Poole, 1995). The dialectic process strives to dissolve these oppositions and meld them into a complementary whole, rather than simply finding a compromise. It is an argument which is designed to create a richer synthesis by revealing underlying assumptions (Churchman, 1971). 
The starting point in a dialectic process is the thesis, a set of beliefs concerning an issue or problem. At some point in time the thesis appears to be inadequate, perhaps due to changes in the environment, or to changes in tastes and values. The inadequacy is revealed through the questioning of certain assumptions/worldviews of the thesis or by bringing to light certain of its properties that have not been obvious before (Singer, 1983). At this time, the antithesis, the opposite or negation of the thesis, emerges. Eventually, the antithesis then also shows itself to be inconsistent or inadequate. Both the thesis and antithesis are one-sided and they are ultimately brought together in a unified manner in a synthesis. It is important to note that both the thesis and the antithesis are drawn from the same set of data. The synthesis emerges as the result of debate and dialogue related to the elements of the thesis and antithesis. An observer of the debate takes the most plausible elements of each to form a synthesis, which ideally dissolves the previous conflict. The synthesis is usually different from both the thesis and the antithesis, but it includes elements of both of them, so that neither the thesis nor the antithesis continues to exist as a separate entity (Ford and Ford, 1994). But the dialectic movement does not stop at this stage. Oftentimes, the synthesis will reveal itself to be inadequate and will then serve as a new thesis (Singer 1983); eventually an antithesis emerges, and the process reiterates.

\section{The Multiple Perspectives Approach}

When dealing with complex problems or decisions, Mitroff and Linstone (1993) proposed the use of a multiple perspective approach, which promotes heterogeneous views of decision-making. In the past DSS were designed solely using the Technical perspective (T). The technical perspective is suitable for well-structured problems but has many limitations when 
dealing with "wicked" situations (Linstone, 1999). Examples of the T perspective are the multicriteria decision making (MCMD) models. Multiple Criteria Decision-Making (MCDM) is defined as the area of decision making which involves multiple attributes, objectives and goals (Carlsson, 1983). Criteria are defined as "measures, rules and standards that guide decision making. Since decision making is conducted by selecting or formulating different attributes, objectives or goals, all three categories or goals which have been judged relevant in a given decision situation by a particular decision maker (individual or group)." (cf Carlsson, p. 2). The main criticism of MCDM is that the approaches that have been proposed in the literature usually produce dissimilar results (Parkan and Wu, 2000).

Mitroff and Linstone (1993) have proposed the development of organizational (O) and the personal (P) perspectives to overcome the limitations of the technical perspective. The $\mathrm{O}$ and P bring to the forefront human beings collectively and individually in all their complexity (Mitroff and Linstone, 1993). These perspectives are not intended to replace the technical perspective but to expand it. Using only one perspective is analogous to seeing a onedimensional representation of a three-dimensional object (Mitroff and Linstone 1993). The multiple perspective approach requires what may be called "Perspectival thinking." Perspectival thinking suggests that we need to consider all the facets of the situation at hand and consider it from different angles. Perspectival thinking is grounded in conviction, values and ethics (Haynes, 2001). Ethics as seen by Polanyi (cf Haynes 2001) is a higher source of thinking than logic and reason. Ethics does not arise from one piece of knowledge, not from one logical element or group of logical elements but the whole system (Haynes, 2001).

In addition to the TOP perspectives, I have included an ethical (E) perspective as well. Mitroff and Linstone (1993) recognize the importance of ethics and posit that they play a 
fundamental role in the selection of problems and in the means to address them. However, they did not consider it as a separate perspective. The multiplicity of the stakeholders in wicked situations and the fact that every stakeholder group has a vested interest in the problem to be solved make ethical and moral concerns a major issue. Thus, DSS designers must not only consider the technical, organizational and individual perspectives but also ethical and moral perspectives in their design.

\section{DSS Framework for Wicked Situations}

The multiple perspective approach and the dialectic process bring many factors into the picture for decision making in wicked situations. Courtney (2001) has proposed a new decision making paradigm for wicked situations, based on the Singerian inquirer and multiple perspectives. At the heart of his approach are mental models. The mental models, either personally or collectively, determine what data and what perspectives one examines. Mitroff and Linstone's multiple perspective approach is then used to develop and analyze the views of relevant stakeholders, and these are melded into a synthesized perspective that forms the basis for the decision.

The proposed DSS design methodology (Figure 2) starts with mental models and uses Courtney's model as the context for analyzing the decision environment in which the DSS is being developed. The mental models determine the factors that the stakeholders use to make decisions. The approach integrates the factors into a composite set to assure that all stakeholders are using the same data set in their discussion of the issues involved and the decision to be made. Next, rather than going directly into analysis, the process consists of developing multiple 
perspectives. The methodology emphasizes that one must go beyond the technical perspective, and include organizational and personal views along with ethical concerns. The perspective analysis then serves as a basis of developing decision factors. Once these decision factors are identified, conflicting assumptions are isolated, two prototypes are designed and developed: one referred to as the "design prototype," and an alternative "counter design" prototype. Next the stakeholders engage in an open dialogue to share their views about the design and the counter design with the intent of revealing tacit assumptions. The purpose of the dialogue is to help create a synthesized design. The role of the ultimate decision-maker (project manager or system designers) who observes the dialogue is to isolate the most plausible and strongest assumptions and formulate the basis for synthesized design. This synthesis represents new tacit knowledge, and the intent is to update stakeholders' mental models. As the models are updated, insight is gained and better understanding of the situation is achieved. The process continues until there are no conflicting assumptions. The synthesis is progressive in that it contains what went before and in that it serves as the basis for the next stage (Ford and Ford, 1994). The final synthesis will then be used to produce the final design. 


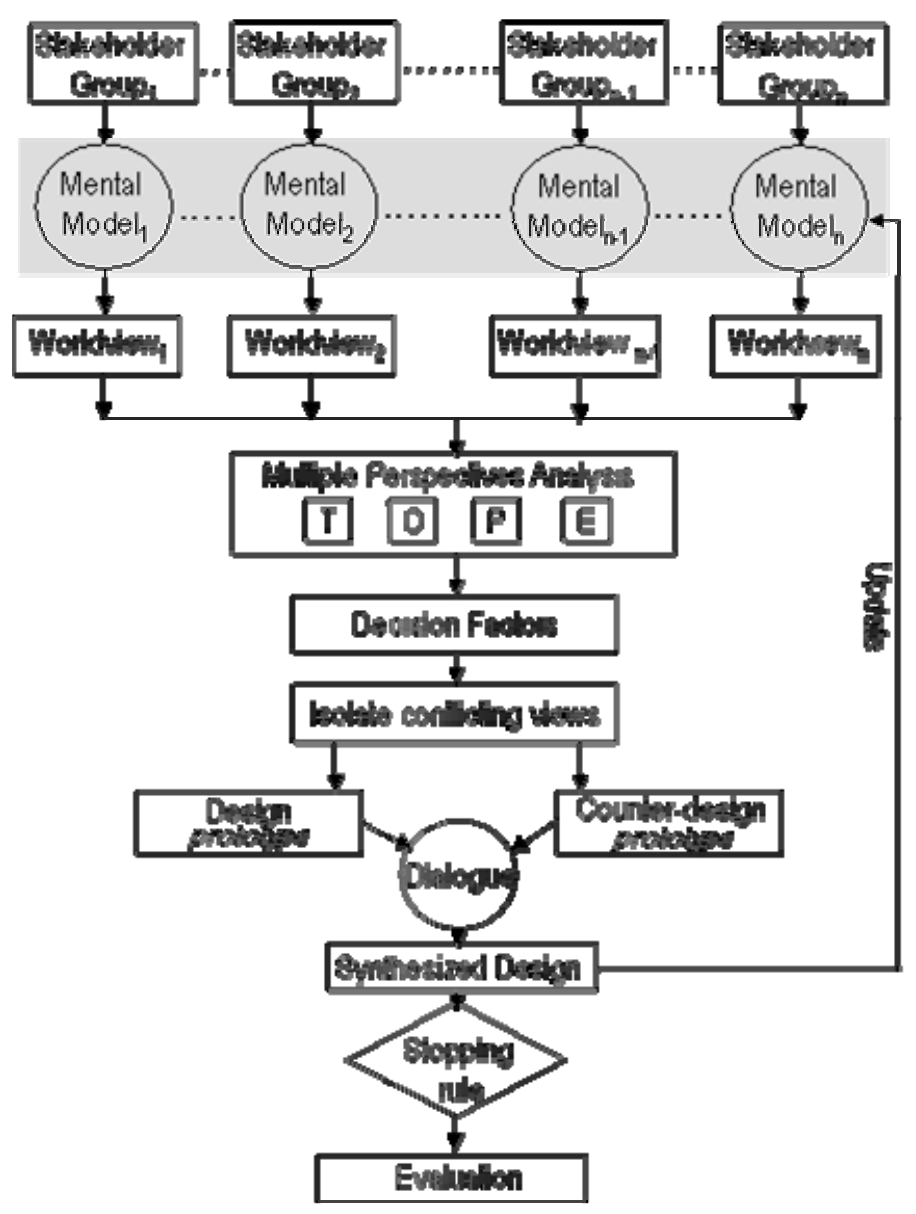

Figure 2. Multiple perspectives and dialectic framework to decision-making

\section{Multiple Perspective Dialectic Process (MPDP) Methodology}

Based on the above framework a methodology is being developed to serve as a step by step guideline to the design of DSS based on both theories. The main goal of the Multiple Perspectives and Dialectic Process (MPDP) methodology is to illustrate the stages presented in the above framework and to provide DSS designers with a procedure to organize data and construct the basis for the DSS. The distinguishing characteristics of the MPDP methodology are: (1) MPDP is a conflict driven approach. It focuses on the isolation of conflicting worldviews 
using the same data; (2) MPDP analyses the problem from a number of distinct perspectives or worldviews.

The MPDP methodology has seven major stages, described below. A pilot study has been conducted to perform a preliminary test of the methodology. The pilot involved the development of a DSS for class scheduling and classroom assignments for the College of Business at a major university in the Southeastern US. There turned out to be a surprising amount of conflict in this application. Administrators want efficient use of resources, faculty want to teach their favorite courses at their favorite times, students want the courses they need to graduate at convenient times, and each department is vying with others for classrooms. Students in a DSS class were used as subjects in this pilot study. Three groups used a conventional prototyping approach and three used the MPDP methodology. Table 2 summarizes the steps of the MPDP illustrating the pilot study context as an example. 
Table 2. Illustration of the MPDP methodology stages using the pilot study as an example

\begin{tabular}{|c|c|c|c|}
\hline $\begin{array}{l}\text { Stakeholder } \\
\text { Identification }\end{array}$ & \multicolumn{3}{|c|}{ Faculty, Students, Administrators } \\
\hline $\begin{array}{l}\text { Worldview } \\
\text { formulation }\end{array}$ & \multicolumn{3}{|c|}{$\begin{array}{l}\text { Faculty want classes at convenient times and convenient locations. They also have } \\
\text { preferences on subjects they want to teach. } \\
\text { Students want more variety of classes offered every semester. They want classes at } \\
\text { convenient times (no 7:30 a.m. classes). } \\
\text { Administrators want to optimize the use of the buildings and classrooms and to offer } \\
\text { the necessary courses every semester. }\end{array}$} \\
\hline $\begin{array}{l}\text { Multiple } \\
\text { perspective } \\
\text { identification }\end{array}$ & & $\begin{array}{l}\text { Technical perspective - what models can } \\
\text { be used to optimize classroom use at } \\
\text { minimal costs? } \\
\text { Organizational perspective - Efficient } \\
\text { use of classrooms, tradeoffs among } \\
\text { satisfaction of stakeholder desires }\end{array}$ & $\begin{array}{ll}> & \text { Individual perspective - Satisfy MY } \\
& \text { desires for scheduling } \\
> & \text { Ethical perspective - Treat all parties } \\
\text { fairly and equitably }\end{array}$ \\
\hline $\begin{array}{l}\text { Decision factors } \\
\text { determination }\end{array}$ & & $\begin{array}{l}\text { Classroom availability } \\
\text { Course offerings }\end{array}$ & $\begin{array}{l}>\text { Faculty preferences } \\
>\text { Schedules }\end{array}$ \\
\hline $\begin{array}{l}\text { Conflict } \\
\text { identification }\end{array}$ & & $\begin{array}{l}\text { Faculty prefer to teach certain classes at ce } \\
\text { Students need certain classes at convenien } \\
\text { Administrators want to minimize cost, ma }\end{array}$ & $\begin{array}{l}\text { ertain times } \\
t \text { times and location } \\
\text { ximize use of classroom space }\end{array}$ \\
\hline $\begin{array}{l}\text { Resolution } \\
\text { generation }\end{array}$ & & $\begin{array}{l}\text { Dialogue session where all stakeholders pr } \\
\text { design prototypes }\end{array}$ & resent their views on the design and counter- \\
\hline Evaluation & & $\begin{array}{l}\text { Survey all stakeholders group to measure } t \\
\text { based on the synthesized design. }\end{array}$ & the success of the developed prototype DSS \\
\hline
\end{tabular}

1. Stakeholder identification: This stage is concerned with gathering information about who is involved in making the decision. The concept of stakeholders can be traced back to 1963 (Freeman,1984). The popularity of stakeholder theory has increased with Freeman's seminal work published in his book Strategic Management: A Stakeholder Approach. Despite stakeholder theory's popularity, there is a continuous debate on the meaning of the term stakeholder. Some definitions are much broader than others. The mostly cited and much broader definition is the one offered by Freeman (1984). He notes that "a stakeholder in an organization is (by definition) any group or individual who can affect or is affected by the achievement of the organization's objectives" (p. 46). Adopting Freeman's definition, a stakeholder in the decision making context is defined as any group or individual who can affect or is affected by the making of the decision. Once these groups and or individuals are identified their views with respect to each other are revealed. This step will help the designers assess the degree of conflict they are to be faced with so they can accommodate it in their design. Examples of stakeholder groups in the class scheduling decision problem include students, faculty and administrators. 
2. Worldview formulation: This stage is concerned with the generation of stakeholders' assumptions and worldviews with regard to the decision based on their respective mental models. The worldviews represent ways of viewing the entire process and/or different stages of the process. Worldviews have a wealth of information embedded in them, which provide pictures of the alternative actions and hence what information is relevant and the ways it should be used. For example, faculty want classes at convenient times and convenient locations. They also have preferences on subjects they want to teach. Students want more variety of classes offered every semester. They want classes at convenient times (no 7:30 a.m. classes). And administrators want to optimize the use of the buildings and classrooms and to offer the necessary courses every semester.

3. Multiple perspective identification: This stage seeks to classify the different worldviews and technical, organizational, personal, and ethical perspectives. This step is crucial to avoid the limitations of considering only the technical perspective. A technical perspective in the illustrated example would be, what models can be used to optimize classroom use at minimal costs? An organizational perspective would include efficient use of classrooms, tradeoffs among satisfaction of stakeholder desires. An individual perspective would be to satisfy MY (students, faculty) desires for scheduling. And an ethical perspective could be to treat all parties fairly and equitably

4. Decision factors determination: This stage seeks to identify the important factors upon which each group draws its worldviews and is concerned with defining factors that are relevant to the decision based on the perspectives identified in stage 3. In the class scheduling situation, some of the factors that are relevant to the decision include, classroom availability, course offerings in each semester, faculty preferences, schedules and expected student demand.

5. Conflict identification: This stage seeks to identify and formulate the thesis and the antithesis. This step is concerned with forming alternative designs, arriving at a design and a "counter design." Both the design and the counter-design are derived from the worldviews formulated and are based on the decision factors identified in stage 4 . Prototypes are developed for each of the designs. In our example, there was a surprising level of conflict between the stakeholders groups. Faculty prefer to teach certain classes at certain times. Students need certain classes at convenient times and location. Administrators want to minimize cost, maximize use of classroom space. It is difficult to accommodate all these conflicting views in one design. Therefore, each group developed a prototype which was later presented to the stakeholders in the next stage.

6. Resolution generation: This stage seeks to formulate and generate the synthesis. At this stage, both supporters of the design and the counter-design engage in a dialogue or a structured debate wherein an observer, the decision-maker (the designer(s), or project leader), 
will form a new and expanded plan - the synthesis. During this phase each decision factor is introduced and is interpreted by the opposing advocates to demonstrate how it supports their decisions. The goal of the dialogue is to expose hidden assumptions and tacit knowledge, which would otherwise not be revealed. This is a crucial stage of the methodology, for it is here that designers gain more insights and better understanding into the different perspectives and different approaches to making the decision. The role of the designer/project leader is to isolate the most plausible and strongest assumptions/worldviews in order to form the basis for the synthesized design. The newly-formed design is presented to the stakeholders. The designers' role is to isolate any new conflicting worldviews with regard to the new thesis (synthesis). If there are no conflicting worldviews, the synthesis is declared the optimal design and the process ends. Oftentimes the process may not lead to a consensus, therefore the process may stop when resources (either time, energy or funds) are depleted. In the pilot study, this stage was operationalized by a dialogue session, where representatives of different stakeholder groups convened in one room and discussed /defended their worldviews after a presentation of each of the prototypes. Stakeholders gave their feedback on the designs. Armed with this feedback the analysts (subjects of the study) went back and developed a synthesized design and a second prototype. The stopping rule in this case was time, as this was a class project and subjects had five weeks to complete the project.

7. Evaluation: This stage seeks to evaluate the success of the final synthesized at stage 6 . During this stage stakeholder groups are surveyed to determine their satisfaction with the final design. Information systems success instruments will be used to measure success factors. In the class scheduling example, all stakeholder groups would be surveyed to determine their satisfaction with the synthesized design and the design process.

Every systems design methodology has advantages and disadvantages and MPDP is no exception. The MPDP methodology is not suited for well-structured problems. For clear-cut problems, conflict may be a time-consuming nuisance (Mason and Mitroff, 1973). MPDP is best suited to ill-structured problems where a variety of stakeholders are involved, conflict is present and the implications and importance of the problem justify the costliness of the approach. MPDP is a flexible methodology in that it does not dictate which tools designers should use to achieve the goals of each step. Designers are free to use any tools, techniques, and models they deem necessary for the situation at hand. For example, in stage one, designers may choose to use brainstorming or any other stakeholder analysis technique to identify the stakeholder groups and their worldviews. The MPDP main advantage is the fact that the 
process produces multiple distinct designs, which increase the likelihood of arriving at the most effective design for the situation at hand. The entire MPDP process leads to ever expanding and more refined designs.

\section{Methodology Comparison}

Comparing methodologies is a very difficult task and the results of any work are likely to be criticized on many counts (Avison and Fitzgerald, 1995, p.445). There are many frameworks available in the IS literature for comparing and contrasting methodologies (Olle et al., 1986, Avison and Fitzgerald, 1995, Hirschhiem et al., 1997, Iivari et al. 1998, 2000/2001). Earlier frameworks focused explicitly on concrete features of the methodologies as basis for comparison (Olle, et al., 1986) whereas the most recent ones focus on the level of approaches addressing more fundamental aspects of the methodologies (Avison and Fitzgerald, 1995, Hirschhiem et al., 1997, Iivari et al. 1998, 2000/2001). The framework used in this study to compare the six methodologies is based in part on the framework proposed by Avison and Fitzgerald (1995) and in part on the framework suggested by Iivari et al. (2000/2001). The units of analysis adopted in the proposed framework for comparing these methodologies focus on the methodology's underlying philosophy and information system development approach adopted. Therefore, the analysis is based on a discussion of the information system development approaches (Iivari et al., 2000/2001) and the methodology's philosophy (Avison and Fitzgerald, 1995). Table 4 summarizes the six methodology comparison. 


\section{ISD Approaches}

The methodologies discussed in this study and the proposed methodology are based on different information system development approaches (ISDA). Iivari et al. (1998) defined an ISDA "as a set of goals, guiding principles, fundamental concepts, and principles for the ISD process that drive interpretations and actions in IS development." The goals of an ISDA specify the general purpose of the approach. The guiding principles form the common "philosophy" which is often implicit in most methodologies (Avison and Fitzgerald, 1995). The fundamental concepts define the nature of an IS implicit in the approach as well as the focus and unit of analysis in ISD. Principles of the ISD process express essential aspects of the ISD process in the approach. Briefly, an IS approach is a set of methodologies that share the same underlying assumptions and fundamental concepts for IS development. Iivari et al. (1998) analyzed the fundamental philosophical assumptions of five information systems development approaches: The interactionist approach, the speech act-based approach, the soft systems methodology approach, the trade unionist approach, and the professional work practice approach. In addition to these five approaches, Iivari et al. (2000-2001) identified six other approaches to IS development which include the structured approach, information modeling, decision support systems, the socio-technical approach, the object-oriented approach, and the infological approach. These approaches are described as functionalist approaches (Iivari et al., 2000-2001). The functionalist paradigm is most dominant in ISD approaches. It is concerned with providing explanation of the status quo, social order, social integration, consensus, need satisfaction, and rational choice (Hirschhiem and Klein, 1989). For a detailed explanation of all the above 
mentioned approaches please refer to Iivari et al. (2000-2001, Appendix1, p.213-215). In the following section, I will limit my discussion to the ISDA of the methodologies discussed above.

Both the traditional SDLC methodology and prototyping fall under the structured approach. The structured approach was developed in the late 1970s by DeMarco and Yourdon. It requires a disciplined environment and a standard set of requirement. The goal of he methodologies that fall under this approach is to provide maintainable software (Iivari et al. 2000/2001). Both SDLC and prototyping have the objective of developing computerized information systems.

ETHICS on the other hand is based on the socio-technical design approach (Iivari et al., 200/2001). The socio-technical approach was originally developed by the Tavistock Institute in Great Britain (Mumford and Henshall, 1979). One major objective of this approach is the improvement of the efficiency of a work system through identifying and analyzing system variances (Mumford and Henshall, 1979). The soft systems methodology obviously belongs to the SSM approach. This approach explicitly focuses on problem formulation by helping the user identify the "relevant" system from the perceptions of possibly disagreeing stakeholders, it aims at supporting a learning cycle (Iivari et al., 1998). Multiview is a methodology that explicitly attempts to reconcile ideas from different ISDAs, including SSM, socio-technical design, structured analysis, and information modeling (Iivari et al., 2000-2001). It is a multiple approach methodology using different approaches at different stages of the methodology.

The MPDP methodology has different underlying assumptions and does not fit under any of the approaches discussed above. Therefore, a new approach is proposed under which the proposed methodology MPDP can be categorized. This approach is the dialectic approach. The distinguishing feature of the dialectic approach is its focus on conflicting worldviews of the 
different stakeholder groups. The dialectic approach aims at supporting multiple views of the problem domain. The dialectic approach has not been adopted explicitly in any of widely accepted and adopted IS methodologies. However, it has been advocated in decision-making and has proven to result in better decisions (Mason, 1969).

Table 3 summarizes the ISDAs discussed above in terms of their goals, guiding principles, fundamental concepts and principles of the ISD process. 
Table 3. Summaries of the Four IS Development Approaches

\begin{tabular}{|c|c|c|c|c|}
\hline Approach & Structured Approach* & Socio-technical Design* & $\begin{array}{l}\text { Soft System } \\
\text { Methodology } \\
\text { Approach** }\end{array}$ & $\begin{array}{l}\text { Dialectic } \\
\text { Approach }\end{array}$ \\
\hline Goal & $\begin{array}{l}\text { To provide an approach } \\
\text { that helps to produce high } \\
\text { quality software in a } \\
\text { productive way }\end{array}$ & $\begin{array}{l}\text { To provide an approach for IS } \\
\text { development that enables future } \\
\text { users to play a major part in the } \\
\text { design of the system, to cater to job } \\
\text { satisfaction objectives in addition to } \\
\text { more technical and operational } \\
\text { objectives, and to ensure that the } \\
\text { new system is surrounded by a } \\
\text { compatible well-functioning } \\
\text { organizational system }\end{array}$ & $\begin{array}{l}\text { To provide a } \\
\text { learning } \\
\text { methodology to } \\
\text { support debate on } \\
\text { desirable and } \\
\text { feasible changes }\end{array}$ & $\begin{array}{l}\text { To provide a } \\
\text { methodology for } \\
\text { uncovering } \\
\text { hidden } \\
\text { assumptions, } \\
\text { accommodating } \\
\text { conflict and } \\
\text { considering } \\
\text { multiple } \\
\text { perspectives. } \\
\end{array}$ \\
\hline $\begin{array}{l}\text { Guiding } \\
\text { Principles }\end{array}$ & $\begin{array}{l}\text { Separation of the essential } \\
\text { model from the } \\
\text { implementation model; } \\
\text { Careful documentation to } \\
\text { make the development } \\
\text { process visible, Graphic } \\
\text { notations; Top-down } \\
\text { partionable } \\
\text { transformation/ process } \\
\text { models to hide } \\
\text { complexity, Unambiguous, } \\
\text { minimally redundant, } \\
\text { Graphic specification, } \\
\text { Balancing of models with } \\
\text { high cohesion and weak } \\
\text { coupling }\end{array}$ & $\begin{array}{l}\text { Self-design of a work system, } \\
\text { Minimal critical specification, } \\
\text { Open-ended design process, Fit } \\
\text { between the social and technical } \\
\text { subsystems, Joint optimization, } \\
\text { Redundant functions }\end{array}$ & $\begin{array}{l}\text { Use of notional } \\
\text { system models } \\
\text { called "human } \\
\text { activity systems" } \\
\text { to illuminate } \\
\text { different } \\
\text { Weltanschauung } \\
\text { which may be } \\
\text { applied to any } \\
\text { social system; An } \\
\text { information } \\
\text { system is a } \\
\text { system to support } \\
\text { the truly relevant } \\
\text { human activity } \\
\text { system. }\end{array}$ & $\begin{array}{l}\text { The use of } \\
\text { dialectic to arrive } \\
\text { at the synthesized } \\
\text { system design, } \\
\text { which is a } \\
\text { superior design } \\
\text { compared to the } \\
\text { designs based on } \\
\text { either one of the } \\
\text { conflicting views }\end{array}$ \\
\hline $\begin{array}{l}\text { Fundamental } \\
\text { Concepts }\end{array}$ & $\begin{array}{l}\text { Essential models vs } \\
\text { implementation model, } \\
\text { Transformation, Data } \\
\text { flow, Data store; } \\
\text { Terminator, Module, } \\
\text { Cohesion, Coupling }\end{array}$ & $\begin{array}{l}\text { Technical system, Social system, } \\
\text { Variance, Unit of operation, } \\
\text { Technical needs, Social needs (job } \\
\text { satisfaction) }\end{array}$ & $\begin{array}{l}\text { Weltanschauung; } \\
\text { Human Activity } \\
\text { Systems; Root } \\
\text { definition; } \\
\text { Relevant system. }\end{array}$ & $\begin{array}{l}\text { Conflicting } \\
\text { Weltanschauung } \\
\text { (Worldviews); } \\
\text { Discourse/debate }\end{array}$ \\
\hline $\begin{array}{l}\text { Principles of } \\
\text { the ISD } \\
\text { Process }\end{array}$ & $\begin{array}{l}\text { A step by step process at } \\
\text { the detailed level of } \\
\text { analysis and design } \\
\text { activities, Situation } \\
\text { dependent at the } \\
\text { "strategic" level (water- } \\
\text { fall, prototyping, } \\
\text { concurrent) }\end{array}$ & $\begin{array}{l}\text { User participation, Socio-technical } \\
\text { design, Evolution }\end{array}$ & $\begin{array}{l}\text { Stream of } \\
\text { cultural analysis; } \\
\text { Stream of logic- } \\
\text { based analysis. }\end{array}$ & $\begin{array}{l}\text { Stakeholder } \\
\text { analysis; multiple } \\
\text { perspective } \\
\text { analysis; } \\
\text { synthesized } \\
\text { design. }\end{array}$ \\
\hline
\end{tabular}




\section{ISD Philosophy}

Philosophy is "a principle or a set of principles that underlie the methodology" (Avison and Fitzgerald, 1995 p.447). The methodology's philosophy is perhaps the most important aspect when comparing methodologies because it underscores all other aspects and features of the methodology (Avison and Fitzgerald, 1995). Avison and Fitzgerald (1995) identified four factors as a guide to philosophy. They consist of paradigm, objectives, domains and applications. Each of these factors is highlighted next.

\section{Paradigm}

A paradigm is a specific way of thinking about problems (Kuhn, 1962). The two paradigms of relevance here are the science paradigm and the systems paradigm (Avison and Fitzgerald, 1995). The science paradigm deals with complexity by breaking complex systems into smaller more manageable parts and assumes that doing so will not disrupt the whole system. Checkland (1981) summarizes the science paradigm as follows:

"We may reduce the complexity of the variety of the real world in experiments whose results are validated by their repeatability, and we may build knowledge by the refutation of hypotheses." (cf. Avison and Fitzgerald, 1995, p.447)

Both SDLC and prototyping seem to belong to the science paradigm. Both methodologies adopt a reductionism approach and do not have any discussion of the real-world as being socially constructed and the encounter of different perceptions of the real world. For example, the SDLC uses the concept of functional decomposition as a tool in analyzing the processes and subprocesses of an IS system. Functional decomposition is the process of breaking a system down into its component elements (Marakas, 2001). Also, prototyping's second phase is concerned with selecting the functions to be included in the prototype. None of these two methodologies recognizes the need to understand the wider context of the problems 
and their implications beyond the scope of the organization. Therefore, it is clear that both the SDLC and prototyping belong to the science paradigm.

The system paradigm on the other hand is concerned with the whole picture and considers breaking the system into smaller parts, a dangerous thing to do because "something is lost when the whole system is broken up in the 'reductionist' approach of scientific analysis" (Avison and Fitzgerald, 1995 p. 365). The system paradigm suggests that we must try to develop systems for the widest possible context of an organization as a whole rather than for functions in isolation (Avison and Fitzgerald, 1995). I suggest that ETHICS, SSM and MPDP belong to the system paradigm.

ETHICS is grounded in the socio-technical approach, which stresses the viewing of information systems development as a social process. It takes no attempt to break down the system into smaller parts in order to better understand the problem. Hence, the underlying paradigm of ETHICS is the system paradigm.

It is clear that SSM adopts a system paradigm. In fact, Checkland explicitly states that it is based on a systems approach. SMM uses many of the systems concepts and does not adopt a reductionist approach.

MPDP is methodology for wicked problems. These types of problems require a pluralistic approach and a consideration of different worldviews. MPDP attempts to understand the problem by looking at the whole picture and does not attempt to break it down into parts thus avoiding the pitfall of the reductionist approach. Therefore, the underlying paradigm of MPDP is also the system paradigm.

In the analysis of paradigm, Multiview presents a little challenge. The multi-approach upon which this methodology is based makes it difficult to classify it under one paradigm or the 
other. Stages one and three of the methodology clearly belong to the systems paradigm whereas the stage two certainly belongs to the science paradigm because it uses the functional decomposition concept in the development of functional models. However, since the focus of our comparison is on the 'essence' of the methodology, I therefore classify it to be in the systems paradigm.

\section{Objectives}

The second factor relating to philosophy is the stated objectives of the methodologies. Objectives determine the boundaries of the area of concern of the methodology. There exist a difference of objectives in that some methodologies are interested only in aspects that are 'computerisable' while others take a wider view and direct their attention to achieving solutions or improvements no matter what it implies (Avison and Fitzgerald, 1995 p. 451). Some methodologies indicate their objectives more explicitly than others. For example, ETHICS has as one of its objectives the improvement of the quality of life and the enhancement of job satisfaction of the system users. Its purpose goes beyond just the building of a computerized system as is the case with SSM, Multiview and MPDP. The objectives of these methodologies are much wider than the development of computerized systems. A stated before, SSM aims to bring about the improvement in areas of social concern (Von Bulow, 1989). Multiview has as objective the analysis of the human and technical aspects of the software development. MPDP aims at analyzing the different perspectives of the all parties affected by the development process in order to arrive at better decisions. The ultimate goal of MPDP may not always be a computerized solution, a better more effective decision-making process could be the result of the process. 
On the other hand, SDLC and prototyping can be classified as having the objective of developing computerized information systems. Both methodologies do not state any objectives other than the building of a system to fulfill specific needs. Even though the SDLC claims that it can be applied to situations where the designed system can be non-automated (Marakas, 2001), in practice it always concerns itself with analyzing the need for a computer solution. The heart of the prototyping methodology is a computerized system the whole process is centered around building a computerized system.

\section{Domains}

The fourth factor relating to philosophy is domain that the methodology seeks to address. It focuses on the aspects of the organization on which the methodology focuses, whether it addresses the general organizational need for an IS or is concerned with the solving of specific problems. Examples of general organizational need for an information system include general planning, organization and strategy of information and systems in the organization. Examples of business needs include specific, pre-identified problem such as providing marketing information to the sales force.

SDLC, ETHICS, and Prototyping are classified as specific problem-solving methodologies, that is they do not focus on identifying the systems required by the organization but begin by assuming that a specific problem is to be addressed (Avison and Fitzgerald, 1995). SSM and MPDP are both classified as methodologies that seek to identify organizational needs. They are both suited for ill-structured, wicked problems. Organizational needs such as planning and strategy are definitely not specific, well-defined problems.

Given the contingency approach of Multiview, it is suited for both well-defined problems and ill-structured problems. Multiview has been used for a wide range of problem situations, 
ranging from solving clerical problem to developing systems for district health authority (Avison and Wood-Harper, 1990). Therefore, Multiview can be classified as serving both domains.

\section{Applications}

The last aspect of the philosophy is the types of applications and types of problems the methodologies are applicable for. Some methodologies are targeted at particular types of problem, environment, or type or size of organization (i.e. MPDP) while others are said to be general purpose (i.e. SDLC).

SSM and MPDP have been developed to be applicable in complex, wicked problem situations. MPDP is not suited for clear-cut, small scale problems, the dialectic process may be considered time consuming and costly. Although MPDP can be used to develop any information system, it is specifically designed for designing decision support systems. SSM has been developed to be applicable in human activity situations where very complex problem situations exist (Avison and Fitzgerald, 1995). Multiview on the other hand has been designed to be applicable in both large and small-scale projects. Multiview is a flexible framework which can be adapted significantly for the particular problem situation. Similarly, ETHICS is a flexible methodology, it has been used by a number of large companies to assist in the building of very large systems (Avison and Fitzgerald, 1995). It has been amended slightly for use by small businesses thinking of acquiring computing system for the first time (Avison and Fitzgerald, 1995).

Even though SDLC and prototyping are stated to be general purpose they are not suitable for large complex applications. In large organizations where there is multiplicity of users, the SDLC methodology may not be feasible because by the time they reach implementation things would have changed and it would be too costly to make any changes. Similarly, prototyping will 
be too time consuming in large scale projects where there are too many users with conflicting needs. Thus the applications of SDLC and prototyping can be classified as small-medium size projects.

Table 4. Summary of the Six Methodology Comparison

\begin{tabular}{|c|c|c|c|c|c|c|c|}
\hline \multicolumn{2}{|c|}{ Methodologies } & SDLC & ETHICS & SSM & Multiview & Prototyping & MPDP \\
\hline \multicolumn{2}{|c|}{ Approach } & $\begin{array}{l}\text { Structured } \\
\text { Approach }\end{array}$ & $\begin{array}{l}\text { Socio-technical } \\
\text { Approach }\end{array}$ & SSM Approach & $\begin{array}{l}\text { Multiple } \\
\text { Approach* }\end{array}$ & $\begin{array}{l}\text { Structured } \\
\text { Approach }\end{array}$ & $\begin{array}{l}\text { Dialectic } \\
\text { Approach }\end{array}$ \\
\hline \multirow{4}{*}{$\begin{array}{l}2 \\
= \\
0 \\
0 \\
0 \\
0 \\
= \\
= \\
= \\
0\end{array}$} & Paradigm & Science & Systems & Systems & Systems & Science & Systems \\
\hline & Objective & $\begin{array}{l}\text { Automation - } \\
\text { Computerized } \\
\text { solution }\end{array}$ & $\begin{array}{l}\text { Organization- } \\
\text { Improved quality } \\
\text { of work life; } \\
\text { enhanced job } \\
\text { satisfaction }\end{array}$ & $\begin{array}{l}\text { Organization - } \\
\text { Improvement of } \\
\text { areas of social } \\
\text { concern }\end{array}$ & $\begin{array}{l}\text { Organization - } \\
\text { analysis of human } \\
\text { and technical } \\
\text { aspects of } \\
\text { software } \\
\text { development }\end{array}$ & $\begin{array}{l}\text { Automation - } \\
\text { Computerized } \\
\text { solution }\end{array}$ & $\begin{array}{l}\text { Better decision } \\
\text { making } \\
\text { process }\end{array}$ \\
\hline & Domain & $\begin{array}{l}\text { Specific } \\
\text { problem- } \\
\text { solving }\end{array}$ & $\begin{array}{l}\text { Specific } \\
\text { problem-solving }\end{array}$ & $\begin{array}{l}\text { General } \\
\text { organizational } \\
\text { need }\end{array}$ & $\begin{array}{l}\text { General } \\
\text { organizational } \\
\text { need }\end{array}$ & $\begin{array}{l}\text { Specific } \\
\text { problem- } \\
\text { solving }\end{array}$ & $\begin{array}{l}\text { General } \\
\text { organizational } \\
\text { need }\end{array}$ \\
\hline & Applications & $\begin{array}{l}\text { General } \\
\text { purpose; } \\
\text { small- } \\
\text { medium size } \\
\text { projects }\end{array}$ & $\begin{array}{l}\text { General purpose; } \\
\text { both small and } \\
\text { large scale } \\
\text { applications }\end{array}$ & $\begin{array}{l}\text { Human activity } \\
\text { situations; } \\
\text { complex } \\
\text { situations }\end{array}$ & $\begin{array}{l}\text { General purpose; } \\
\text { both small and } \\
\text { large scale } \\
\text { applications }\end{array}$ & $\begin{array}{l}\text { General } \\
\text { purpose; small- } \\
\text { medium size } \\
\text { projects }\end{array}$ & $\begin{array}{l}\text { Decision- } \\
\text { making in } \\
\text { wicked } \\
\text { situations }\end{array}$ \\
\hline
\end{tabular}

\section{Conclusion}

The MPDP methodology addresses three main limitations associated with other development methodologies. First, the approach presented broadens the scope of stakeholders. It creates more opportunities by including a wider range of affected parties whereas other methodologies are limited in their inclusion of participants. Second, by considering stakeholder groups multiple perspective, a richer set of goals and criteria is identified which leads to more effective solutions. As noted by Ackoff (1978, p.78) "increasing the number of dimensions in which we think about the problems can often reveal new and more effective solutions." Third, 
the MPDP methodology includes processes that encourages sharing of information and guard against unethical behavior because of the uneven distribution of information and power among and between stakeholders. The open dialogue and the explicit ethical perspectives that characterizes MPDP both contribute to effectively resist the obstacles that may arise because of asymmetrical power relations. 


\section{CHAPTER FOUR: RESEARCH METHODOLOGY}

Within the field of information system, many research approaches may be appropriate namely conceptual study, mathematical modeling, laboratory experiment, field experiment, surveys, case studies, phenomenological research/hermeneutics, and action research (Avison and Fitzgerald, 1991). In this chapter, I describe the several methodological approaches used to test the design theory proposed in the previous chapter. I argue for the feasibility of system development and action research in testing design theories and discuss strengths and weaknesses of each research method. I also discuss the steps to developing a DSS success factor instrument to evaluate the design, counter-design and the synthesized design.

\section{$\underline{\text { Research Approach }}$}

In order to test the effectiveness of the proposed design methodology, I will adopt a multi-methodological approach involving design science, systems development and action research methods. The goal is to try out the proposed theory-based methodology (MPDP) in realworld settings by developing a DSS and evaluating it and using the gained feedback to refine the methodology and apply it again. This scenario fits the description of action research and design science research approaches. Additionally, to show the effectiveness of the design methodology, a prototype will be built based on the synthesized design resulting from the application of the MPDP methodology. This scenario fits the description of the design science method. As mentioned earlier, the design theory process suggested by Walls et al. (1992) has been used to 
develop the design theory for DSS design for wicked situations. This design theory will be formally tested on another wicked situation using an action research project.

\section{System Development}

The use of system development (SD) as a research methodology has been argued and defended by many IS researchers (Nunamaker and Chen, 1990, Nunamaker et al., 1991, Gregg et al., 2000, Burstein and Gregor, 1999). IS research has been criticized for the lack of the artifact in subject studies (Weber, 1987, Orlikowski and Iacono, 2001). Orlikowski and Iacono (2001) strongly propose that IT artifact, by itself, should be a central phenomenon to focus on. System development presents a viable research methodology that researchers can use to fill the gap between the social and technological aspect of IS research. SD has been classified as constructive research method (Iivari et al. 1998). Constructive methods, according to Iivari et al (1998, p.175) are concerned with "the engineering of artifacts, which may be either purely conceptual or more technical." Concomitantly, Nunamaker et al. (1990) argue that system development is a central part of a multi-methodological approach to IS research. This pivotal role of system development stems from the fact that the developed system serves both as a proofof-concept for the fundamental research and theoretical underpinnings and provides an artifact that can become the focus of other research project.

There are various theories, research journal articles and dissertation that have contributed to the advancement of IS research resulted from the development of new systems. For example, the group decision support system that was developed at the University of Minnesota resulted in the development of Adaptive Structuration Theory (AST) by DeSanctis and Poole (1994). The 
development of AST was based on observations of how a group decision support system developed at the University of Minnesota was used and adopted by its users. Another series of examples summarized by Courtney and Paradice (1993) demonstrate how system development can be the embryo of many studies: Pratch $(1984,1986,1988)$ developed software known as GISMO, a Graphical, Interactive, Structural Modeling Option. This system permits the interactive development of structural models in either graphic or tabular form. Pratch used the system to test the hypothesis that subjects with good spatial ability would be most capable of using GISMO. Loy (1986) tested GISMO in a small group decision-making context. The main objective of the experiment was to test whether small groups using GISMO would better understand he problem domain and perform better in terms of net income. Ata (1985, 1987, 1988) extended the GISMO system to include problem diagnosis and tested it and found that the extension did not achieve the intended result. This limitation of the GISMO system has led Paradice $(1986,1987)$ to develop SmartSLIM, a system that controlled biases through the use of linear and higher order statistical models. This is a good example of how system development can lead to a series of research studies that add to the body of knowledge and contribute to the advancement of the IS discipline.

The research process of any research method is the application of scientific methods to the complex task of discovering answers to research questions. Nunamaker et al. (1990) proposed a research process for the system development approach that consists of five stages:

1. Construct a conceptual framework: In this stage, researchers must first state a research problem and question. The problem and question must be significant, involve the use of new methods, techniques or design. The conceptual framework should lead to theory building by formulating concepts and frameworks, constructing a method and developing a theory. 
2. Develop a system architecture: It provides with a road map or a blueprint of the system building process. Researchers must identify the constraints imposed by the environment, state the focus of the research and define functionalities and interrelationships.

3. Analyze and design the system: During this stage, requirements are analyzed, databases and user interfaces are designed. Different alternative designs are proposed and explored and a final decision design decision is made.

4. Build the system: A prototype is built and implemented to demonstrate the feasibility of the design and usability of the features and functions of the system. This stage serves as a proofof-concept. It allows researchers to "learn about the concepts, frameworks, and design through the system building process and gain insights about the problems and the complexity of the system." (Nunamaker et al. 1991, p. 98)

5. Experiment, observe and evaluate the system: The final stage is to observe the implemented prototype system developed in stage 4 by using case studies and field studies. The system is evaluated using laboratory or field experiments to determine compliance with the stated requirements and assess its impact on the users and the environment where it was implemented. New theories/models are developed and experiences learned are consolidated.

Systems development is not simply developing a piece of software. In fact, Nunamaker et al. (1990, p. 103) posit that "building a system in and of itself does not constitute research." However, the synthesis and expression of new technologies and new concepts in a tangible product can act as both the fulfillment of the contributing basic research and as an impetus to continuing research.

The rigor of the SD methodology as a research methodology has been questioned and the evaluation criteria issues have been raised by many researchers (Weber, 1987). Nunamaker et al. (1990) proposed five criteria to which SD research must conform (p. 101): (1) the purpose is to study an important phenomenon in areas of information systems through system building, (2) the results make a significant contribution to the domain, (3) the system is testable against all the stated objectives and requirements, (4) the new system can provide better solutions to IS 
problems than existing systems, and (5) experience and design expertise gained from building the system can be generalized for future use.

Parker et al. (1994) expanded these criteria and developed a more comprehensive set of criteria for the conduct and evaluation of system development research based in part on Miles and Huberman (1994). These criteria are discussed below (Parker et al., 1994 p. 128-129):

1. Significance: The study must be significant either theoretically, practically, or both. Basically, the new system that developed must provide with better solutions to IS problems than existing ones. Additionally, the researcher must show that he/she is aware of other known solutions to the problem and demonstrate that the proposed one is a superior solution.

2. Internal validity: In experimental design, internal validity refers to degree of correctness of the inferences about causal relationships between variables. In systems development studies, internal validity can apply to both the proposed method and system itself, and also to the argument that is put forward for the worth of the method.

3. External validity: External validity refers to the extent to which a study's results generalize to and across target persons, settings, treatments, outcomes, and times. In system development studies, generalizations can be made on the basis of some underlying theoretical base, or on a case-by-case basis.

4. Objectivity/Confirmability: This criteria is taken from Miles and Huberman (1994) who say that an important basic issue is one "of relative neutrality and reasonable freedom from unacknowledged researcher biases -- at the minimum, explicitness about the inevitable biases that do exist"(p. 278). Given the nature of system development approach research bias can be a problem especially in the case where the researcher him/herself constructs and tests the system.

5. Reliability/Dependability: This criterion is also taken from Miles and Huberman (1994) who state that the underlying issue here is whether the process of the study is consistent, reasonably stable over time and across researchers and methods. The question is one of quality control: Have things been done with reasonable care.

Table 5 summarizes some of the questions that researchers can ask during the analysis to assure the study conform to the criteria stated above. 
Table 5. Evaluation criteria for system development research methodology

\begin{tabular}{|c|c|}
\hline Significance & $\begin{array}{l}\text { 1. Is there theoretical significance? } \\
\text { 2. Is there practical significance? }\end{array}$ \\
\hline Internal Validity & $\begin{array}{l}\text { 1. Does the method works? } \\
\text { 2. Have rival methods been considered? } \\
\text { 3. Has sufficient evidence been collected in evaluating the methods? }\end{array}$ \\
\hline External Validity & $\begin{array}{l}\text { 1. Are the findings congruent with prior theory? } \\
\text { 2. Can the findings be applied elsewhere? }\end{array}$ \\
\hline Objectivity/Confirmability & $\begin{array}{l}\text { 1. Are the studies methods described in detail? } \\
\text { 2. Are the researchers explicit about personal assumptions, values } \\
\text { and biases? }\end{array}$ \\
\hline Reliability/Dependability & $\begin{array}{l}\text { 1. Are the research questions clear? } \\
\text { 2. Are basic constructs clearly specified? }\end{array}$ \\
\hline
\end{tabular}

Baskerville and Wood-Harper (1996) suggest that system development methodology as an ideal domain for the use of action research. In fact, in a study conducted by Lau (1997) where he reviewed articles that have used action research over a twenty-five year period found that 11 out of the 30 articles were categorized as system development. Additionally, Parker et al. (1994) argue that system development is a form of action research when the researcher is involved in the construction and testing of a method or an information system in real-world setting. The next section presents action research and discusses its strengths and limitations.

\section{Action Research}

Action research was first introduced by Kurt Lewin in the 1940's, as a research strategy to study social change in naturalistic settings. It is a qualitative research method that emphasizes collaboration between researchers and practitioners. Action research differs from other qualitative methods in many ways. In action research, researchers create the change and simultaneously study the process of change. Unlike case study for example, where the research 
studies the change but does not make the change. In $\mathrm{AR}$, the researcher must intervene in the action, he/she is not only concerned with studying the action of the others as is the case of most other qualitative methods. In AR participants are viewed and treated as collaborators not just subjects.

There are numerous definitions of AR. One of the most widely cited definition is by Rapoport (1970) who defines AR in the following manner:

"AR aims to contribute both to the practical concerns of people in an immediate problematic situation and to the goals of social science by joint collaboration within a mutually acceptable ethical framework (Rapoport, 1970, p. 499)"

Hult and Lennung (1980) provide one of the most comprehensive definitions:

"Action research simultaneously assists in practical problem-solving and expands scientific, as well as enhances the competencies of respective actors, being performed collectively in an immediate situation using data feedback in a cyclical process-aimed at an increased understanding of a given process in social, primarily applicable for the understanding of a given process in social systems and undertaken within a mutually acceptable ethical framework."

All of these definitions have the notion of the practical and collaborative aspects of the research method. A particular strength of action research is that it combines both theory and practice. Additionally, the outcome is tangible and is applied in real life contexts and is used to improve a situation and/or solve a real life problem (Baskerville and Wood-Harper, 1996).

Action research is "an iterative process that involves practitioners and researchers working together on a particular cycle of activities including problem diagnosis, action intervention, and reflective learning" (Avison et al., 1999). It is a process whose input consists of the problem to be solved and the theories that helps the researcher understand the environment of the problem at hand and the output is the solutions to the problem and/or the lessons learned and experiences gained (Figure 3). 


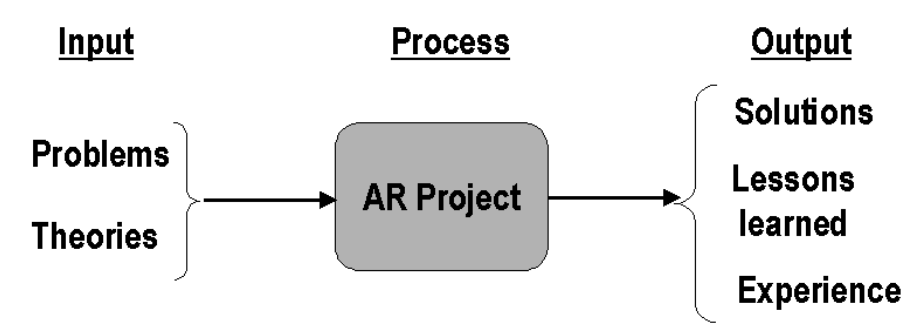

Figure 3. Action Research as a Process

Action research was first explicitly introduced to the information systems research community as a purely research methodology by Wood-Harper (1989). He incorporated the concepts of AR into his well-known systems development methodology, Multiview. AR research articles are scarce in major North American journals (Baskerville, Wood-Harper, 1996). In fact, Orlikowski and Baroudi (1991) uncovered only one research article that used action research between 1983 and 1988. Despite the unpopularity of AR in the IS discipline, Baskerville and Wood-Harper (1996) posit that IS discipline seems to be a very appropriate field for the use of AR. Additionally, Avison et al. (1999) suggested that action research is more suitable to information system development than case study. They argue that case study is not enough in the case of information system development because it does not allow for the iterative process inherent in action research method. In case study, researchers report what practitioners say they do, whereas in action research, they focus more on what practitioners actually do (Avinson et al, 1999). The rigor in action research is achieved through the iterative nature of the process.

Action research produces relevant research findings. Relevance has long been advocated by IS research community leaders (Keen, 1980, Benbasat and Zmud, 1999, Whetten, 1989, Robey and Markus, 1998, Saunders, 1998) as an important elements in the IS discipline. 
Researchers should make their work relevant by addressing issues that are relevant to practitioners. Action research promotes relevant research, it aims at providing change through action and understanding through research.

Galliers and Land (1987) found that out of the available research methods, mathematical modeling and laboratory experiments were inappropriate for research into methodologies. They identified six general application areas in IS research: society, organization, small group, individuals, technology and methodology. They argued that the complex, multivariate settings of systems development methodologies inevitable open a validity question for any method that assumes abstracted causality. Case studies, under the characteristic constraint of nonintervention (Jenkins, 1985) are incapable of studying new or change methodologies, since the introduction of such change is necessarily interventionist. We cannot study a new technique or methodology without apply the new technique in a real-world setting, meaning 'go into the world and try them out' (Land, quoted in Wood-Harper, 1989). Thus, the practical and theoretical nature of action research makes it one of the few valid research methods available to researchers to study the effects of specific systems development methodologies (Baskerville and WoodHarper, 1996).

Action research has made five key contributions in developing information systems (Avinson et al., 1999, p.2):

The Multiview contingent systems development framework (Avison and Wood-Harper, 1990);

The soft system methodology (Checkland, 1981);

> The Tavistock School's sociotechnical design (Mumford, 1978);

> Scadinavian research efforts intended to empower trade unions and strengthen the bargaining positions of users in systems development (Bjerknes, Ehn, and Kyng, 1987); and The Effective Technical and Human Implementation of Computer-based Systems (ETHICS) participative and ethical approach to information systems development (Mumford, 1978). 
Because action research encourages collaboration between researchers and practitioners, it is an ideal research methodology for the development of information systems. Since my research involves a systems design methodology, action research seems to be the ideal research method.

In using the action research, I have adopted the AR model suggested by Susman and Evered (1978). This model consists of five cyclical phases, which, they argue are all necessary for a comprehensive definition of action research. The first phase in this model is called diagnosing; it corresponds to identifying and defining the problem to be solved within the client organization. Diagnosing involves self-interpretation of the complex organizational problem, not through reduction and simplification, but rather in a holistic fashion (Baskerville, 1999). The second phase is called action planning, which involves specifying the course of action(s) for solving the diagnosed problem. This plan of action is guided by the theoretical framework proposed by the researcher. The plan establishes the target for change and the approach to change (Baskerville, 1999). The third phase, action taking is concerned with the implementation of the planned action. At this phase the change is introduced by intervention from both the researcher and the practitioner. The fourth phase is called evaluation, which involves studying the consequences of the actions and assuring whether the intended outcome(s) of the planned actions was achieved. The last phase, specifying learning identifies general findings and specifies what was learnt during the study.

The evaluation phase may lead to the start of a new cycle. The cycle continues to improve and enhance the knowledge about the problem to be solved, the theories applied and the organization's environment. Figure 4 presents an illustration of my dissertation research strategy using Susman and Evered's cyclical approach to action research. Action research seems to be the ideal research method for this study. 


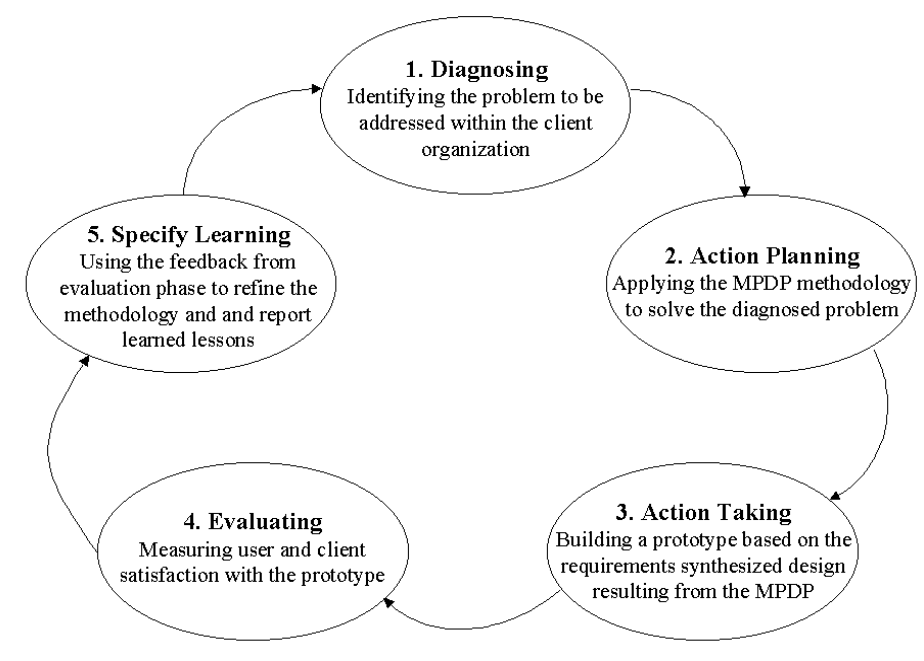

Figure 4. Research Strategy Using Susman and Evered’s Cyclical Approach

\section{DSS Success Model}

To evaluate the success of the design approach, I developed a DSS success model for wicked situations. Given the nature of wicked problems and the magnitude of conflict present in such context, I postulate that the success factors will be far more complex than those for measuring other IS success factors. Concomitantly, the multiplicity of stakeholders with different levels of expertise and the focus of the methodology on both users and non-users of the system may result in different dimensions to evaluate the different prototypes. I reviewed the appropriate literature and developed success factors in order to measure the success of the design, counter design and the synthesized design. Delone and McLean proposed an IS success model based on a review and integration of 180 research studies that used some form of system success as a dependent variable. They identified six different system success constructs showed how they relate to each other. Additionally, Doll and Torkzadeh (1988) and Sanders and 
Courtney (1985) developed and validated instruments for measuring end-user satisfaction and DSS success factors respectively. The Sanders and Courtney instrument focuses on three factors: decision context (degree of problem structure), level of task interdependence (degree of interaction with others), and level of task constraints (degree of decision maker authority and autonomy). The Doll and Torkzadeh instrument measures end-user computing satisfaction across five components - content, accuracy, format, ease of use, and timeliness - using twelve questions with Likert-type scales.

\section{$\underline{\text { Conclusion }}$}

The use of action research as a research methodology seems to be the most appropriate and feasible methodology despite its limitations. Applying the MPDP design theory in a real world situation would demonstrate both its feasibility and applicability. Additionally, since the proposed design theory is for the design of decision support systems in contentious situation, the use of system development approach as research methodology is also appropriate and feasible. 


\section{CHAPTER FIVE: THE MPDP METHODOLOGY FIELDWORK - PART I}

In the previous chapters the conceptual framework of the MPDP methodology was described. In this chapter, the MPDP methodology is applied to develop a web based DSS for zoning decisions. The contentious nature of zoning decisions and availability were the main reasons for choosing the site where the action research was carried out.

The chapter is organized as follows, first the site is described, followed by a presentation of the current decision making process, then the first six steps of the MPDP are illustrated. These steps consist of (1) stakeholder identification, (2) worldview formulation, (3) multiple perspective identification, (4) decision factors determination, (5) conflict identification, and (6) design and counter design prototype description. The last two steps of the MPDP methodology are presented in the following chapter.

\section{$\underline{\text { Site Description }}$}

The use of information technology in public sector organizations can lead to better communications, cost savings, and more simplified transactions. Most government agencies today strive to embrace information technology to overcome barriers of time and distance. Decision making in the public domain is a complex task. Oftentimes, decision-making requires several steps and interaction among a plethora of stakeholder groups. The kinds of decisions and problems that government agencies deal with - societal problems-- are inherently wicked (Rittel and Weber, 1973). In fact, Rittel and Webber (1973, p.160) described all public policy issues - 
"whether the question concerns the location of a freeway, the adjustment of a tax rate, the modification of school curricula, or the confrontation of crime" - as ill-defined and wicked.

Recently, many government officials have shown a growing interest in developing ways in which public sector organizations can use information technology to improve processes, service delivery and relationships with citizens. The search for more effective methods of delivering public services began in the early 1980s in most industrialized countries (Gant and Gant, 2001). The National Performance Review recommended that government agencies should "re-engineer government activities, making full use of computer systems and telecommunication to revolutionize how we deliver services" (NRP, 1993, p.v).

In an attempt to find a wicked situation to test the MPDP design methodology, local county planning officials were contacted. A DSS application involving zoning decisions was developed using the MPDP methodology.

As cities continue to grow in size and population, zoning decisions are becoming one of the major problems facing urban areas today. Hence, the need for an effective zoning decision management system is becoming increasingly urgent. The zoning decision-making process is a "wicked problem" as it is a complex process that is difficult to describe where the different stakeholder groups have different interests, opinions and judgments on zoning decisions. Zoning decision-making is embedded in a complex system that involves a wide array of stakeholders, ranging from the general public, to contractors, developers, public works departments, politicians, regulatory agencies, and many others. These factors influence the decision-making process about zoning in complex ways. 


\section{The Context}

The MPDP was applied to develop a decision support system for Orange County, Florida re-zoning decisions. Zoning is a planning tool for regulating and controlling the use of private property. Zoning decisions determine how land is to be used and the siting of building or other improvements to be placed upon that land. The main goal of zoning is to avoid or minimize disruptive land use patterns involving incompatible land uses (Chandler and Dale, 2001, p.13) and to have a city with attractive and well-functioning business and residential areas. There are many types of zoning districts including commercial, single family residential, multi-family residential, office and industrial.

Zoning decisions must be based upon information that can be supported and is accurately and carefully presented (Smith, 1979). Often time these decisions may involve emotional arguments or extraneous statements. However, decision-makers should not be interested in these type of statements regarding the reasons the applicant thinks he/she ought to be entitled to do what he/she would like to do.

\section{The Orange County re-Zoning Decision Process}

The rezoning process is the process whereby a property owner fills out a rezoning application form to change the zoning of his/her property. Through the process, County staff from various departments and divisions coordinate information and the Planning Division prepares a detailed report regarding the request. In this staff report, the Planning Division makes a recommendation to the Planning and Zoning Board (P\&Z). The P\&Z holds an advertised public hearing regarding the request. The P\&Z then makes a recommendation to the Board of 
County Commissioners (BCC), which makes the final County decision on approval, denial, or approval with conditions.

There are three major bodies that are involved in every re-zoning request: the Planning Department, the Planning and Zoning board and the Board of County Commissioners.

\section{The Planning Department}

The Planning Department reviews each request and gathers information about the request and makes a recommendation of approval, denial or approval with conditions to the P\&Z. The Planning division recommendation is made solely from a technical perspective. They base their decision solely on compatibility with the surrounding neighborhood and the development trends of the area and consistency with the comprehensive policy plan. The Comprehensive Policy Plan (CPP) is a plan that is prepared in accordance with the State of Florida's "Local Government Comprehensive Planning and Land Development Act" (Chapter 163, Part II, Florida Statutes), which establishes the context and legal authority for growth management in Florida. The goals, objectives, and policies of the CPP provide for growth in a sustainable manner that creates a compact urban form. The CPP is comprised of eighteen elements that address specific topic areas, such as transportation, land use, public schools, economic development, and urban design. In order for a property to be rezoned, its use must coincide with the future land use of that property as indicated in the future land use map (FLUM). In situations where the request does not coincide with the FLUM designation then the applicant must change the future land use designation first by going through a different process of Comprehensive Plan Amendment.

\section{Planning and Zoning Commission}

The P\&Z Commission consists of seven members appointed by the members of the BCC to serve as an advisory body on many land use issues including rezoning issues. There is one 
representative for each district and one chairman of the commission. Every district commissioner appoints a representative of his/her district in the $\mathrm{P} \& \mathrm{Z}$ commission. The $\mathrm{P} \& \mathrm{Z}$ meets every third Thursday of each month in a public hearing where rezoning cases are presented and citizens can voice their concerns about any particular rezoning application. A week prior to the $P \& Z$ public hearing, the planning division submits the staff recommendation reports to each member of the commission in order to review the cases before the public hearing. During the public hearing, the $P \& Z$ members review each application and make a recommendation to the BCC for approval, denial or approval with conditions. The BCC then makes the final decision.

\section{The Board of County Commission}

The BCC consists of seven members, six members representing the six districts in Orange County and one Chairman. These members are elected by the citizens of each district. The BCC is the ultimate decision maker in the zoning decision process. Cases are reviewed during the BCC meeting and members of the BCC vote on each case. A majority vote determines the outcome of each case.

\section{Public Hearing}

Whenever there is a zoning decision to be made, a public hearing is held to inform the public and to allow them to express their views on the decision. Public hearings are very important in zoning. It is a representation of the democratic process that can prevail where zoning is perfectly administered (Smith, 1979). It is designed to provide a check and balance system in the adoption of or varying from legislation that directly concerns the public (Smith, 1979). In Orange County, public hearings are held once a month. Information about the cases to 
be presented to the commission is published online for the public. Additionally, notices about the rezoning applications are mailed in advance to the adjacent properties of each of the requests.

\section{Data Collection}

The action research study was performed from August 2003-August 2004. Data gathering consisted of unstructured and semi-structured interviewing of stakeholders groups, review of past rezoning decisions from 2002-2004 and documentation review. Planning and zoning public hearings were attended as well as the development review committee (DRC) meetings and staff meetings where zoning issues and problems for particular applications were discussed. This triangulation across several data collection techniques is beneficial because it provides multiple perspectives and yields stronger substantiation of constructs (Orlikowski, 1993). The face to face interviews are necessary if one wants to get multiple perspectives (Techincal (T), Organizational (O) and Personal (P)). Mitroff and Linstone (1993, p.107) stated that "In obtaining information, recognize that $\mathrm{O}$ and $\mathrm{P}$ require greatly different methods than $\mathrm{T}$. The $\mathrm{T}$ perspective generally relies on the analysis of scientific data and models. One-on-One interviews have proven advantageous in revealing what makes an organization and individual actors 'tick'." The interviews were conducted at three stages of the MPDP methodology as indicated in Figure 5. The first set of interviews was aimed at identifying key stakeholders and determining their perspectives and worldviews with regards to zoning decisions. Additionally, information regarding the current process and the factors considered in the decision process were also compiled in the first stage. The second set of interviews aimed at evaluating the two prototypes: the design and the counter-design. The third and last set of interviews intended to 
evaluate the synthesized design and the process used to reach the final design. A total of 43 interviews was conducted. To assure consistency, all interviews were conducted by the same researcher. In few occasions two researchers attended the interview but only one person did the questioning. All interviews were taped and transcribed.

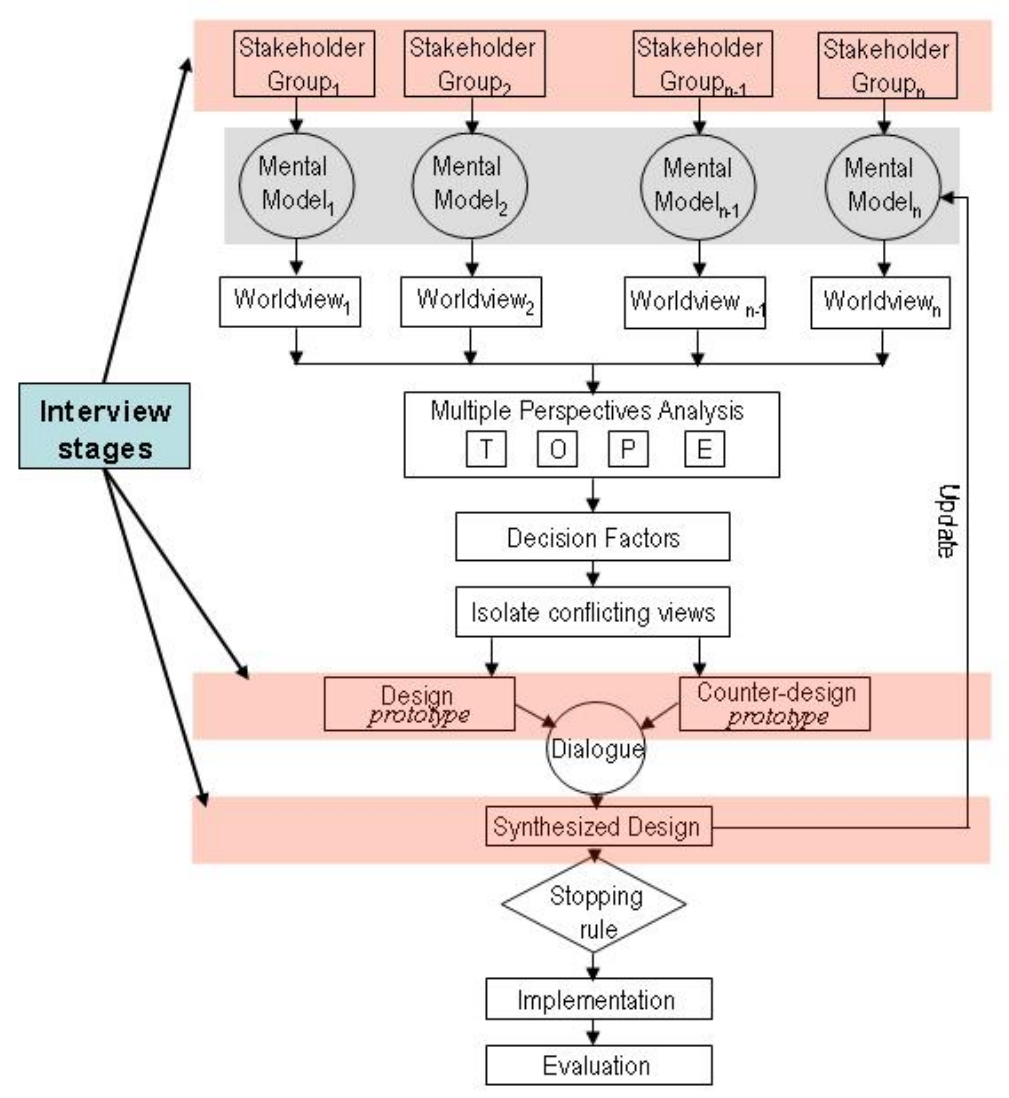

Figure 5. Interviews stages in the MPDP methodology

\section{$\underline{\text { Stakeholder Identification }}$}

Stakeholders are defined as individuals that are either affected by the decision or can affect the decision. Based on this definition and by reviewing past decisions and attending public hearings the following five stakeholder groups were identified: applicants, neighborhood 
associations/citizens, elected officials, environmental groups, and staff. These groups interact at many levels during the decision process and exercise different level of influence on the final decision. Table 1 lists the stakeholder groups along with a brief description of their role and stake in the decision process. The complexity of the relationship between the five stakeholder groups is depicted in a stakeholder relationship diagram in Figure 6.

Table 6. Stakeholder groups

\begin{tabular}{|l|l|}
\hline Stakeholder Group & Description \\
\hline $\begin{array}{l}\text { Applicants (Owners, } \\
\text { developers) }\end{array}$ & $\begin{array}{l}\text { Individual citizens or developers wanting to propose a rezoning of } \\
\text { a property. Their concern is about an expensive and protracted } \\
\text { permitting process that may wind up in court. }\end{array}$ \\
\hline $\begin{array}{l}\text { Neighbors / } \\
\text { neighborhood } \\
\text { associations } \\
\text { (citizens) }\end{array}$ & $\begin{array}{l}\text { Citizens who are concerned about the effect of a proposed } \\
\text { plan/project on the quality of their lives and their asset values. }\end{array}$ \\
\hline $\begin{array}{l}\text { Environmentalists } \\
\text { (Interest groups) }\end{array}$ & $\begin{array}{l}\text { Environmental organizations who are dismayed by sprawl and the } \\
\text { damage it may cause to the environment. }\end{array}$ \\
\hline $\begin{array}{l}\text { Elected Officials } \\
\text { (P\&Z commission, } \\
\text { BCC) }\end{array}$ & $\begin{array}{l}\text { Elected officials and planning commission members who wish } \\
\text { that their work would achieve more productive improvement for } \\
\text { their communities with shorter less controversial meetings. }\end{array}$ \\
\hline $\begin{array}{l}\text { Planning Staff } \\
\text { (Staff) }\end{array}$ & $\begin{array}{l}\text { Planning division staff members who prepare the staff report and } \\
\text { are responsible for the accuracy and objectivity of the facts in the } \\
\text { report. Their role is to make a recommendation based solely on } \\
\text { technical fact. }\end{array}$ \\
\hline
\end{tabular}




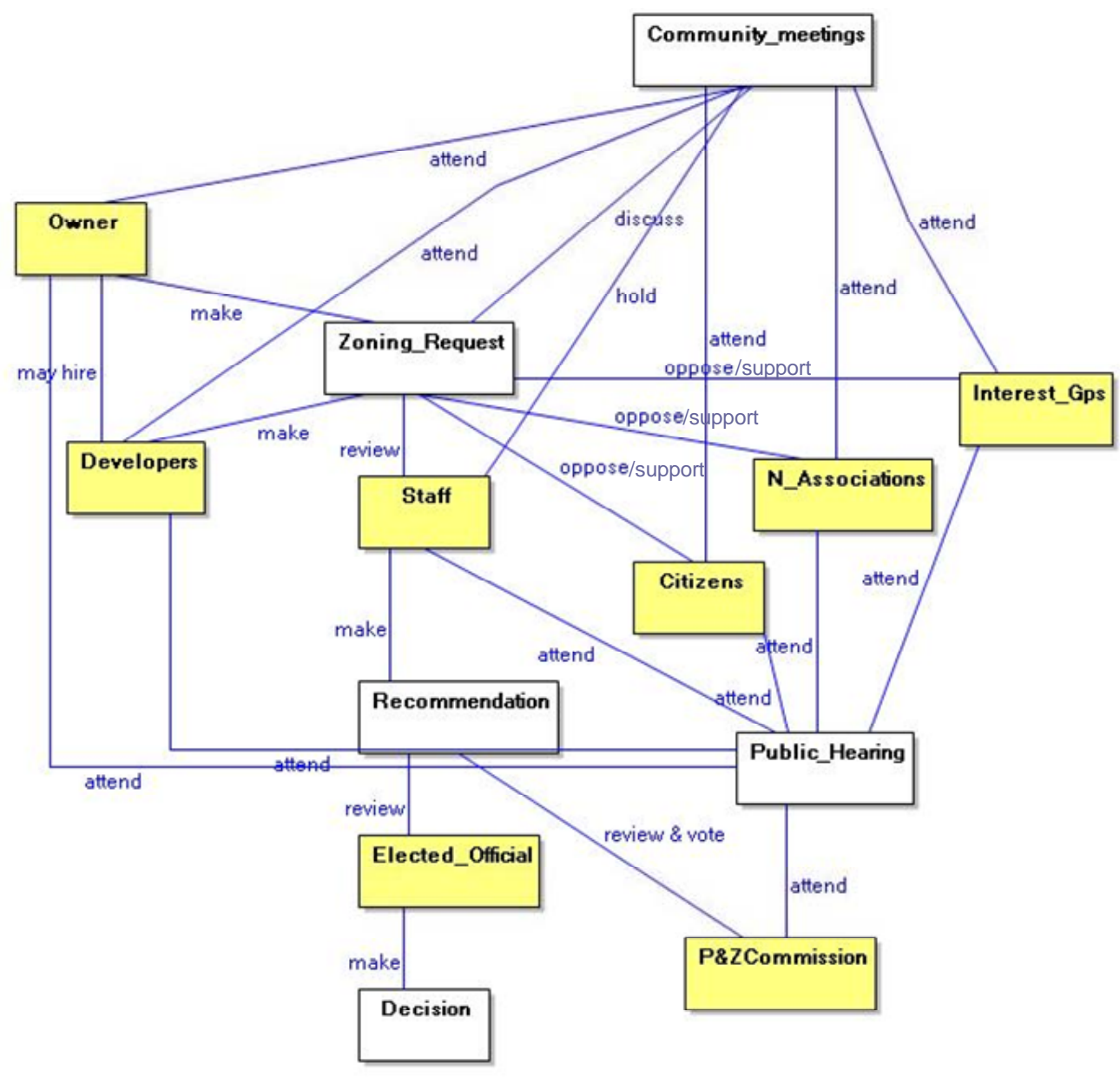

Figure 6. Stakeholder Relationship Diagram

Note: Shaded boxes are stakeholders and non-shaded boxes are events.

Once stakeholder groups were identified, efforts were made to contact individuals from each group and schedule interviews. Several members from the applicant, neighborhood associations and environmentalist lists provided by the planning division were randomly selected and solicited by phone and/or email. Since neighborhood associations are the most dominant groups among citizens, I chose to select citizens' subjects from representatives of different neighborhood associations. Of the ones that responded to the request only those that have been involved in zoning process were selected for the interview. Three members from each group 
were interviewed, a total of 15 subjects. The interviews lasted an average of 45 minutes, they were taped and transcribed.

An interview guide reflecting the multiple perspectives were developed to guide the interviews (Appendix B). This guide was slightly modified to suit the different groups of stakeholders. The role of these interviews was to gather information about the stakeholders and identify their relationships and interactions. The constructs of importance are: the role that stakeholders play in the decision process, the relationship with other stakeholders and to the decision process, their perspectives and worldviews on the current process, how they understand the current process, and presence of any conflict. This information was necessary to be able to extract their mental models and to be able to compare stakeholder groups and to identify conflicting views.

In order to build the stakeholder group mental models, causal maps were derived from the transcripts for each individual. Then these maps were aggregated to form a group map. Causal maps are representations of individual (or group) beliefs about causal relations (Markoczy and Goldberg, 1995). According to Markoczy and Goldberg (1995) causal maps have two elements: relevance and influence relationship. Relevance is represented by nodes and represents the factors that the individual thinks are relevant. Nodes are labeled to indicate the factor in consideration. Influence relationships are represented by arrows linking the nodes, these arrows may be accompanied by signs (+ or -) indicating a positive or negative influence. Appendix C presents cognitive maps of each stakeholder group. 


\section{Worldview Formulation}

The worldview formulation stage helps the designer understand the views of each of the stakeholder groups. Different stakeholder groups view the decision process differently. Staff members view it as strictly a technical issue where decisions are based solely on technical facts, whereas interest groups and neighborhood associations tend to view it as a strictly political issue. In the next paragraphs I will present the different views of the different stakeholder groups.

\section{Staff}

Staff members consider zoning as a top priority on their agenda. Ninety percent of their work deals with zoning issues and zoning applications. According to staff members the adjacent property owners are the most influential group in the process. Staff members view the zoning decision process as strictly a technical issue where decisions are based solely on technical facts. They do not view the other factors such as economic, transportation and environmental issues as relevant to making their recommendation. As stated by one of the staff members:

"There is a lot of stuff that is irrelevant because over the years the board of county commissioners have said they wanted to see that information in the report, such as parks, why do I care where the parks are in relation to a rezoning request?... Transportation, they want to know what roads and what the capacity on the roads are. Well that's not really a re-zoning issue, but they want to know about it anyways and they ask us to provide them."

Staff sees public education as a major problem in the zoning process. When people, purchase a property, they often do not take the time to research the neighborhood and understand what is allowed and what is not allowed as far as zoning, variances, and special conditions that have been granted in the neighborhood. 
Staff members seem to be satisfied with the current process. "The current process works!" stated one of the senior planners. Their main complaint is that there is a lot of information that they compile that they think is not relevant to zoning such as wetlands, drainage, "Those are technical issues that are determined whether you zone commercial or residential, if you got wetlands on your site you are going to have to abide by our regulations anyway, zoning is not going to make a difference.” says one of the planners. The two main criteria upon which staff members make their recommendation are consistency with the comprehensive plan and compatibility with the surrounding areas. While they see the process mainly as an issue of professional standards, they think that elected officials tend to view it as an issue of constituent satisfaction.

Constituent opposition is a main issue to staff even and though their role is to bring only the technical perspective, they still have to deal with political and sometimes personal issues. Their main goal is to avoid any opposition during the public hearing. One of the staff members clearly stated when asked about the main goal and objectives he is trying to achieve in the whole process "Get through the public hearing with my behind intact."

\section{Elected Officials}

Elected officials are the ultimate decision makers in the zoning process. Their votes determine the final outcome of a zoning application. Before each meeting each elected official receives a staff report which contains detailed information about each zoning case presented for that period. This report includes the staff recommendation and P\&Z recommendation along with details on the public hearing. Elected official consider zoning issues as top priority on their 
agendas. The most influential group according to elected officials is the adjacent property owners. Zoning is considered as one of the government policies that encourage citizen participation. According to elected officials, the main problems in the zoning process are the fact that people do not want change and lack of enforcement. Because zoning decisions directly affect someone's property value, they do not want anything that will negatively impact it. People are very protective of their properties and their investment so their involvement in the process is very important.

Some elected officials do not seem to be satisfied with the current process: "I am dissatisfied with it and I do not think there is anything that would be better. It is a difficult process. It is torturous at times. People (citizens/applicant) can be very emotional at times in the process." To improve the process, an elected official proposed taking the politics out of the process by having the decision made by an administrative type officer. This type of process is currently used in Hillsborough County, Florida where the P\&Z commission has been eliminated and replaced by one officer responsible for making a recommendation to the board.

The criteria used by elected officials in making their decisions are compatibility, consistency with comprehensive plan and common sense. They also consider and weight heavily the opposition and more specifically the size of the opposition. As mentioned by one elected official "most elected officials are elected to represent those people and would feel that those are the motivators.” When asked about the measures used to evaluate zoning decisions one elected official said "if the commissioners get reelected!"

Elected officials consider all the information presented in the staff report to be relevant. The most important piece of information they seek from the report is the details of what happened during the public hearing. This seems to be a major determinant in deciding which 
factors the elected official considers in his/her decision. The elected officials work closely with staff when making their decisions. They sometimes work with the applicant and the interest groups in case of controversial zoning cases.

\section{Applicants}

Applicants do not seem to be satisfied with the process. Their main concern is that the current process depends too much on emotions. One applicant stated that "The biggest problem that occurs when the decision is not made on fact and the decision is made on empathy or emotions." Another one said that the zoning decision process "is purely an emotional reaction based on the temperature of the crowd or the re-election objectives, whether they are up for elections next year. That's a lousy process generally.”

The applicant group members feel that the most influential group in the zoning process is the adjacent property owners as evidenced by the following quote "The most powerful people in Orange County are the heads of the home owners associations because on any given day they can pack the chamber by people from their home owner's organization and they would have the ear of the county commissioners.”

The applicants emphasize very much the need for the decision makers to put emotions aside and focus mainly on facts. They believe that "zoning should not be a politically driven, it never should be. Zoning should be based on what's good for the community and it is hard to separate that from political issues.” They suggest that the decision makers must be proactive as opposed to being reactive to zoning issues. They should educate the public and explain to them 
the process and why decisions were made a certain way. Doing so according to applicant group members will enhance the decision process.

One of the applicants feels that planning/zoning is very specific and one cannot generalize and therefore trying to develop a DSS is a waste of time. Zoning issues are case specific and what might be a key determinant in one case may not be important in another.

\section{Interest Groups/Environmental Groups}

Environmental groups represent the interest groups. Interest groups may include groups other than environmental groups however, in our case the environmentalist represent the most prominent and strongest interest group. Therefore, I focused solely on this group and refer to it either as interest group or environmental group in this study.

Environmental groups are mostly concerned with the damage growth and land development is causing to the environment. Zoning issues become top priority in their agenda when a zoning application involves natural resources such as wetlands, lakes, and/or endangered species. According to this stakeholder group, some of the problems with the zoning decision process include the lack of complete impact evaluation of projects, approving more development than the natural resources, particularly water, can sustain, lack of commitment and lack of notification of the people that are affected. They are very dissatisfied with the current process and think that politics and corruption dominate the process. All three interviewed members of this stakeholder group believe that the applicant is the most influential stakeholder and that the commissioners tend to be on their sides, especially the big development firms, as shown by the following quote: 
"I would say that the developers and their lawyers are given the highest priority and they're given much more, given that they have a financial gain from the outcome. I think that they are over represented and over accommodated.”

Environmentalists advocate the use of scientific and biological data in making zoning decisions. They believe that it is the fairest way to make decisions as shown in this quote:

"We can never really choose fairly but if we say well there is endangered species over here and not over there well that's a fair way to make decisions. Biological data is an unbiased way to make decisions and it is intelligent."

\section{Neighborhood Associations}

Neighborhood associations represent all the citizens living in a certain neighborhood. They provide a united voice to governmental entities. Their purpose is to identify and resolve neighborhood issues that may arise such as crime, zoning, compliance, etc... When a zoning issue arises it usually becomes a top priority on the associations' agenda according to the interviewees. Analysis of the interviews and observations from the public hearings showed that there is a lack of public education. Citizens do not know much about zoning or the zoning decision process. As evidenced by a member of this group when asked about their opinion of the process, "I don't know what the process is!" Some think that zoning has many steps which makes it a cumbersome process. This lack of education and complexity of the process affects citizen participation. One citizen interviewee attested that "the general public has little to no participation in the process.”

With regards to staff, some believe that they are overworked and understaffed which leads them to take the path of least resistance in order to avoid any problems. One of the staff 
interviewees stated, "they are looking for the quickest, the easiest, most non-confronted resolution they can find.”

Neighborhood association interviewees seem to believe that the most influential group is the applicant's group. Referring to a zoning issue, one interviewee said "The question is why would one person [the applicant] be able to keep the county in check for 3.5 years where you and I could not do that as individuals.” They believe that staff and elected officials are influenced by “certain powers that we [citizens] are not aware of.”

Neighborhood association members believe that residents must have a direct voice in zoning decisions that affect their neighborhood. They feel that they, not staff or elected official, should make the final decisions because they are in a better position to judge what's best for them and their neighborhoods not a third party that is influenced by political factors.

\section{Multiple Perspectives Identification}

This is the third stage in the MPDP methodology. It seeks to classify the different worldviews into technical, organizational, personal, and ethical perspectives. This step is crucial to avoid the limitations of considering only the technical perspective. In analyzing the interviews, I attempted to look at the problem from all different perspectives. Based on the transcripts, it seems that the planning department and staff tend to hold a technical perspective. Staff tend to use a rational approach in formulating their recommendations. As mentioned by a staff member, "The two basic things that we always have to look at are: Compatibility with the area and consistency with the CPP.” Most stakeholder groups seem to agree that staff bring in 
the technical perspective. One elected official stated "planning and zoning staff bring technical expertise to the process." Most of the elected officials interviewed acknowledged their reliance on staff in technical issues. The interest group members seem to believe that staff do not conduct a scientific review of the applications and that politics dominate their perspectives. A member of the interest group said "we need more science and less politics.” According to the interest group members, the decisions must be based only on scientific facts especially for big development projects. One member of the applicant group warned from the danger of the technical perspective stating that "some of them view it (zoning decision process) as black and white and they are missing it.”

The organizational $(\mathrm{O})$ and personal $(\mathrm{P})$ perspectives tend to sweep in human beings, their emotions and ethics (Linstone, 1999). They sweep in societal and human aspects that are often present in all complex systems (Mitroff and Linstone, 1993). The O and P perspectives were difficult to separate in this case. It was not easy to distinguish between an $\mathrm{O}$ and a $\mathrm{P}$ perspective, especially when considering the elected officials perspectives. Are they giving their own or the organization's perspective? The organizational perspective in this case is represented by elected and appointed officials. One elected official said "Your elected official and your advisory boards bring both citizens’ perspectives and real world perspective.”

The personal perspective is based on individual experiences, intuition, personality factors and attitude about risk among other things (Courtney, 2001, p. 30). Personal perspectives of decision makers tend to sometimes influence the final decision. As mentioned by one elected official stated that "there have been in my experience occasions when the special interests will get involved at the end of the process.” Staff also bring in their own personal perspectives to the process, their personal experiences and knowledge does affect their recommendation. One 
senior staff member stated "I have been doing zoning for so long. I have institutional knowledge." The personal perspective sometimes masks the organizational perspective and oftentimes creates some confusion among junior staff members because they lack the institutional knowledge and therefore it appears as if senior staff base their decision using their own personal perspectives.

Ethical perspective governs a stakeholder's behavior in choosing between what is "right" or "wrong." The ethical values and judgments are implicit in the assumptions made and the selection of criteria used in the final decision and/or recommendation. At the elected official level, different members base their decisions on different criteria. Sometimes the final decision seems to be influenced by the number of people opposing the request and by elected officials interest in the number of votes. Other time it is the applicant that may exert certain powers on elected officials to influence their decisions. And occasionally, environmental factors can be the overriding factors in the elected official decision. From the environmentalist ethical perspective, decisions must be made based on avoiding harm to the environment. From the applicant ethical perspective, decisions must be based on protecting individual's property rights. From the staff ethical perspective, decisions must be based on fairness. From the neighborhood associations' ethical perspective, decisions must be made based on the wants of the majority of the citizens.

In order to determine the subjects’ perspectives vis-à-vis the importance of the political, technical, economic, ethical and quality of life factors in the current process, I asked each subject to rate how important these factors are in the current decision process. The results are summarized in Table 7. I would like to emphasize here the fact that the views presented in table 7 are the stakeholders view about the current process not how they would want the process to be. For instance, elected officials believe that the political factors are not very important (weak) in 
the current decision process whereas the interest groups think that the political factors are very important (strong) in the current decision process. Concomitantly, staff believe that technical factors are very important (strong) in the current process whereas the interest groups think that technical factors are not considered in the decision making process at all (none).

Table 7. Stakeholders perspectives and their views on the current process decision factors

\begin{tabular}{|l|l|l|l|l|l|}
\hline $\begin{array}{l}\text { Factors } \\
\text { Categories }\end{array}$ & $\begin{array}{l}\text { Elected } \\
\text { Officials (O, } \\
\text { P, E) }\end{array}$ & $\begin{array}{l}\text { Planning } \\
\text { Staff (T) }\end{array}$ & $\begin{array}{l}\text { Applicant } \\
\mathbf{( P )}\end{array}$ & $\begin{array}{l}\text { Neighborhood } \\
\text { Associations/citizens (O, } \\
\mathbf{P})\end{array}$ & $\begin{array}{l}\text { Interest groups } \\
\mathbf{( T )}\end{array}$ \\
\hline Political & weak* & medium & Strong & Weak & strong \\
\hline Technical & weak & strong & Strong & Weak & none \\
\hline Ethical & strong & medium & Weak & Strong & weak \\
\hline Economic & weak & weak & Weak & Weak & medium \\
\hline QOL** & strong & weak & Medium & None & medium \\
\hline $\begin{array}{l}* \text { indicates the strengths of importance that factor in the current process as viewed by that group. None means that } \\
\text { the group does not think the factor is considered in the current process. } \\
* * \text { Quality of Life }\end{array}$
\end{tabular}

\section{$\underline{\text { Decision Factors Determination }}$}

Zoning decisions include several factors that are considered in making a recommendation and/or decision. However, these factors differ in relevance and importance depending on the case and on the level at which the decision is made. For example, technical factors such as consistency with CPP and compatibility are important in all cases and mostly at the staff level. Staff members compile an array of information about the impact of a certain zoning change but they base their recommendation solely on consistency and compatibility.

Stakeholder groups participate differently in the decision process and have different degrees of influence on the decision. Environmental groups, for example, may oppose and voice 
their concern in the public hearings but have little direct influence on the decisions, while staff collect and organize data about all applications make recommendation which carry a heavy weight in the final decision. Citizens and neighborhood associations are interested in increasing their property values and the quality of life in their neighborhoods while applicants and developers are interested in getting their applications approved. These different groups have different preferences as to what criteria to be used in the decision making process and their weights in the final decision. This range of stakeholders in this decision making process and the different degrees of influence and participation poses a challenge for the designer to accommodate these different views in the DSS design.

Based on past and present zoning decisions and based on the analysis of the interviews and field notes, the following set of criteria appeared to take part in the current complete decision process (numbers in parentheses correspond to the questions addressing that issue in Figure 7):

- Consistency with CPP including the Future Land Use Map (1)

- Compatibility with the surrounding area (2)

- Consistency with existing land use and development of the area $(3,4)$

- Consistency with previous zoning decisions in the area (5)

- Consistency with the dimensional requirements of the zoning district to which the proposed property is being rezoned. (6)

- Existence of any environmental issues (7)

- Availability of public utilities infrastructure, such as water and sewer, transportation, schools, parking, and parks and recreations to support the zoning change (8-11)

- Neighborhood and adjacent property owner response to notification (12)

Figure 7 shows how these factors relate to each other in the making of the final decision in the current process. These factors are not necessarily considered in the order presented in figure 7. These criteria vary in importance from case to case and from district to district. In some districts environmental issues are a major decision factor. Consistency and compatibility however remain the common denominator and the minimum requirement of all zoning decisions. 
In addition to these criteria, there are various constraints that make designing a DSS for these types of decisions a complex process. These constraints are imposed by the political nature of this process. The BCC make the final decision using a majority voting rule. Additionally, the fact that these BCC members have term limits also makes the decision criteria to be included in the DSS a very challenging task as different elected officials have different criteria and different interests in zoning decisions. Additionally, the elected officials' personal perspectives may overrule the recommendation given by the DSS.

One challenge that I faced in the design phase is the difficulty of quantifying certain aspects of the decision such as the political factors and ethical factors that seem to dominate the decision process mostly at the elected official level. Additionally, the weights of the different criteria and different factors differ from one application to another and from one decision maker to another, which makes the task of building the DSS very difficult. For example, as opposed to what one might think, economic factors do not play an important role in the decision. Economic factors become a factor only in very large scale projects. 


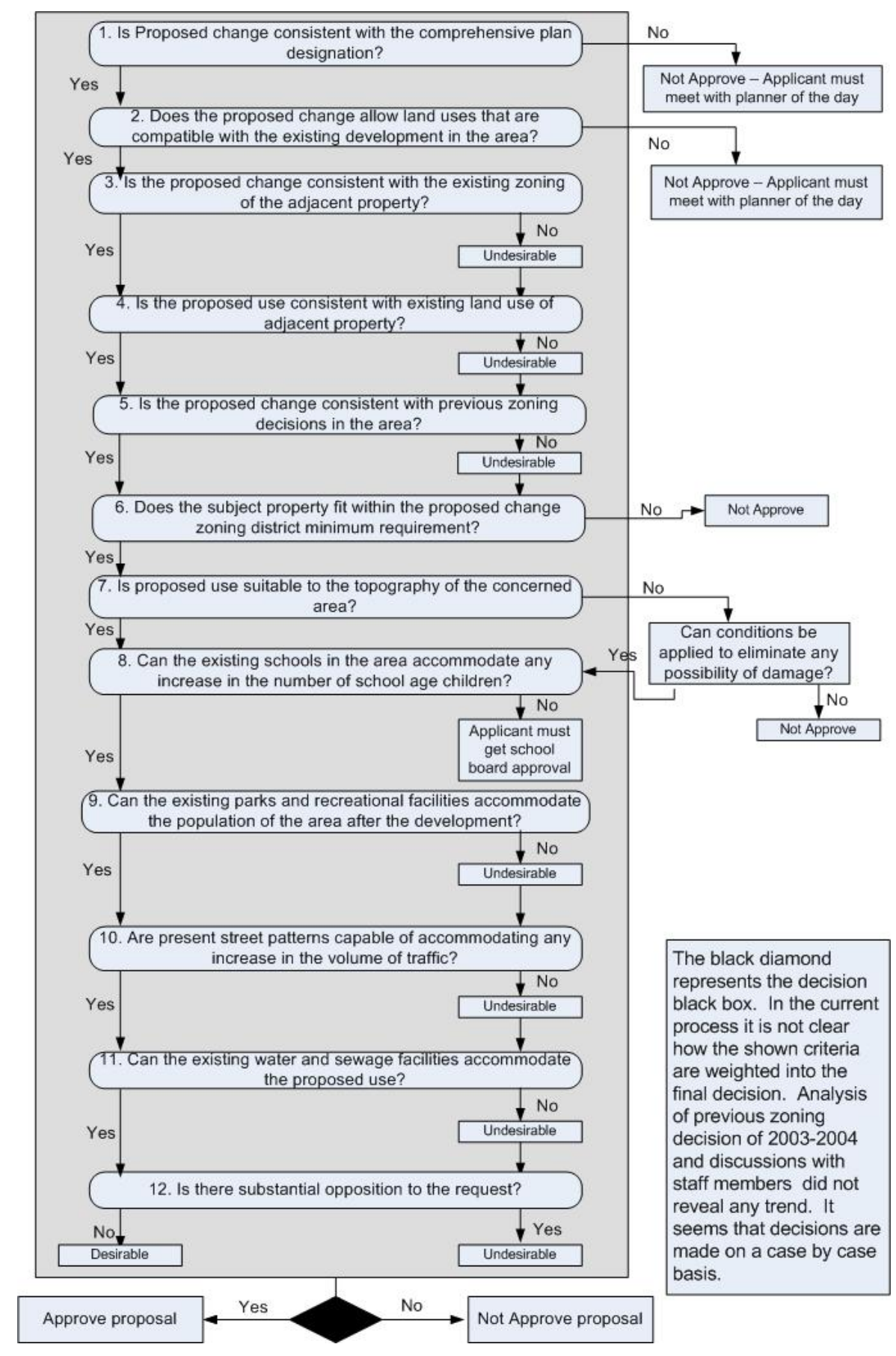

Figure 7. Decision criteria of the current process 


\section{Conflict Identification - Thesis and Anti-thesis}

The next step in the methodology is to determine the thesis and anti-thesis. The methodology suggests comparing the cognitive maps in order to determine the group representing the dialectic view to the current process. This group's views will then constitute the anti-thesis. The anti-thesis is not necessarily the opposite of the thesis but an alternative explanation or point of view. Both the thesis and the anti-thesis use the same data. This data is used by different stakeholder groups holding different perspectives, it is interpreted differently and hence each group arrives at different conclusions. As stated by Mason and Mitroff (1973, p. 482) "data are not information, information results from the interpretation of the data." In our case, since there are multiple views and multiple interpretations, we need to narrow these views to the two which would constitute the thesis and anti-thesis of the dialectic method. Churchman described the anti-thesis as being the deadliest enemy of the thesis (not necessarily its negation). In order to determine the anti-thesis, I used the method proposed by Markoczy and Goldberg (1995) to compare group cognitive maps of the different stakeholder groups. The formula used in this method is derived from Langfield-smith and Wirth's (1992) distance ratio formula. Figure 8 shows the formula used. In doing the computations I used a software called Distrat. Distrat performs the distance ratio calculations and can handle a large number of maps efficiently. Distrat is available for free on the Internet by its author, Jeff Goldberg. Appendix D contains an example of how distance ratio is calculated. The matrices derived from the cognitive maps are available in Appendix E. Table 8 summarizes the pairwise comparison results. The distance ratios range between 0 and 1 where 0 indicates complete similarity and 1 indicates

complete difference between the maps. From the results presented in Table 8 one can see that 
the Neighborhood association group has relatively the largest distance with all groups and that the largest distance is between the neighborhood association group and staff. Based on this result, the Neighborhood association group would represent the anti-thesis in our case. The staff viewpoint will then be the basis of the thesis. Staff support a strong technical view. According to staff, zoning decisions must be based solely technical factors such as compatibility with the surrounding areas, consistency with the comprehensive plan and infrastructure capacity.

$$
\begin{gathered}
D R=\frac{\sum_{i=1}^{p} \sum_{j=1}^{p} \operatorname{diff}(i, j)}{6 p_{C}^{2}+2 p_{C}\left(p_{u_{A}}+p_{u_{B}}\right)+p_{u_{A}}^{2}+p_{u_{B}}^{2}-\left(6 p_{C}+\left(p_{u_{A}}+p_{u_{B}}\right)\right.} \\
\operatorname{diff}(i, j)= \begin{cases}0 & \text { if } \mathrm{i}=\mathrm{j} ; \\
1 & \text { if } \mathrm{i} \text { or } \mathrm{j} \notin \mathrm{P}_{\mathrm{c}} \text { And } \mathrm{i}, \mathrm{j} \in \mathrm{N}_{\mathrm{A}} \text { or } \mathrm{i}, \mathrm{j} \in \mathrm{N}_{\mathrm{B}} ; \\
\left|a_{i j}-b_{i j}\right| \text { otherwise. }\end{cases}
\end{gathered}
$$

Where $A$ and $B$ are two extended association matrices of size $p, a_{i j}$ (or $b_{i j}$ ) is the value of the $i$ th row and $j$ th column of $A$ (or $B$ ), $\mathrm{P}_{\mathrm{c}}$ is the set of nodes common to both maps, $p_{c}$ is the number of such nodes, $p_{u A}$ is the number of nodes unique to map $A$ and $p_{u B}$ is the number of nodes unique to $B$. $N_{A}$ and $N_{B}$ are the sets of nodes in the maps $A$ and $B$.

Figure 8. Distance ratio formula by Markoczy and Goldberg (1995)

Table 8. Pairwise distance ratios

\begin{tabular}{|l|l|l|l|l|l|}
\hline & App & EO & Staff & Nass & Int \\
\hline App & & $\mathbf{0 . 0 4 4 3}$ & $\mathbf{0 . 0 4 3}$ & $\mathbf{0 . 0 6 3 3}$ & $\mathbf{0 . 0 5 1 8}$ \\
\hline EO & & & $\mathbf{0 . 0 5 4}$ & $\mathbf{0 . 0 6 5 3}$ & $\mathbf{0 . 0 5 3 8}$ \\
\hline Staff & & & & $\mathbf{0 . 0 6 8 1}$ & $\mathbf{0 . 0 4 1 1}$ \\
\hline Nass & & & & & $\mathbf{0 . 0 5 6 5}$ \\
\hline Int & & & & & \\
\hline $\begin{array}{l}\text { App: Applicant, EO: Elected Officials, Nass: Neighborhood } \\
\text { Associations, Int.: Interest Groups }\end{array}$ \\
\hline
\end{tabular}


The Neighborhood association strongest viewpoint is that zoning decisions should be determined by the adjacent property owners and the people living in the area. They advocate the right for citizens to vote on any zoning decision, especially those regarding big development projects. In fact, there is a group in Florida entitled, Florida Hometown Democracy, Inc. who is promoting an amendment to the Florida constitution that is intended to help control growth by making it more difficult to change a land use in the СРP (http://www.floridahometowndemocracy.com). The idea is to allow citizen voters rather than elected officials to decide whether a change should occur or not. Based on this view the counterdesign DSS will use citizen's votes as the main decision factor in zoning decisions. The next section will present the design and counter-design prototypes. I adopted an object oriented approach in designing both prototypes using the Unified Modeling Language (UML).

\section{The Design prototype - Process description}

To start a process, one must submit an application requesting a zoning change. A complete application consists of the following:

- Completed application form including reason for the rezoning request

- Copy of deed for the property

- Notarized authorization of the property owner, if the applicant is not the owner

- Legal description and survey of the property

- Processing and review fee.

Once the application is complete, it is submitted to staff for review. Staff sends notification to the adjacent property owners notifying them of the zoning change request in their neighborhood. Staff also gathers information with regards to the impacts of the request on the infrastructure of the area. Staff then makes a recommendation which is presented to P\&Z 
commission at the public hearing. Citizens may attend the public hearing a voice their concerns with regards to the change. The $\mathrm{P} \& \mathrm{Z}$ commission then votes on a recommendation to the BCC. The BCC then makes the final decision. Figures 9, 10 and 11 present respectively a use case diagram, an activity diagram and a class diagram modeling the described process.

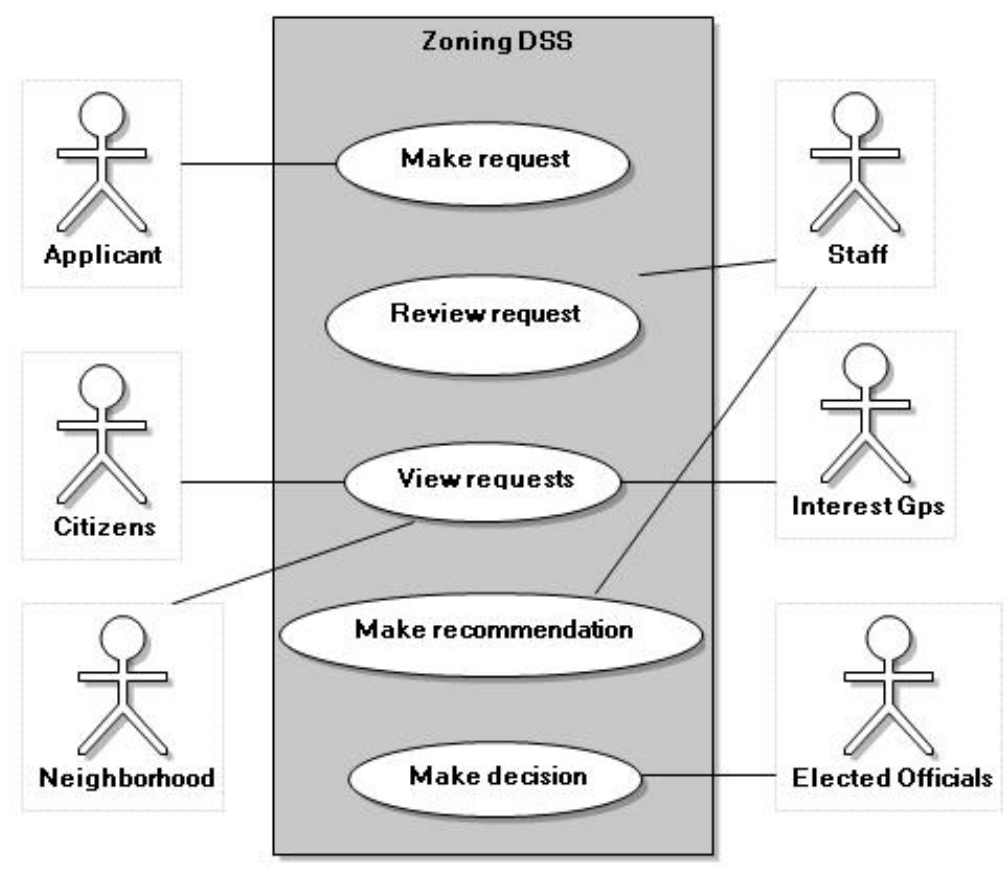

Figure 9. Design prototype Use Case diagram 


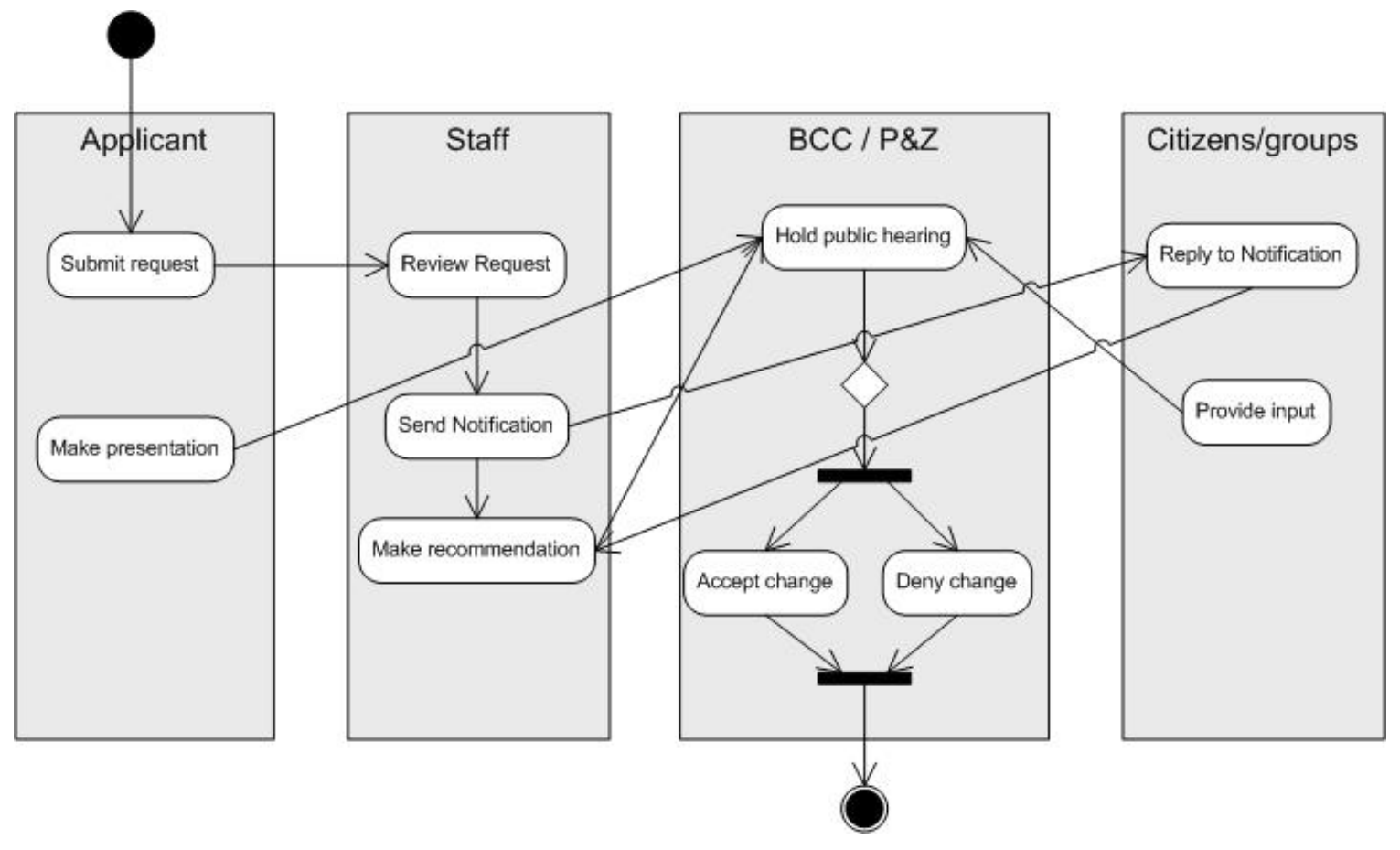

Figure 10. Design prototype Activity Diagram 


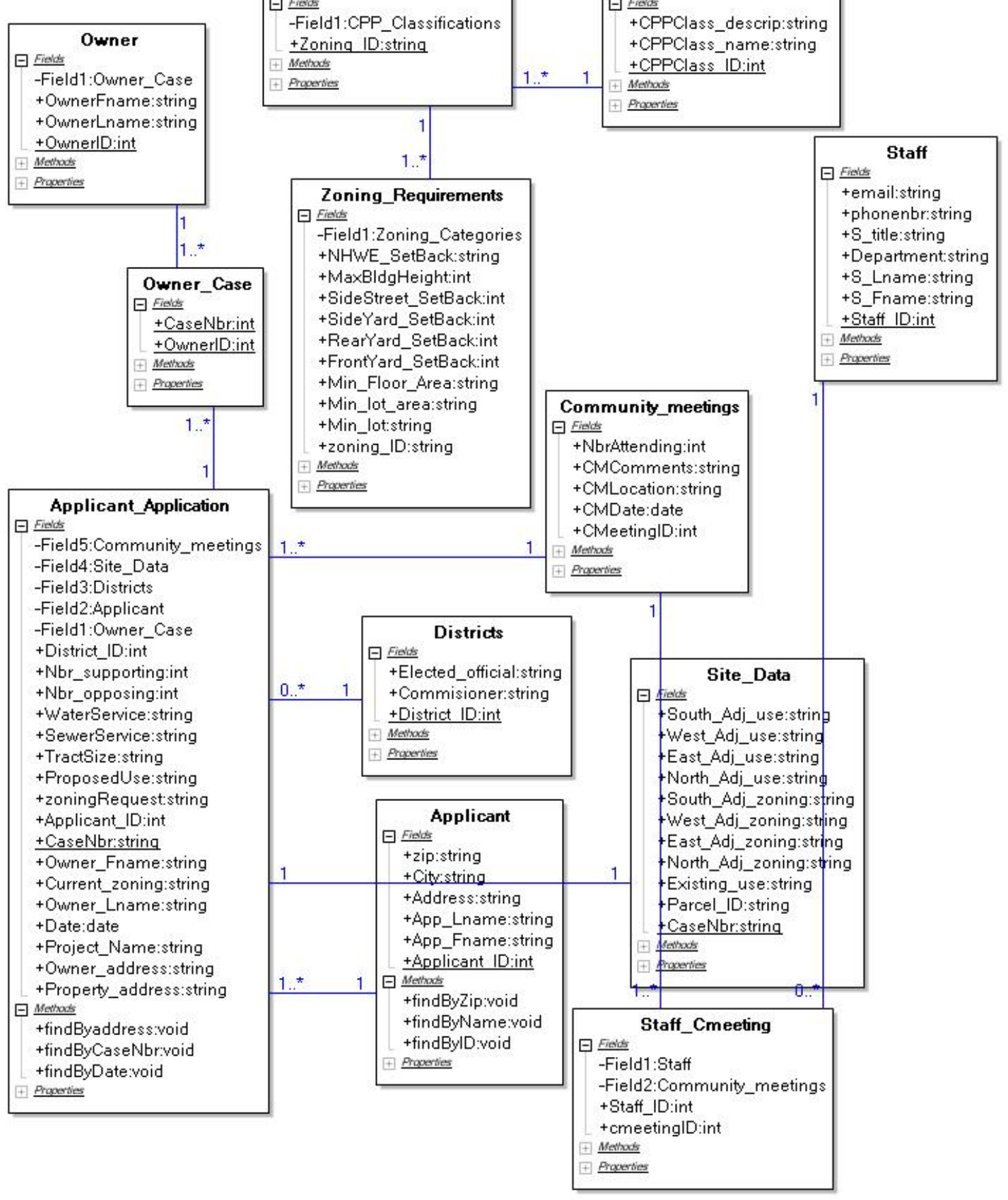

Figure 11. Design prototype Class diagram 


\section{The Counter-design Prototype - Process Description}

To start a process, one must submits an application requesting a zoning change. A complete application consists of the following:

- Completed application form including reason for the rezoning request

- Copy of deed for the property

- Notarized authorization of the property owner, if the applicant is not the owner

- Legal description and survey of the property

- $\quad$ Processing and review fee.

Once the application is complete, it is submitted to staff for review. Staff sends notification to the adjacent property owners notifying them of the zoning change request in their neighborhood and asking them to vote on the requested change. The citizens then cast their votes. Based on the majority votes, staff then makes and announce the final decision. As one may notice, the steps of the process remained almost unchanged, the main change is in the criteria used for making the decision. In the design prototype several information about the impacts of the requested change are gathered and used as criteria in the making of the final decision. However, in the counter design prototype, citizen's votes are the determining factor for accepting or rejecting a requested zoning change. Figures 12, 13 and 14 present a use case diagram, a class diagram and an activity diagram respectively. 


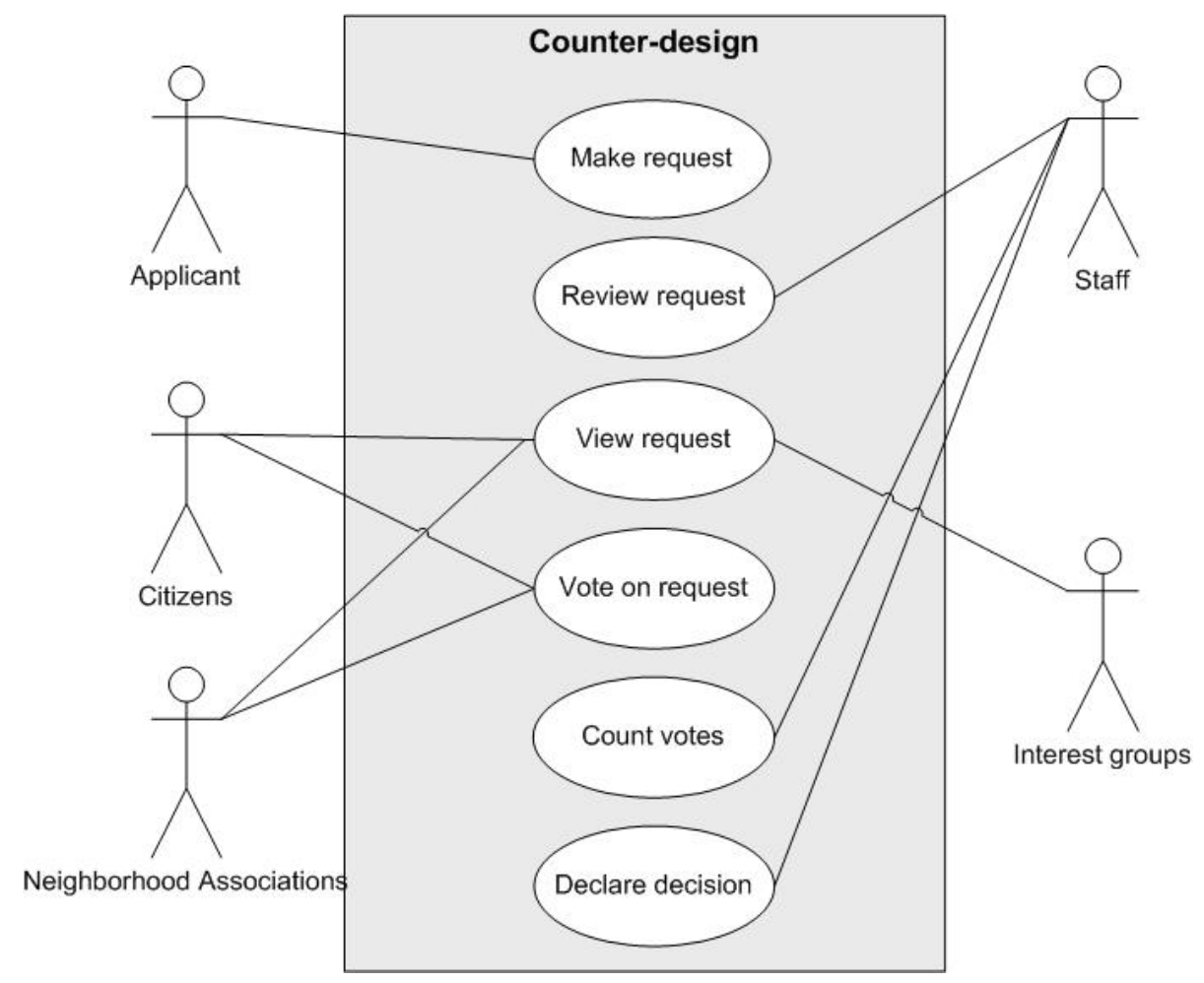

Figure 12. Counter-design prototype Use Case diagram

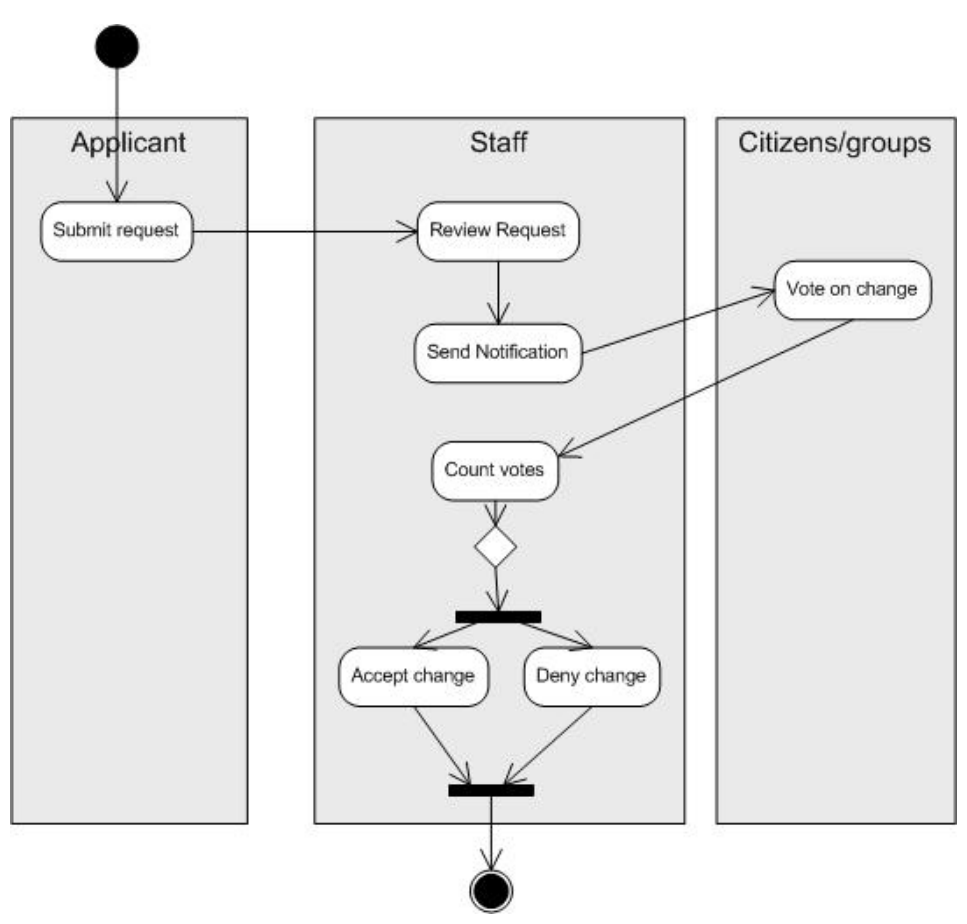

Figure 13. Counter-design prototype Activity Diagram 


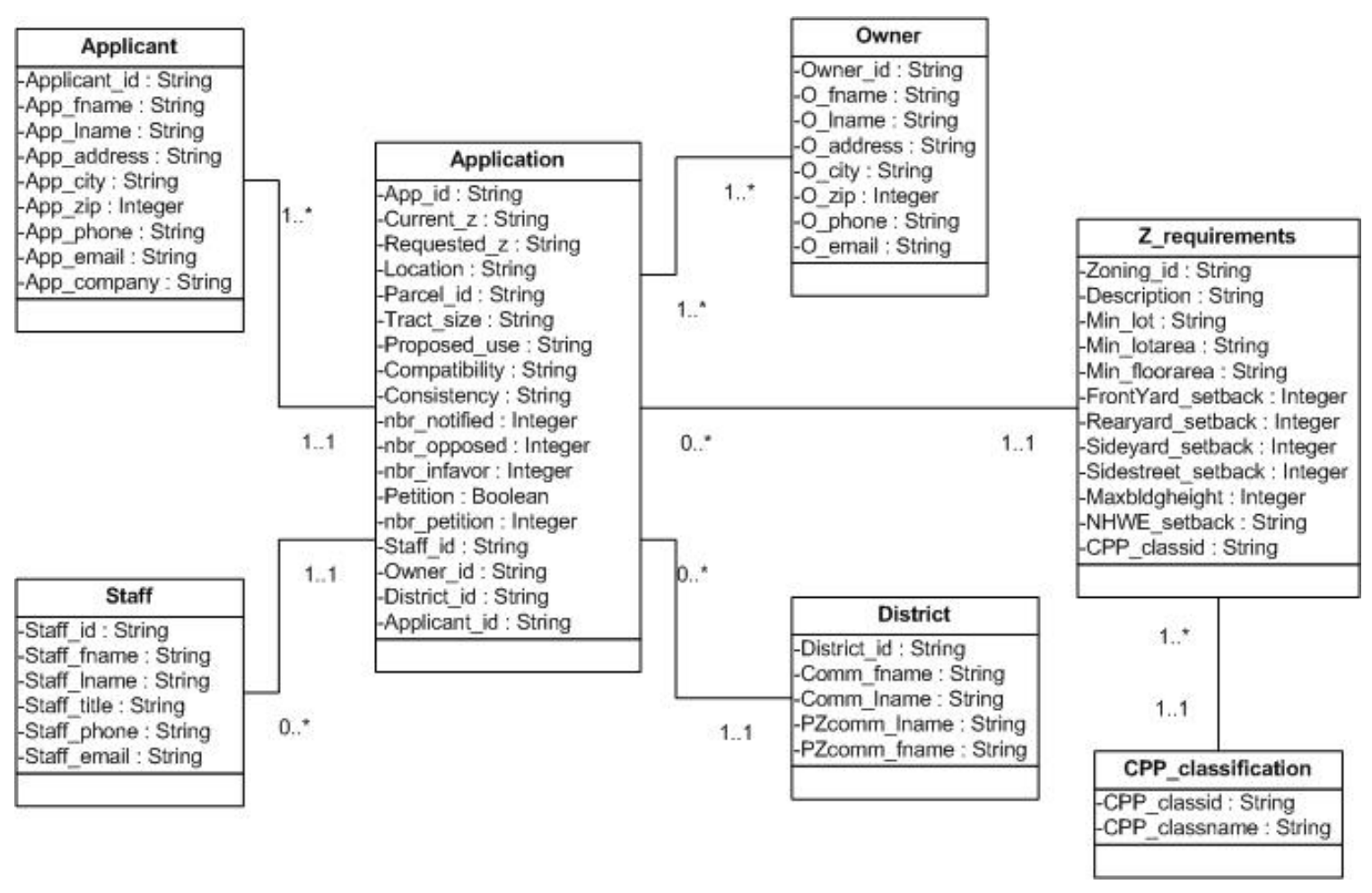

Figure 14. Counter-design prototype Use Case diagram

\section{Conclusion}

In this chapter, I have attempted to operationalize the first six steps of the MPDP methodology and model the design and the counter design using UML. The design supports the views of the staff and the counter design supports the neighborhood associations (citizens) views. In chapter 6, I will describe the remaining steps of MPDP, starting with the evaluation of the design and counter design prototypes. I will also describe how the synthesized design was conceptualized and evaluated. Finally, I will report results on the evaluation of the whole process by the members of the different stakeholder groups. 


\section{CHAPTER SIX: THE MPDP METHODOLOGY FIELDWORK - PART II}

In the previous chapter, the organization and context where the MPDP methodology was applied were presented along with the first six steps of the methodology. The stakeholder groups and their worldviews were identified. These worldviews were then analyzed using the multiple perspective approach. Decision factors were then determined, the two opposing views were isolated and the designs of the prototypes supporting each view were developed. In this chapter, I will describe the last two steps of the MPDP methodology namely, resolution generation and evaluation. I will also discuss the stakeholders' reaction to the whole design process.

The chapter is organized as follows: first I present the resolution generation phase in which I describe the steps taken to develop the instrument used to evaluate the prototypes. Then I analyze the data and report the results. After that I present the synthesized design and report results of its evaluation. Finally, I discuss results of the whole design process evaluation.

\section{$\underline{\text { Resolution Generation }}$}

As described in Chapter 3, the role of the resolution generation phase is to evaluate the design and counter design and formulate the synthesized design. The methodology calls for a dialogue among and between the stakeholders. In this case, face-to-face dialogue was not possible due to the multiplicity of the stakeholders and their conflicting schedules. An alternative was to present the two designs to each individual stakeholder separately and have them evaluate each design separately. Since the MPDP methodology calls for the designer to be 
the observer of the dialogue, in this alternative solution the designer will act as a third party that facilitates the dialogue asynchronously. This alternative solution is feasible because in the dialectic process the design is the guarantor and hence he/she is the one to come up with the synthesized design. A structured interview guide was developed for that purpose. Since the stakeholders were evaluating the decision factors upon which each of the designs was based, scenarios were carefully developed and validated by staff for completeness and appropriateness. In order to avoid any biases, the scenarios used fictitious applicant names, districts and streets. The key objective of this evaluation is to measure the stakeholder satisfaction with the information used to make the zoning decision. In order to determine the constructs to be used in the structured interview guide, I conducted a literature review on user information satisfaction and information quality.

\section{Stakeholder Information Satisfaction and Information Quality}

Information quality plays an important role in user satisfaction. Many information systems success models have identified information quality as one of the dimensions or categories of success (Delone and Mclean, 1992, 2003; Seddon, 1997). Information quality is often viewed as an antecedent to (Delone and Mclean, 1992, 2003) or dimension of use and user satisfaction (Doll and Torkzadeh, 1988, Bailey and Pearson, 1983). It has also been suggested that information quality indirectly affects individual and organizational impacts (Delone and Mclean, 1992). Additionally, it has been empirically shown that information quality is directly

related to perceived net benefits (Wixom and Watson, 2001), managerial satisfaction and organizational impacts (Teo and Wong, 1998). 
Information quality has been defined as how good the system is in terms of its output (Jennex, et al., 1998). It is complex and multidimensional. Table 9 shows 23 dimensions of information quality as identified by Delone and Mclean (1992) in their review of 100 plus studies on IS success. Larcker and Lessgi (1980) identified two distinct factors for information quality: perceived importance and perceived usableness. Perceived importance is defined as the "quality that causes a particular information set to acquire relevance to a decision maker," and the extent to which the information items are a "necessary input for task accomplishment," and perceived usableness is defined as the degree to which "the information allows a decision maker to utilize a set as an input for a problem" and the extent to which the information is "clearly presented and readable or can be easily transferred" (p.123). These two dimensions seem to be equivalent to Davis's (1989) notion of perceived usefulness and ease of use respectively which have been used as a measure of IS success in other studies (Garrity and Sanders, 1998).

Table 9. Information quality measures (adopted from Delone and Mclean 1992)

\begin{tabular}{|ll|}
\hline Importance & Precision \\
Relevance & Conciseness \\
Usefulness & Sufficiency \\
Informativeness & Completeness \\
Usableness & Reliability \\
Understandability & Currency \\
Readability & Timeliness \\
Clarity & Comparability \\
Format & Quantitativeness \\
Appearance & Freedom from bias \\
Content & Accuracy \\
\hline
\end{tabular}

Poor data quality leads to poor decision making (Redman, 1998). Information quality is often discussed in the decision making literature. The quality of the information produced by an IS in general and a decision support system (DSS) in particular affects the quality of the decision 
made. In fact, many research studies have empirically demonstrated a direct relationship between the quality of information used by decision makers and the quality of their decisionmaking performance (Jones and Mcleod, 1986; Porat and Haas, 1969; Streufert, 1973). Hence, assessing the quality of information during the design stages of an IS or a DSS is an important step in assessing the user satisfaction with the system itself.

The purpose of this step in the MPDP methodology is to evaluate the quality of the information produced by both the prototype and the counter-prototype of the zoning DSS and gain feedback from the stakeholders in order to build the synthesized prototype. Stakeholder groups, which are groups that either affect or are affected by the decision to be made based on the information provided, were presented with both output screens and then asked to answer a questionnaire designed to measure their satisfaction with the information produced. While quality is usually measured from the user perspective (Delone and Mclean, 1992) in the present study the focus is on the stakeholder groups (which may not necessarily all be direct users of the systems). This focus is important in order to assure that stakeholder perspectives are represented in the design of the DSS.

In order to determine the construct to include in the structured interview guide to evaluate the design and counter design prototypes, I performed a thorough analysis of 23 studies that have measured information quality. These 23 studies are presented in Table 10. In analyzing these articles, I attempted to determine the dimensions of information quality used and their respective definitions. Table 11 shows the definition of these dimensions. Table 12 lists the 27 different dimensions of information quality found in the articles and its corresponding study. A total column was added showing the frequency of each dimension. It shows that "relevance," "timeliness" and "accuracy” are the most frequently used dimension of information quality. A 
closer look at the different definitions of these dimensions and the items used to measure them showed some overlap in definitions. Hence, I tried to synthesize these dimensions. Results of the synthesis are presented in Table 13. These results were verified by several researchers, members of my committee.

Table 10. Articles included in the study

\begin{tabular}{|c|c|l|}
\hline & Year & \multicolumn{1}{|c|}{ Authors } \\
\hline 1 & 1974 & Gallagher \\
\hline 2 & 1974 & Swanson \\
\hline 3 & 1978 & Zmud \\
\hline 4 & 1980 & Ahituv \\
\hline 5 & 1980 & Larcker \& Lessig \\
\hline 6 & 1983 & King \& Epstein \\
\hline 7 & 1983 & Bailey \& Pearson \\
\hline 8 & 1983 & Ives, Olson \& Baroudi (based on Pearson) \\
\hline 9 & 1984 & Blaylock \& Rees \\
\hline 10 & 1985 & Mahmood \& Medewitz \\
\hline 11 & 1985 & Rivard \& Huff \\
\hline 12 & 1985 & Srinivan \\
\hline 13 & 1986 & Jones \& Mcleod \\
\hline 14 & 1987 & Iivari \& Koskela \\
\hline 15 & 1987 & Mahmood \\
\hline 16 & 1987 & Miller \& Doyle \\
\hline 17 & 1988 & Doll \& Torkzadeh \\
\hline 18 & 1988 & Baroudi \& Orlikowski \\
\hline 19 & 1998 & Goodhue \\
\hline 20 & 1995 & Rainer \& Watson \\
\hline 21 & 1998 & $\begin{array}{l}\text { Teo \& Wong (used King \& Epstein, 1983), Miller } \\
\text { and Doyle 1987, MISQ 11(4)) }\end{array}$ \\
\hline 22 & 2001 & Wixom \& Watson \\
\hline 23 & 2002 & Lee, Strong, Khan and Wang \\
\hline
\end{tabular}


Table 11. Dimensions’ definitions and their equivalent constructs

\begin{tabular}{|c|c|c|}
\hline Items & Definition & Equivalent to \\
\hline Accessibility & $\begin{array}{l}\text { Ease of access to desired data (Goodhue, 1998) } \\
\text { The extent to which data are available or easily and quickly retrievable. (Accessibility of IQ dimension, Wang \& Strong, } \\
\text { 1996) }\end{array}$ & \\
\hline Accuracy & Correctness of the data (Goodhue, 1998) & \\
\hline Aggregation & The degree to which data should be aggregated. (Ahituv, 1980) & \\
\hline Believability & $\begin{array}{l}\text { Extent to which data are accepted or regarded as true, real and credible (intrinsic data quality dimension) (Wang \& } \\
\text { Strong, 1996) }\end{array}$ & Reliability \\
\hline Clarity & The extent to which the information is not ambiguous. (Gallagher, 1974) & $\begin{array}{l}\text { understandability and } \\
\text { usableness }\end{array}$ \\
\hline Comparability & The degree to which the information could be compared (Esptein \& King, 1982) (Snavely, 1967) & compatibilty \\
\hline Compatibility & Ease with which data from different sources can be aggregated or compared without inconsistencies (Goodhue, 1998) & consistency \\
\hline Completeness & $\begin{array}{l}\text { The extent to which data are of sufficient breath, depth, and scope for the task at hand. (Contextual IQ dimension, Wang } \\
\text { \& strong, 1996). }\end{array}$ & \\
\hline Conciseness & $\begin{array}{l}\text { The extent to which the information is to the point. (Gallagher, 1974) } \\
\text { The extent to which data are compactly represented without being overwhelming (ie. Brief in presentation, yet complete } \\
\text { and to the point). (representational IQ dimension, Wang \& Strong, 1996). }\end{array}$ & \\
\hline Consistent & $\begin{array}{l}\text { The extent to which the data are always presented in the same format and are compatible with previous data. } \\
\text { (representational IQ dimension, Wang \& strong, 1996). }\end{array}$ & Compatibility \\
\hline Convenience & The ease of getting the desired outputs (Iivari et al. 1987) & Ease of use? \\
\hline Currency & The data is current enough for the question of interest (Goodhue, 1998) & Timeliness, recentness \\
\hline Flexibility & Ease of changing the content or format of the data to meet changing business (Goodhue, 1998) & \\
\hline Format & $\begin{array}{l}\text { Includes items such as the medium by which information is presented, the way the data is arranged, and the graphic } \\
\text { settings such as colors, letter sets and font... (Ahituv, 1980) }\end{array}$ & \\
\hline Free of errors & Same as accuracy. & Accuracy \\
\hline $\begin{array}{l}\text { Freedom from } \\
\text { bias }\end{array}$ & The extent to which information have been impartially determined and reported (Snavely, 1967) & \\
\hline Importance & $\begin{array}{l}\text { Information quality that causes particular information set to acquire relevance to a decision maker. (Lacker and Lessgi, } \\
\text { 1980) }\end{array}$ & Relevance, usefulness \\
\hline Informativeness & $\begin{array}{l}\text { The potentiality of IS to produce the information required. It includes items such as information structure, recentness and } \\
\text { reliability. (Iivari \& Koskela, 1987) }\end{array}$ & $\begin{array}{l}\text { Relates to the system not to } \\
\text { the information or data. }\end{array}$ \\
\hline Interpretability & The extent to which data are in appropriate language and units and the data definitions are clear. (representational IQ & Meaning, understandability \\
\hline
\end{tabular}




\begin{tabular}{|c|c|c|}
\hline & dimension, Wang \& strong, 1996). & \\
\hline Localability & Ease of determining what data is available and where (Goodhue, 1998) & \\
\hline Meaning & $\begin{array}{l}\text { Ease of determining what a data element or report or file means, or what is included or excluded in calculating it } \\
\text { (Goodhue, 1998) }\end{array}$ & Understandability \\
\hline Objectivity & $\begin{array}{l}\text { The extent to which data are unbiased (unprejudiced) and impartial. (Intrinsic IQ dimension, Wang \& Strong, 1996). } \\
\text { (same as free from bias) }\end{array}$ & Free from bias \\
\hline Precision & The variability of the output information from that which it purports to measure. (Bailey \& Pearson, 1983) & \\
\hline Quantitativeness & The degree to which the information could be quantified (Esptein \& King, 1982) & \\
\hline Quantity & $\begin{array}{l}\text { Gallager (1974) used two semantic differential attribute to measure quantity: complete/incomplete and } \\
\text { enough/insufficient. }\end{array}$ & Completeness, sufficiency \\
\hline Recentness & The extent to which the information is recent. No def provided. (Iivari et al. 1987) & Currency, timeliness \\
\hline Relevance & $\begin{array}{l}\text { The extent to which information bears upon or is usefully associated with actions it is designed to facilitate or results to } \\
\text { be produced. (Snavely, 1967). } \\
\text { Degree of congruence between what the user wants or requires and what is provided by the information products and } \\
\text { services. (Bailey \& Pearson, 1983) }\end{array}$ & Usefulness, importance \\
\hline Reliability & User can depend on it as a representation of what it purports to be. (Snavely, 1967) & \\
\hline Reputation & $\begin{array}{l}\text { The extent to which data are trusted or highly regarded in terms of their source or content. (Intrinsic IQ dimension, } \\
\text { Wang \& Strong, 1996) }\end{array}$ & Reliability, believability \\
\hline Security & $\begin{array}{l}\text { The extent to which access to data can be restricted and hence kept secure. (Accessibility IQ dimension, Wang \& Strong, } \\
\text { 1996) }\end{array}$ & \\
\hline Sufficiency & Maintaining the needed data at the right level of details for the intended task (Goodhue, 1998) & completeness \\
\hline Timeliness & $\begin{array}{l}\text { The extent to which the age of the data is appropriate for the task at hand (Contextual IQ dimension, Wang \& strong, } \\
\text { 1996). }\end{array}$ & Currency, recentness \\
\hline Understandability & $\begin{array}{l}\text { The extent to which information is understandable and the user of the information is able to comprehend the message } \\
\text { being communicated (Snavely, 1967) } \\
\text { The extent to which data are clear without ambiguity and easily comprehended. (representational IQ dimension, Wang \& } \\
\text { strong, 1996). }\end{array}$ & \\
\hline Usableness & $\begin{array}{l}\text { Information quality that allows a decision maker to utilize the set as an input for the problem solution. It is related to } \\
\text { whether the information is unambiguous, clear and readable. (Lacker and Lessgi, 1980) }\end{array}$ & Understandability \\
\hline Usefulness & The degree to which one believe that using the information will enhance his/her performance (Davis, 1989) & Relevance, importance. \\
\hline Value-added & $\begin{array}{l}\text { The extent to which data are beneficial and provide advantages from their use. (Contextual IQ dimension, Wang \& } \\
\text { strong, 1996). }\end{array}$ & $\begin{array}{l}\text { Usefulness, relevance, } \\
\text { importance }\end{array}$ \\
\hline Volume & The amount of information conveyed to a user from computer-based systems. (Bailey \& Pearson, 1983) & \\
\hline
\end{tabular}


Table 12. Information quality dimensions used in the studies sample

\begin{tabular}{|c|c|c|c|c|c|c|c|c|c|c|c|c|c|c|c|c|c|c|c|c|c|c|c|c|}
\hline Year & $1 *$ & 2 & 3 & 4 & 5 & 6 & 7 & 8 & 9 & 10 & 11 & 12 & 13 & 14 & 15 & 16 & 17 & 18 & 19 & 20 & 21 & 22 & 23 & Total \\
\hline Accessibility & & & & & & & & & & & & & & $\mathbf{x}$ & & & & & $\mathbf{x}$ & & & & $\mathbf{x}$ & 3 \\
\hline Accuracy & & & & $\mathbf{x}$ & & & $\mathbf{x}$ & $\mathbf{x}$ & & & & $\mathbf{x}$ & & $\mathbf{x}$ & $\mathbf{x}$ & $\mathbf{x}$ & $\mathbf{x}$ & $\mathbf{x}$ & $\mathbf{x}$ & $\mathbf{x}$ & $\mathbf{x}$ & $\mathbf{x}$ & & 13 \\
\hline Adaptability & & & & & & & & & & & & & & $\mathbf{x}$ & & & & & & & & & & 1 \\
\hline Aggregation & & & & $\mathbf{x}$ & & & & & & & & & & & & & & & & & & & & 1 \\
\hline Believability & & & & & & & & & & & & & & & & & & & & & & & $\mathbf{x}$ & 1 \\
\hline Clarity & & $\mathbf{x}$ & & & & & & & & & & & & & & & & & & & & & & 1 \\
\hline Comparability & & & & & & $\mathbf{x}$ & & & & & & & & & & & & & & & & & & 1 \\
\hline Compatibility & & & & & & & & & & & & & & & & & & & $\mathbf{x}$ & & & & & 1 \\
\hline Completeness & & & & & & & $\mathbf{x}$ & $\mathbf{x}$ & & & & & & & & $\mathbf{x}$ & & & & & & $\mathbf{x}$ & $\mathbf{x}$ & 5 \\
\hline Comprehensiveness & & & & & & & & & & & & & & $\mathbf{x}$ & & & & & & & & $\mathbf{x}$ & $\mathbf{x}$ & 3 \\
\hline Conciseness & & $\mathbf{x}$ & & & & & $\mathbf{x}$ & & & & & & & & & & & & & $\mathbf{x}$ & & & $\mathbf{x}$ & 4 \\
\hline Consistent & & & & & & & & & & & & & & & & & & & & & & $\mathbf{x}$ & $\mathbf{x}$ & 2 \\
\hline Convenience & & & & & & & & & & & & & & & & & & & & $\mathbf{x}$ & & & & 1 \\
\hline Credibility & & & & & & & & & & & & & & $\mathbf{x}$ & & & & & & & & & & 1 \\
\hline Currency & & & & & & $\mathbf{x}$ & $\mathbf{x}$ & & & & & & & & & & & & $\mathbf{x}$ & & & & & 3 \\
\hline Ease of use & & & & & & & & & & & & & & & & & $\mathbf{x}$ & & & & & & $\mathbf{x}$ & 2 \\
\hline Flexibility & & & & & & & & & & & & & & & & & & & $\mathbf{x}$ & & & & & 1 \\
\hline Format Quality & & & $\mathbf{x}$ & & & & $\mathbf{x}$ & & & & & & & & & & $\mathbf{x}$ & & & & & & & 3 \\
\hline Formatting & & & & $\mathbf{x}$ & & & & & & & & & & & & & & & & & & & & 1 \\
\hline Free of errors & & & & & & & & & & & & & & & & & & & & & & & $\mathbf{x}$ & 1 \\
\hline Freedom from bias & & & & & & $\mathbf{x}$ & & & & & & & & & & & & & & & & & & 1 \\
\hline Importance & $\mathbf{x}$ & & & & $\mathbf{x}$ & & & & & & & & $\mathbf{x}$ & & & & & & & & & & & 3 \\
\hline Informativeness & $\mathbf{x}$ & & & & & & & & & & & & & $\mathbf{x}$ & & & & & & & & & & 2 \\
\hline Interpretability & & & & & & & & & & & & & & & & & & & & & & & $\mathbf{x}$ & 1 \\
\hline Localability & & & & & & & & & & & & & & & & & & & $\mathbf{x}$ & & & & & 1 \\
\hline Meaning & & & & & & & & & & & & & & & & & & & $\mathbf{x}$ & & & & & 1 \\
\hline Objectivity & & & & & & & & & & & & & & & & & & & & & & & $\mathbf{x}$ & 1 \\
\hline Precision & & & & & & & $\mathbf{x}$ & $\mathbf{x}$ & & & & & & & & & $\mathbf{x}$ & $\mathbf{x}$ & & & & & & 4 \\
\hline Quantitative ness & & & & & & $\mathbf{x}$ & & & & & & & & & & & & & & & & & & 1 \\
\hline Quantity & & & $\mathbf{x}$ & & & & & & & & & & & & & & & & & & & & & 1 \\
\hline Readability & & $\mathbf{x}$ & & & & & & & & & & & & & & & & & & & & & & 1 \\
\hline Recentness & & & & & & & & & & & & & & $\mathbf{x}$ & & & & & & & & & & 1 \\
\hline
\end{tabular}




\begin{tabular}{|c|c|c|c|c|c|c|c|c|c|c|c|c|c|c|c|c|c|c|c|c|c|c|}
\hline Relevance & $\mathbf{x}$ & & & $\mathbf{x}$ & & $\mathbf{x}$ & $\mathbf{x}$ & $\mathbf{x}$ & & & & $\mathbf{x}$ & $\mathbf{x}$ & & $\mathbf{x}$ & & & $\mathbf{x}$ & $\mathbf{x}$ & $\mathbf{x}$ & $\mathbf{x}$ & 12 \\
\hline Reliability & & & $\mathbf{x}$ & & & $\mathbf{x}$ & $\mathbf{x}$ & $\mathbf{x}$ & & & & & & & & & $\mathbf{x}$ & & & & & 5 \\
\hline Reputation & & & & & & & & & & & & & & & & & & & & & $\mathbf{x}$ & 1 \\
\hline Security & & & & & & & & & & & & & & & & & & & & & $\mathbf{x}$ & 1 \\
\hline Sufficiency & & & & & & $\mathbf{x}$ & & & & & & & & & & $\mathbf{x}$ & $\mathbf{x}$ & $\mathbf{x}$ & & & & 4 \\
\hline Timeliness & & & $\mathbf{x}$ & $\mathbf{x}$ & & $\mathbf{x}$ & $\mathbf{x}$ & $\mathbf{x}$ & & & & $\mathbf{x}$ & $\mathbf{x}$ & $\mathbf{x}$ & & $\mathbf{x}$ & & & $\mathbf{X}$ & $\mathbf{x}$ & & 11 \\
\hline Understandability & & & & & & $\mathbf{x}$ & & & & & & $\mathbf{x}$ & & & & & & & & & $\mathbf{x}$ & 3 \\
\hline Uniqueness & & $\mathbf{x}$ & & & & & & & & & & & & & & & & & & & & 1 \\
\hline Usableness & & & & & $\mathbf{x}$ & & & & & & & & & & & & & & & & & 1 \\
\hline Usefulness & $\mathbf{x}$ & & & & & & & & $\mathbf{x}$ & $\mathbf{x}$ & $\mathbf{x}$ & & & & & & & & & & & 4 \\
\hline Valuable & & & & & & & & & & & & & & & & & & & & $\mathbf{x}$ & & 1 \\
\hline Volume & & & . & & & 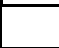 & & $\mathbf{x}$ & & & & & & & & & & & & & $\mathbf{x}$ & 2 \\
\hline
\end{tabular}


Table 13. Results of the definitions' analysis

\begin{tabular}{|l|l|}
\hline Items & Equivalent items in the literature \\
\hline Relevance & Importance, Usefulness, Value-added \\
\hline Understandability & $\begin{array}{l}\text { Meaning, Interpretability, Clarity, } \\
\text { Usableness }\end{array}$ \\
\hline Completeness & Sufficiency, Quantity \\
\hline Reliability & Believability, Reputation \\
\hline Timeliness & Currency, Recentness \\
\hline Compatibility & Consistency, Comparability \\
\hline Accuracy & Free of errors \\
\hline Objectivity & Free from bias \\
\hline Ease of use & $\begin{array}{l}\text { Convenience, Localability, Accessibility, } \\
\text { Flexibility }\end{array}$ \\
\hline Format & \\
\hline Quantitativness & \\
\hline Precision & \\
\hline Aggregation & \\
\hline Security & \\
\hline
\end{tabular}

In the present study, information quality will be evaluated by stakeholders who are not necessarily direct users of the system. Stakeholder groups may not have the ability to evaluate all dimensions presented in Table 13. Dimensions such as timeliness, accuracy, format and compatibility were omitted because the majority of the stakeholders will not be able to evaluate them accurately. Hence, the dimensions that were retained in the final interview guide are completeness, relevance, understandability and freedom from bias. Table 14 shows items related to each one of these dimensions. All items in the interview guide were developed based on existing instruments from the literature on user information satisfaction, information quality and DSS success instruments.

In addition to evaluating the quality aspect of the information produced by the system, I assessed whether the stakeholders believe that their perspectives and views have been represented. Paradice, et al. (2003) posit that perspectives are composed of language and 
subject. Additionally, Baldwin (1993) defined a view as a set of beliefs that partially describe a general subject of discourse. Thus, in order to capture the stakeholders' views about the system, open ended questions at the end of the structured interview guide were used to let them express their views openly. A complete interview guide containing all the items of information quality and the open ended-questions is included in Appendix F.

Table 14. Constructs’ operationalization

\begin{tabular}{|c|c|c|}
\hline Construct & Items & Reference/notes \\
\hline Completeness & $\begin{array}{l}\text { 1. Is the information missing any critical data? } \\
\square \text { Yes } \square \text { No } \\
\text { a) If Yes, what is the missing information? } \\
\text { b) Do you find it difficult to make a decision effectively because } \\
\text { the data you mentioned is not available to you? } \\
\text { 2. Is the information applicable and helpful for the decision? } \\
\square \text { Yes } \\
\text { a) If No, probe why? }\end{array}$ & Goodhue (1998) \\
\hline Relevance & $\begin{array}{l}\text { 1. What portion of the information presented is essential for or } \\
\text { instrumental in completing a zoning decision. } \\
\text { 2. What portion of the information presented is irrelevant in } \\
\text { completing a zoning decision. }\end{array}$ & $\begin{array}{l}\text { Lacker \& Lessig } \\
\text { (1980) }\end{array}$ \\
\hline Understandability & $\begin{array}{l}\text { 1. Do you think the information presented in the reports is easy to } \\
\text { understand and that the exact meaning of data elements is } \\
\text { obvious and easy to find? } \\
\square \text { Yes } \\
\text { a) If No, which information do you find difficult to understand? } \\
\text { b) b) What suggestions do you have to make it more } \\
\text { understandable? }\end{array}$ & $\begin{array}{l}\text { Goodhue (1998) } \\
\text { Lee et al. (2002) }\end{array}$ \\
\hline Freedom from bias & $\begin{array}{l}\text { 1. Do you think the information presented contains a substantial } \\
\text { amount of bias? } \\
\square \text { Yes } \square \text { No } \\
\text { a) If Yes, what part of the information do you think has bias? } \\
\text { b) What suggestions do you have to overcome this bias? }\end{array}$ & $\begin{array}{l}\text { Epstein \& King } \\
\text { (1982) }\end{array}$ \\
\hline
\end{tabular}




\section{Scenario Development}

To evaluate the prototypes produced by the previous stage an experimental vignette design was used (Singleton and Straits, 1999). Different scenarios followed by structured interviews were administered to the same stakeholders. The two variables of interest in the scenarios are the decision produced by the two systems. The variables (decision by prototype 1 and decision by prototype 2) were varied dichotomously (Yes - approve zoning request, No- do not approve zoning request). Three versions of the vignettes were developed (See Appendix G). These versions represent the possible combination of the two variables. Table 15 presents the different combinations of the prototype decision. The three versions were then adapted to the two prototypes, a total of six scenarios were developed (three for each prototype). A pilot test of the scenarios by staff was conducted to determine the effectiveness of the manipulations. The pilot study resulted in minor modifications in some scenarios. Participants were asked to review each prototype scenario and then answer a few questions. The interviews were taped and transcribed. The order of the prototypes was randomly selected for each participant.

Table 15. Decisions of the three scenarios by each prototype

\begin{tabular}{|c|c|c|c|}
\hline & \multicolumn{2}{|c|}{ Prototype 1} \\
\hline & & Yes & No \\
\hline \multirow{2}{*}{ 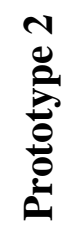 } & Yes & & Scenario \#3 \\
\hline & No & Scenario \#1 & Scenario \#2 \\
\hline
\end{tabular}




\section{$\underline{\text { Results }}$}

\section{Prototype 1 Evaluation Results}

Table 16 summarizes the decisions made by the subjects for all three scenarios. The result shows that most stakeholders tend to agree with the decision produced by the system. The one person that denied scenario 1 belonged to the applicant stakeholders group, this subject's decision was based on the permitted use stating that "the fact that he (the person requesting the zoning change) can raise cattle and horses to me is inconsistent with RC-E and with what is surrounding it (the property). It seems that the area is changing into a residential area and that to downzone it would not make any sense because the uses he is allowed are incompatible with the surrounding area.”

Concerning scenario 2, the two members that approved the requested zoning change belong to the applicant and the citizen group. The applicant decision was made on the fact that the change is not causing any major issues for schools and traffic and that mobile homes seem appropriate to the surrounding area. The citizen on the other hand approved the change because it is permissible in the area and consistent with CPP. In scenario 3, there seems to be a split between the participants. All staff members’ and interest groups members’ decisions matched with the system's decision which is denying the requested change. However their reasons for denial are different, staff denied it because it is inconsistent and incompatible and the interest groups denied it because of increase in density. The other two members belonged to the elected official's group and the citizen's group. Both subjects justified their decisions with the impact analysis citing inconsistency and incompatibility as major factors for denying the requested 
zoning change. On the other hand, all applicant group members approved the zoning change of scenario 3 despite the impact analysis data which states that the requested change is inconsistent and incompatible. They based their decision on the site data and the zoning of the adjacent properties. Two of the elected officials approved scenario 3 stating that there are no valid arguments to deny this case especially since the surrounding areas have similar zoning as the requested zoning. It is important to note here that surrounding areas zoning were approved prior to the adoption of the current future land use map (FLUM). Similarly, two of the citizens interviewed approved the zoning for the same reasons mentioned by the elected officials and the applicants.

Table 16. Prototype 1 Evaluation Results

\begin{tabular}{|c|c|c|}
\hline Prototype 1 results & Approve & Deny \\
\hline Scenario 1 (a)* & $\mathbf{1 4}$ & $\mathbf{1}$ \\
\hline Scenario 2 (d) & $\mathbf{2}$ & $\mathbf{1 3}$ \\
\hline Scenario 3 (d) & $\mathbf{7}$ & $\mathbf{8}$ \\
\hline
\end{tabular}

*The letters between parentheses show the recommendation by the prototype (a) = approve and $(d)=$ deny

All subjects found the information presented in the reports applicable and helpful but not sufficient for the decision and missing some critical data for the decision. Table 17 summarizes the missing data grouped by stakeholder groups. When asked whether the information presented contains any irrelevant information, all subjects believed that none of the information is irrelevant. Similarly, they all find the reports easy to understand and that the exact meaning of data elements is obvious and easy to find.

Concerning whether the information presented contained any bias, seven (7) of the subjects answered affirmatively. These include the three members of the interest group, two of 
citizen's group, one elected official and one applicant. The interest group members think that the bias is mainly by omission of important information such as environmental data and the biology of the sites. Additionally, all seven members believe that the compatibility statement in the impact analysis can contain some bias. As one subject stated "compatibility is somewhat a subjective term." Another one mentioned that "what might be compatible to me might be incompatible to others.” The staff does not seem to see any bias in the information presented in this prototype.

As a manipulation check, subjects were asked whether the information provided in the report is consistent with their views. Prototype 1 was designed based on the assumptions and worldviews of staff. Staff members believe that the information provided is consistent with their views. The elected officials and the citizens all thought that this prototype is not consistent with their views. They all mentioned missing public input and public notification as reasons why the information provided does not support their views. The interest group members also thought that this prototype does not support their views, mostly because it is lacking environmental data. They feel that the environmental data provided is not sufficient and does not give a good picture of the site from a biology stand point. One member of this group said "to me the environmental data, the ability of the land to withstand what ever is proposed is like the first layer of decision making after that I would worry about the roads and the schools and I think the roads and the schools and the services are very much a concern I am not trying to belittle that I think that's critical." The one applicant that did not think that this prototype supports his views stated "If I am the applicant, I would want them to base it (the decision) on the information I provide to them. Things like, I have always wanted a horseback riding business, my daughter likes horses.....etc. I have a sick mother-in-law and I want to build her a separate house...” 
Table 17. Missing data from prototype 1 report grouped by stakeholders groups

\begin{tabular}{|c|c|}
\hline & Missing information \\
\hline Interest groups $(3)^{*}$ & $\begin{array}{l}\text { In depth environmental data (3)**, maps and aerial photos (2), } \\
\text { more detailed information about the request (1). }\end{array}$ \\
\hline Staff (3) & Maps (3), public notification (1), photos of the site (2). \\
\hline Elected Officials(3) & $\begin{array}{l}\text { Public opinion (3), maps (1), economic impact (1), size of } \\
\text { surrounding lots (1, this can be shown through maps) }\end{array}$ \\
\hline Applicants (3) & $\begin{array}{l}\text { Maps (2), site visit information (2), people’s opinions (1), } \\
\text { staff recommendation (1) }\end{array}$ \\
\hline Citizens (3) & Public information and their issues (2) \\
\hline
\end{tabular}

\section{Prototype 2 Evaluation Results}

Analysis of the respondents' transcripts revealed some interesting results. Prototype 2 received an interesting reaction from most subjects. Most respondents objected to the factors used for decision making in this prototype. Table 18 summarizes the results. The applicant group members' reaction to prototype \#2 was the same among all participants. They believe that prototype 2 does not represent their views and that prototype 2 is biased. One of the applicants described the prototype as “an irresponsible prototype.” Another one said when presented with this prototype “It is ridiculous! You can’t make decisions based on that.” Another applicant described this prototype as "The most politicized process," and then added "it is an irresponsible way to manage growth.”

For scenarios 1 and 3 the majority's decision was in contradiction with the decision produced by the prototype. In scenario 1 , the public notification results indicated that the majority of the people living in the area opposed the requested change. The subjects that voted 
against the public wants all mentioned that counting votes is not a sufficient condition for denying a request that is both consistent and compatible with the area. One of the subjects noted that "they (the public) are probably against taxes too." It seems that what is most important to these subjects is the reasons and the issues raised by the public. Most of the subjects wanted to know the reasons behind the opposition. Because in some cases, the public might raise some important issues that staff may have overlooked or do not know about. Therefore including the issues and reasons for the opposition is important to these subjects.

In Scenario 3, again the majority denied the request despite the support of the adjacent property owners. All staff and two of the applicants denied it mainly because it is both inconsistent and incompatible. The interest group members denied it because of intensification since the requested change would allow for higher density. The one elected official that denied this request despite the public support strongly believe that the applicant can get what he wants through other venues such as applying for CPP amendments or variances. It is important to note here that all citizens' group members denied this request despite the public support. They based their decisions mostly on the impact analysis (compatibility and consistency) and the intensity of use. They also emphasized the importance of public education stating that the public sometimes may not know exactly what they are supporting or opposing. By analyzing the respondents' replies I noticed that opposition seems to matter most when it is in large numbers. One elected official stated that the most important factor is:

"The feelings of the people. We are representing the people in the community. This is affecting their daily lives and that weighs much more heavily than something that has been put on paper (CPP) years and years ago by a bunch of people that was representing a different group of people.” 
For scenario 2 where the opposition was massive, the majority denied the request citing opposition as one of the major reasons for denial. The only person that approved this case belonged to the applicant's group and stated that "one cannot discriminate against mobile homes.”

Table 18. Prototype 2 Evaluation Results

\begin{tabular}{|l|c|c|c|}
\hline Prototype 2 & Approve & Deny & Can’t decide \\
\hline Scenario 1 (d)* & $\mathbf{1 0}$ & $\mathbf{2}$ & $\mathbf{3}$ \\
\hline Scenario 2 (d) & $\mathbf{1}$ & $\mathbf{1 3}$ & $\mathbf{1}$ \\
\hline Scenario 3 (a) & $\mathbf{2}$ & $\mathbf{1 1}$ & $\mathbf{2}$ \\
\hline
\end{tabular}

*The letters between parentheses show the recommendation by the prototype $(\mathrm{a})=$ approve and $(\mathrm{d})=$ deny

Eleven of the subjects did find the information presented in prototype 2 reports applicable and helpful for the decision. Three of the four subjects that did not find the information applicable and helpful belong to the interest group and one member to the elected official group. These individuals found it hard to make a decision based on the information provided. However, most subjects agreed on the fact that critical information is missing, more specifically technical information. Table 19 summarizes the missing data grouped by stakeholder groups. When asked whether the information presented contains any irrelevant information, all subjects believed that none of the information is irrelevant. Similarly, they all find the reports easy to understand and that the exact meaning of data elements is obvious and easy to find.

Concerning whether the information presented contained any bias, twelve (12) of the subjects answered affirmatively. These include all members of the interest group, all staff, all citizens, two from the applicant's group and one elected official. 
Table 19. Missing data from prototype 2 report grouped by stakeholders groups

\begin{tabular}{|l|l|}
\hline & \multicolumn{1}{|c|}{ Missing information } \\
\hline Interest groups (3)* & $\begin{array}{l}\text { Environmental data (3)**, maps (2), adjacent land uses and zoning (1), } \\
\text { issues raised by the public (1) }\end{array}$ \\
\hline Staff(3) & $\begin{array}{l}\text { Site data information (3), environmental issues (1), impact on } \\
\text { transportation and schools (1) }\end{array}$ \\
\hline Elected Officials (3) & Maps (1), adjacent uses and zoning (2), issues of the public (1). \\
\hline Applicants (3) & Site data (2), impact on transportation and schools (1), maps (1) \\
\hline Citizens (3) & adjacent land uses and zoning (2), issues raised by he public (2) \\
\hline
\end{tabular}

* The number of subjects in each group.

**The numbers between parentheses (x) represent how many individuals in that particular group have mentioned that information as critical and missing from the report.

Most of them stated the lack of information as a source of bias. "There is a bias to just make a bad decision because you don't have all the information" said one member of the interest group. Compatibility analysis was also mentioned again here as a source of bias. "Compatibility is the only place where you might have some disagreement” stated a staff member. Another one affirmed "you are always using your own judgment (speaking of compatibility). We (staff) are supposed to be professionals but we all have our own bias of what looks good and what does not...We try to balance as much as we can.”

Concerning the interest group members, they all see bias in the information provided for different reasons: First, by omitting critical information to the decision such as environmental data of the area. Second, by focusing only on the quantitative data, the number of votes as opposed to more qualitative data such as the issues raised by the public and reasons for opposition. Third, by the fact that the number of votes opposing the requested change may not reflect reality, one member of this group stated "They (the public) probably are not going to be spontaneous responses, there is probably going to be one or two people organizing the whole thing and that's a bias.” 
Prototype 2 was designed based on the assumptions and worldviews of the citizens group. Despite the fact that their decisions were contrary to the prototype's decision for both scenarios 1 and 3, they still believe that the information provided is consistent with their views. Two of staff members also believe that this prototype represents their views because as one of them stated "The impact analysis represents our views. Compatibility and consistency are the most important info to us." The third member of the staff group believes that transportation and schools information are big issues in this community and hence must be considered in the decision. Concerning the elected official's group, only one subject thinks that this prototype represents his/her views. The other two stated having more information about public opinion and including economic impact would better represent their views. Finally, the interest group members and the applicant group members all think that this prototype does not support their views. The interest group members believe that including more environmental and scientific data would best represent their views whereas the applicant group members believe that technical data rather than emotional data better represent their views.

\section{Discussion}

In comparing the two prototype results, staff and interest group members' decisions did not change from one prototype to the other, however the citizens, elected officials and applicant group decision changed for scenarios 1 and 3 (the scenario 2 decision is the same for both prototypes for different reasons/factors). Table 20 summarizes the information used in each prototype. By analyzing responses of staff and the interest group, I noticed that they were consistent in the factors that they choose to base their decisions on. Staff use impact analysis 
information which is present in both prototypes and interest group members use environmental data which is lacking in both prototypes (prototype 1 did include some environmental data however the interest group members think that it is very insufficient). The two elected officials that changed their decision for Scenario 1 stated public opposition as an important factor in the making of their decisions. The third member of the elected official group that approved scenario 1 despite opposition stated that "my personal opinion is 'approve' - but I would want to know why they don't want it, what the issues are.” To this elected official knowing that the public is opposing alone is not sufficient to sway his decision one way or the other. Concerning the applicant group, two members have changed their decision for scenario 3 from prototype 1 to prototype 2 . In prototype 1 , they based their decisions mainly on site data which does not exist in prototype 2. In prototype 2 , where site data is lacking, they looked at the impact analysis as the major factor for their decisions. The citizens group, which is quite important to us in this case since their worldviews represent the anti-thesis, did not seem to use public opinion as their main factor in their decisions. This is contrary to their original worldviews in which they stated that public opinion is instrumental to zoning decision. This shift in their views can be attributed to the fact that when presented with concrete example of their worldviews their underlying assumptions have changed. They all mentioned the importance of knowing why the public is opposing a certain request and the issues they raise. One citizen said when looking at scenario 1 "there is a lot of opposition but I want to know why they are opposing, what their motives are." When probing into the importance of knowing the issues raised by the public, subjects stated that it helps to see whether these issues can be dealt with through putting conditions and restrictions on the requested change. However, not knowing these issues would make it difficult to make a 
fair decision according to some stakeholders. In the next section, I will introduce the synthesized design and its conception.

Table 20. Information used in the decision of the design vs. the counter-design

\begin{tabular}{|c|c|}
\hline Design (Prototype 1) & Counter-design (Prototype 2) \\
\hline 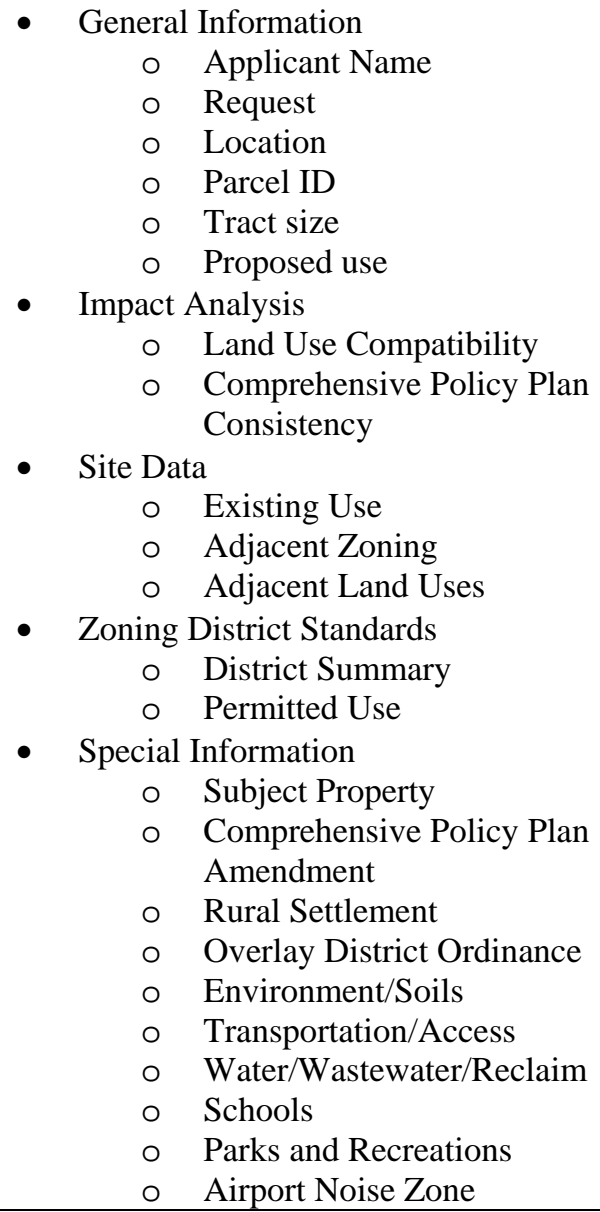 & $\begin{array}{ccl}\text { - } & \text { General Information } \\
0 & \text { Applicant Name } \\
0 & \text { Request } \\
\text { o } & \text { Location } \\
\text { o } & \text { Parcel ID } \\
\text { o } & \text { Tract size } \\
0 & \text { Proposed use } \\
\text { - Impact Analysis } \\
\text { o } & \text { Land Use Compatibility } \\
\text { o } & \text { Comprehensive Policy Plan } \\
& \text { Consistency } \\
\text { - Public Notification }\end{array}$ \\
\hline
\end{tabular}

\section{Synthesized Design}

As a result of the evaluation of both the design and the counter-design, I attempted to come up with a new synthesized view of the decision process. According to Mason (1968), one of the 
characteristics of the synthesis in the dialectic method is that the new concept that results from the structured debate (in this case the evaluation process) can be formulated on one of three ways (p.73):

1. A new more general and broader concept is formed under which both original concepts (thesis and anti-thesis) are subsumed.

2. A new more refined or more specific concept is formed that is subsumed by both original concepts.

3. A different, not necessarily more general or coarser or more specific or finer concept, but one contrary to the original one is formed. Straightforward subsumption is not possible.

In this situation, the first way of formulating the new concept seems more appropriate for several reasons. First, by looking at the data presented in table 21, we can see that both technical data and public information are viewed as essential and instrumental in completing a zoning decision. Second, by analyzing tables 17 and 19 above, we can see that data available in prototype 2 is considered as critical and missing from prototype 1 and vice versa. Additionally, data such as maps, issues raised by the public and more environmental data are considered as critical and missing from both prototypes by the majority of stakeholder groups. Therefore, the new synthesized design is formulated as "general broader concept under which both original concepts (thesis and anti-thesis) are subsumed.” Hence, this new design will include information presented in both prototypes in addition to maps, a list of issues raised by the opposition, photos of the site and more environmental data such as water capacity, endangered species and biology of the site (wetlands/floodplain/waterbodies). Table 22 summarizes the information used in the synthesized design. Figures 15, 16 and 17 present respectively a use case diagram, an activity diagram and a class diagram modeling the new synthesized design. 
Table 21. Portion of the information presented in each prototype that is considered essential for or instrumental in completing a zoning decision

\begin{tabular}{|l|l|l|}
\hline Stakeholder groups & \multicolumn{1}{|c|}{$\begin{array}{c}\text { Essential Information } \\
\text { (Prototype 1) }\end{array}$} & \multicolumn{1}{|c|}{$\begin{array}{c}\text { Essential Information } \\
\text { (Prototype 2) }\end{array}$} \\
\hline Interest groups (2)* & $\begin{array}{l}\text { Intensification (1)**, impact } \\
\text { analysis (2), site data (1) }\end{array}$ & $\begin{array}{l}\text { Impact analysis (3), intensification } \\
(1)\end{array}$ \\
\hline Staff (2) & $\begin{array}{l}\text { All (1), Site visit (1), impact } \\
\text { analysis (2) }\end{array}$ & $\begin{array}{l}\text { Impact analysis (3), public } \\
\text { notification (2) }\end{array}$ \\
\hline Citizens (3) & $\begin{array}{l}\text { Impact analysis (3), site data } \\
\text { (2), proposed use (1), schools } \\
\text { and transportation (1) }\end{array}$ & $\begin{array}{l}\text { Impact analysis (3), public } \\
\text { opposition (2) }\end{array}$ \\
\hline Elected officials (2) & $\begin{array}{l}\text { Site data (3), impact analysis } \\
\text { (3) }\end{array}$ & $\begin{array}{l}\text { Impact analysis (3), public opinion } \\
\text { (3), intensification (1) }\end{array}$ \\
\hline Applicants (3) & $\begin{array}{l}\text { Impact analysis (3), site data } \\
\text { (1), permitted use (1) }\end{array}$ & Impact analysis (2), intended use (1) \\
\hline
\end{tabular}

* The number of subjects in each group.

**The numbers between parentheses $(\mathrm{x})$ represent how many individuals in that particular group have mentioned that information as essential or instrumental in completing a zoning decision. 
Table 22. Information used in the synthesized design decision

- General Information

o Applicant Name

o Request

o Location

o Parcel ID

o Tract size

o Proposed use

- Impact Analysis

o Land Use Compatibility

o Comprehensive Policy Plan Consistency

- Public Notification

- Site Data

$0 \quad$ Issues raised by the public

o Existing Use

o Adjacent Zoning

o Adjacent Land Uses

- Zoning District Standards

o District Summary

o Permitted Use

- Special Information

o Subject Property

o Comprehensive Policy Plan Amendment

o Rural Settlement

o Overlay District Ordinance

o Environment Data

- Soils

- Endangered Species

- Wetlands/Floodplains/Waterbodies

o Transportation/Access

o Water/Wastewater/Reclaim

o Water Capacity

o Schools

o Parks and Recreations

- Airport Noise Zone 


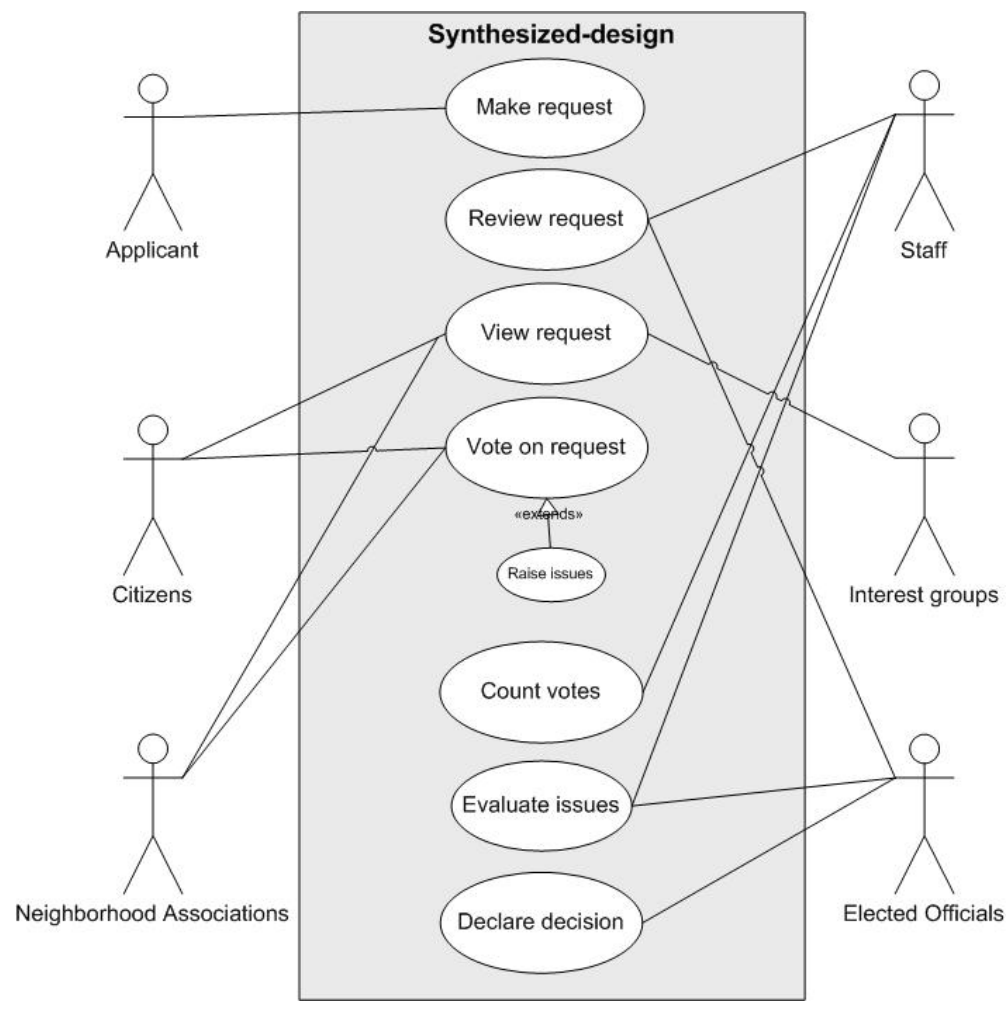

Figure 15. Synthesized Design Prototype Use Case diagram

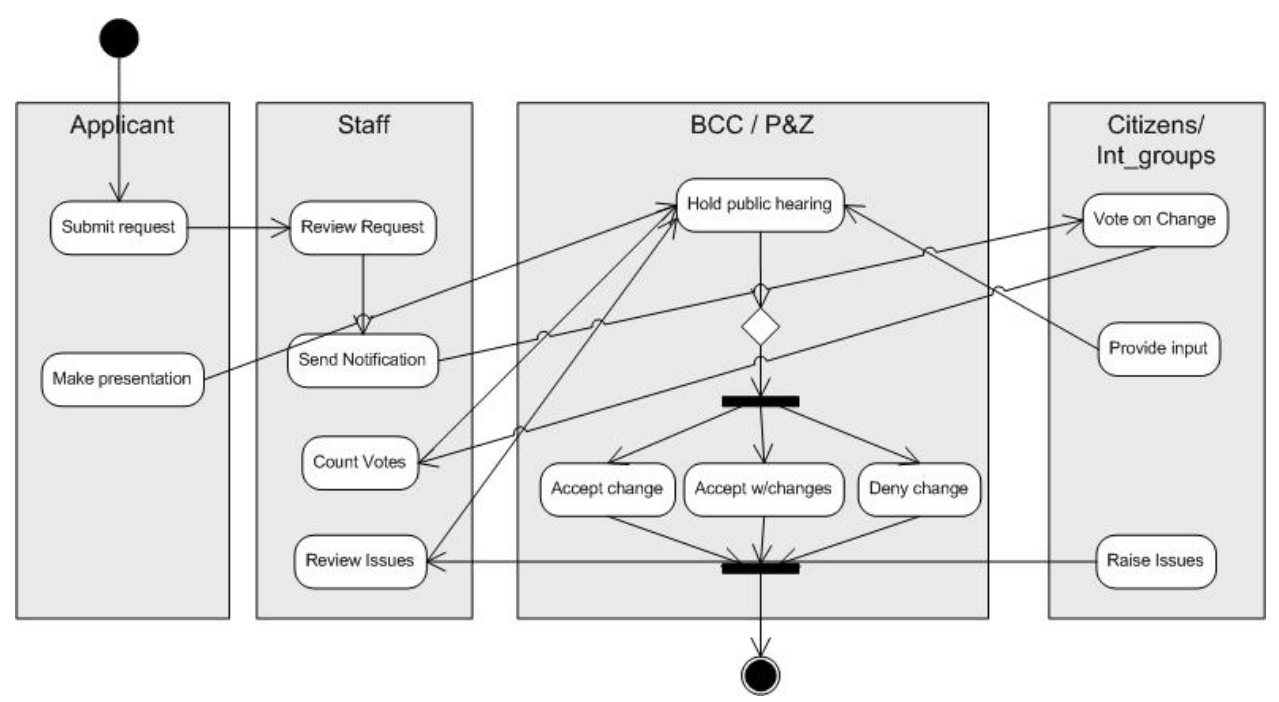

Figure 16. Synthesized Design Prototype Activity Diagram 


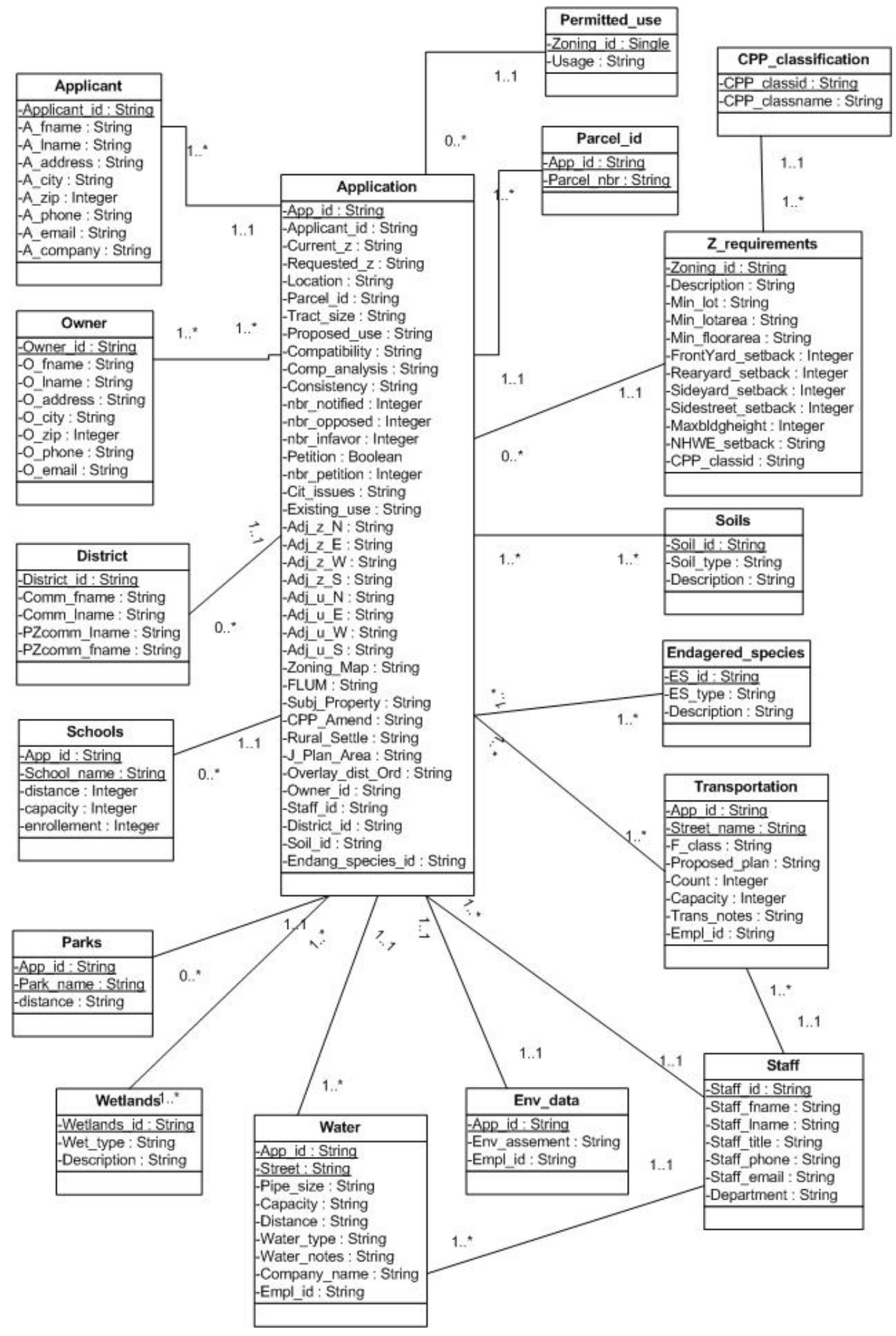

Figure 17. Synthesized Design Prototype Class diagram 


\section{$\underline{\text { Evaluation }}$}

The evaluation stage of the MPDP methodology consists of evaluating the synthesized design. The same procedure used to evaluate the design and counter design was used to evaluate the synthesized design. The three scenarios were adapted to the synthesized design (See Appendix K) and the interview guides were kept unchanged. The interviews were scheduled during the month of September 2004 about two months after the design and counter design evaluation interviews, thus mitigating chances that the subjects would remember their decisions or the details of prototypes 1 and 2. Only 12 interviews were conducted because during the months of August and September, three hurricanes hit the area of Orlando and 3 of the subjects (a staff member, an elected official and a member of the interest group) cancelled the interviews that were scheduled during that week, attempts to reschedule the interviews were unsuccessful for different reasons.

Table 23 summarizes the decisions made by the different stakeholder groups. As one might notice from this table, there is an overall agreement between the decision produced by the system and the decisions made by the majority of the stakeholder. It seems that for scenario 1 , most of the critical issues raised by the opposing public could be addressed by adding restrictions and variances such as setbacks and fences. The availability of the maps was helpful because I noticed that the majority of stakeholders used them to a greater extent in understanding the layout of the site and its adjacent property as well as the sizes of the lots surrounding the lot in question. It was very apparent that subjects used the maps to also determine the compatibility of the site therefore reducing the inherent bias in the compatibility judged by staff. In fact most of the subjects responded negatively when asked whether the information presented contains any 
substantial bias. One of the subjects stated "compatibility is subjective. It is an inherent bias. But with the information provided one can easily evaluate this judgment.” The availability of the maps and the site data makes it relatively easy for stakeholders to determine compatibility even though some of them preferred to have photos of the surrounding areas.

Table 23. Prototype 3 Evaluation Results

\begin{tabular}{|l|c|c|}
\hline Prototype 3 & Approve & Deny \\
\hline Scenario 1 (a)* & $\mathbf{1 0}$ & $\mathbf{2}$ \\
\hline Scenario 2 (d) & $\mathbf{2}$ & $\mathbf{1 0}$ \\
\hline Scenario 3 (a) & $\mathbf{8}$ & $\mathbf{4}$ \\
\hline
\end{tabular}

*The letters between parentheses show the recommendation by the prototype $(\mathrm{a})=$ approve and $(\mathrm{d})=$ deny

All subjects believe that the information is understandable except for one member of the interest group who suggested that the environmental data needs to be interpreted, she affirmed “The info available now makes sense to me but may not mean anything to an elected official or regular citizen. You need an interpretation of that in other words, what would be helpful to know whether soils, that are well drained, are suitable for building or soils that are not in order for those not familiar with the terminology to understand the meaning of the information presented.” Interestingly enough and as predicted all subjects except one believe that this prototype captures their views. This member belongs to the interest group and stated that "This prototype represents partly my views. I think an environmental tool would be very useful for what you are trying to do.” The subjects did not think that this prototype was missing any critical data or any information presented is irrelevant to the decision. According to the 
interviewed subjects, the synthesized design has captured most of the information necessary to make an informed decision.

At the end of the structured interview, subjects were presented with all prototypes and asked to determine which one they would vote for to be adopted by the planning and zoning department of Orange County, they all voted for the synthesized design stating that it is more comprehensive and provides a better and complete picture of the situation. One staff member said about the synthesized design that "it (prototype 3) has more information than our current report.”

The "new intellectual model of the world" (Mason, 1968, p. 73) represented by the synthesized design seem to be accepted by most stakeholders and the evaluation results did not reveal any strong tensions or conflicts between the stakeholder groups. There was no strong reaction to the synthesized system as there was to the other prototypes especially prototype 2 . This was a sufficient reason to stop the process and declare the synthesized design the final design.

Since the final designed prototype was developed to be used mainly by staff, I demonstrated it to them in order to get their feedback. The demo was done to two members of the staff group and the director of IT of the planning department. After the demo, these three members were asked a few questions measuring their reaction. The conduct of these questions was very informal. Their answers were taped and transcribed. Overall the reaction was very positive. The director of IT said that

"This application would be a great add-on to the zoning analyst (an application they are implementing in the planning department). This looks good and this is definitely something we can use. This is something we are definitely interested in and we definitely will pay for those services as a consultant separate from your dissertation. I like what you have done." 
Another staff member stated that "this would make it easier and faster to get information from other departments.” This reaction was very encouraging and supports my thesis.

\section{MPDP Methodology Evaluation}

In order to evaluate the effectiveness of the methodology, subjects were asked open ended questions at the end of the synthesized design evaluation interviews. The questions used were adapted from Mason (1968). The results of these questions are reported below.

Before I started asking the questions, I first briefly described the whole process of the MPDP methodology to the subjects. Then I gave them a chance to ask any questions to clarify the different steps of the methodology. It is important to note here that all subjects were blind to the methodology during the whole process. Once the subject stopped asking questions about the process, I moved to asking them questions as described in Appendix L.

The first question was directed towards determining the first reaction of the respondent to the MPDP methodology. In general, all 12 subjects responded positively to the MPDP methodology. Comments such as "it is a good process," "it makes sense," "it is useful," "it is very thorough” were common among the respondents answers. One respondent related that this process "is very difficult to implement." Another one stated that "There are two fascinating things in your process: One giving them a context in which policy is applied and two revealing the bias that people may have and not realize they have in determining what they think is the best policy.” 
Five of the 12 subjects mentioned that looking at the situation from two sides is a strength of the process. Four stated that involving the different stakeholders is alone an important feature of this process, one commented "It is great to involve all stakeholders.” Another one said "What I like about your design is that it does not take for granted or make the assumption that one person is got to have all the answers. It really tries to include perspectives from all the experts and parties that have something to say about this. We can't all look at this from the same direction.” The iterative process of the methodology was also appreciated by two respondents; one stated that "this gives you the opportunity to relook at the situation without having to say yeah or neah! This is really good.”

The second question dealt with determining whether they think that this methodology would be useful for other situations other than zoning decisions. The answers to this question varied but seem to focus on situations that are contentious in nature. Table 24 summarizes quotes from several respondents.

Table 24. Quotes from some respondents concerning the type of situations the MPDP methodology would be useful for

\begin{tabular}{|l|}
\hline "This process could be used in any service program design." \\
\hline "This process could also be used for comp plan amendments even though comp plan is \\
more subjective than objective." \\
$\begin{array}{l}\text { "It would be useful for other decision making processes and other development } \\
\text { decisions." }\end{array}$ \\
"As the process goes I think it could be used in most decisions, a lot of government \\
decisions." \\
"This process could be applied to the comprehensive plan, amendments, and what the \\
local government think should be the basis for changing the local CPP, basically looking \\
at policies and testing whether certain policies actually implementing the objectives. I \\
think you can even taking back to developing goals and objectives of the community. \\
You can use it as a check and balance. It can also be used in an innovative way to \\
identify the kind of factors that really should be considered in evaluating whether a plan \\
is effective, sometimes we call them benchmarks."
\end{tabular}


The third question involved asking the subjects to suggest any improvements to the methodology. Three respondents stated that they would not change anything in the methodology, one stated “I don’t think I will change anything, you have everybody involved, everybody has a say. And everybody has been listened to and you did your best to synthesize the issues." The other eight respondents interpreted this question as evaluation of the process. Most the comments focused on the limitations of the process. Six of the respondents explicitly mentioned "time consuming" as a major drawback of the methodology. One respondent added that "people involved in it need to be totally immersed in it to understand it. Also the tremendous pressure of time sometimes can be an inhibitor." Another one related that the methodology can be difficult to implement stating that "I think you are very idealist to try this!” Another one stated that the MPDP methodology is only suitable to certain situations.

From the above summary of responses, one can see that in general the respondents did appreciate several things in the MPDP methodology namely including the multiple stakeholders, looking at problems from two different perspectives and the iterative process. Additionally, the limitations suggested by the stakeholders were inline with the predictions that the MPDP methodology is time consuming and only suitable for contentious decisions.

\section{Conclusion}

In this chapter, I presented the final steps of the MPDP methodology as well as results of the evaluation of the MPDP by the stakeholders. There is clear evidence that confirm that the synthesized design was a better design; there was no clear objection to the synthesized design 
and all stakeholders unanimously voted for it as the preferred design. Additionally, the evaluation process revealed that the MPDP methodology can only work in certain conditions. Most of the respondents thought that the MPDP is time consuming and hence it is more feasible for many governmental and community decisions which are characterized by the multiplicity of stakeholders and the conflict between the different groups than for other less contentious decisions. The subjects also appreciated the multiple perspective approach used in MPDP. Involving stakeholders from different groups and different levels, listening to their concerns and trying to accommodate their views in the design of the systems has proved very challenging but doable. This challenge was due mainly to the fact that there are so many factors involved in the decision most of which are "soft" factors such as personal opinions and emotions. Trying to isolate the underlying assumptions upon which these personal opinions and emotions are based is no easy task. MPDP methodology does provide a mechanism for understanding such factors and identifying these assumptions. The dialectic method is such mechanism. The use of two prototypes each based on different thesis and the iterative process did help clarify assumptions and emerge new views. For instance, during the first interviews, members of the citizen' groups strongly advocated the importance of using citizen's input as the main and sometimes the only factor in making zoning decision. After being introduced to a prototype that supports their views, those same members of the citizen group emphasized the importance of other factors such as the character of the area and the intensity of use in making zoning decisions. By allowing the stakeholders to simultaneously evaluate different prototypes, they are offered with an opportunity to make a fully informed choice between different alternatives. The result is a “better” more accepted system by all stakeholders. Despite the challenges faced, the MPDP methodology proved practical and useful in dealing with situations where conflict is present. 


\section{CHAPTER SEVEN: SUMMARY, CONTRIBUTIONS, AND SUGGESTIONS FOR FUTURE RESEARCH}

In this dissertation, a theory for designing effective DSS for wicked situations using multiple perspectives and the dialectic process is proposed and tested using action research methodology. The principle theme of the multiple perspective dialectic process is that decision makers learn about the key assumptions of the problem at hand and come to understand them by isolating conflicting assumptions and observing a dialogue concerning a design prototype and a counter design prototype. The goal is to formulate a synthesized design. This synthesized design is then evaluated by all stakeholders involved and if there are no conflicting assumptions, the synthesized design is declared the optimal design and the process of the MPDP methodology ends. The MPDP methodology consists of seven steps: 1) Stakeholder identification, 2) Worldview formulation, 3) Multiple perspective identification, 4) Decision factors determination, 5) Conflict identification, 6) Resolution generation and, 7) Evaluation. These seven steps are iterative.

In this chapter, I will present summary of findings, reflect on the research work and attempt to draw lessons learned, discuss limitations and contribution of the research and finally, suggest recommendations for future research.

\section{$\underline{\text { Summary of Findings }}$}

The findings of the study presented in this dissertation can be summarized as follows:

1. It is feasible to implement the MPDP methodology proposed in this dissertation. This is evidenced by the results obtained at Orange County Planning and Zoning department. All steps of the methodology were carried out as described except for the structured 
debate which was not possible to implement in this case due to the conflicting schedules and the multiplicity of the stakeholders involved in the study. This step was replaced by an individual evaluation of the opposing worldviews. This evaluation was then used by the designer to attain the synthesis.

2. The MPDP methodology resulted in a synthesized design that accommodates the different views of the stakeholders. This was evidenced by the results of the synthesized design evaluation phase, 11 of the 12 subjects interviewed during this last phase attested that the synthesized design represented their views. Only one member of the interest group stated that it "partly" represented her views because according to her the environmental data presented in the synthesized design is not sufficient. Additionally, the synthesized design received an overall acceptance from all stakeholders by voting for prototype 3 as the optimal design.

3. The MPDP methodology is suitable for contentious situations and may not be feasible for structured decisions. This was supported by the subjects' reaction to the whole process. Most of them cited government decisions and community decisions as the type of decisions for which the MPDP methodology is feasible. They also mentioned that it is time consuming and time pressure may be an inhibitor. In fact the implementation of the MPDP methodology lasted about two years.

4. Most of the subjects did achieve a greater understanding of the decision process. This was evidenced by the shifts in their views when presented with different scenarios and different information supporting opposing views and their reactions to the different prototypes. As one subject stated "if they (stakeholders) don't understand it the first time they have an opportunity to re-look at it and this gives them the opportunity to try to determine the big picture of what is best.”

The MPDP methodology is still in it early stages of development. The above findings attest to its applicability and usability. However, applications of the methodology in other situations and by other designers are a necessary next step in the evolution of the MPDP methodology. 


\section{Lessons Learned}

The following represent some of the lessons drawn and reflections on the implementation of the MPDP methodology.

\section{Successful implementation is contingent}

Successful implementation of MPDP is contingent on the organization, the stakeholders and the developers. MPDP requires that designers be skilled interviewers and develop well structured interviews. They must also be familiar with the elicitation of cognitive maps from interview transcripts and be able to use a tool for drawing cognitive maps. Because MPDP requires involving members of all stakeholder groups some of which may not be working inside the organization, it is difficult to keep some outside stakeholders on board as they may either lose interest during the lengthy process or lack commitment. Stakeholders must be kept motivated and the designer must encourage them to participate in the process by highlighting the importance of their participation.

\section{A methodology must be flexible}

A design methodology must be flexible to be adaptive to the different situation in which it is to be applied. The sequence of the steps and stages in the methodology are not set in stone. Some stages can be conducted in parallel or combined even if they are shown to be consecutive in the framework. The step by step and top down approach may not always be appropriate. For example, in this research, I started identifying the decision factors while I was still identifying the multiple perspectives. Additionally, the structured debate as depicted in the framework was not feasible in this case; therefore individual evaluation of the carefully designed scenarios representing both the design and counter-design was used to replace it. One might argue that the 
structured debate might have revealed different assumptions and worldviews. However, the fact that there was only one person (myself) doing the interviews and interacting with all individual stakeholders allowed me to see the shifts in the views and probe more where necessary playing in some cases the devil's advocate.

\section{The conceptual phases are the most important}

The MPDP methodology consists of seven stages. These stages move from the abstract (mental models) to the concrete (actual designs). The most abstract phase in the MPDP is the formulation of the stakeholder worldviews and mental models. Designers/developers must be very careful during this stage as it sets the tone for the subsequent stages. Interviews must be carefully conducted and analyzed in order to develop cognitive maps. The worldview formulation phase is the most crucial of all stages. In this study, this phase was the longest of all phases. Because of the soft and conceptual and complex nature of this phase, designers might be reluctant to adopt the methodology. In order to avoid this problem, designers/developers wishing to use MPDP must be trained on how to elicit cognitive maps from interview transcripts.

\section{Contributions of the Research}

This thesis offers several theoretical and practical contributions to IS research.

First, the proposed research is concerned with providing a design theory for developing decision support systems in wicked situations. This design theory is a contribution to the IS literature because it addresses a special type of problems, wicked problems, which represent an important class of problems that have not yet been adequately addressed by existing types of design

theories. This class of problems is characterized by the multiplicity of stakeholders and the 
existence of conflict between the stakeholder groups. These problems require a pluralistic approach which allows it to be viewed from different perspectives and involving all parties that are affected by the problem or that can affect the situation. Hence to develop systems to solve these problems requires a totally new approach to the design stages. The development of MPDP methodology is an attempt to fill this gap.

Second, while other design theories strive for consensus among user requirements (Slazman and Rosenthal, 1994), the proposed design theory emphasizes dialectic inquiry as a way of achieving more effective DSS design and therefore leading to more effective decisions. The MPDP design theory is the first attempt of using dialectic inquiry in the design process of DSS. This study has provided evidence of the feasibility of using dialectic method in the development of DSS.

Third, this thesis adds to the growing field of action research. It represents an example of action research and demonstrates the validity of information system development as a form of action research. The design of DSS for contentious situations using the MPDP methodology has several implications for any organization interested in developing such systems. Firstly, the methodology facilitates the identification of conflict among different stakeholder groups. The identification of conflict is done through identifying the different stakeholders' mental models and cognitive maps. These techniques allow for a deeper understanding of the underlying assumptions that lead to certain worldviews and positions. Secondly, the methodology enhances learning and understanding of the decision process through comparing various stakeholder groups' interpretations. Thirdly, the methodology helps reduce ambiguity that results from the multiple perspectives and the conflicting views about the decision. The ambiguity and 
complexity of the decision process is reduced through the methodology's iterative process and the evaluation of the multiple designs by the different stakeholder groups.

Fourth, a practical contribution of this research is that the MPDP methodology provides a guide to developers and system designers in contentious situations, which are often characterized by the multiplicity of the stakeholders and the conflicts among them. Developers can influence the design of the system being developed. Their past experiences, personal opinions and the tools and techniques they use can greatly affect the design choices. This influence is reduced with the use of the MPDP methodology because it forces them to consider the different views of the stakeholders and identify the multiple perspectives. Additionally, the fact of developing distinct designs of the same problem isolate the

Fifth, this research work resulted in the development of a web-based prototype DSS for zoning decisions for Orange County Planning and Zoning Department. Staff members were very receptive to the synthesized design and confirmed that they would consider using the system as an add-on to the zoning analyst, a system they are currently implementing. As stated by staff members, the advantages of the prototype is that it is customized to their needs and considers all possible stakeholders in its design. As opposed to the "zoning analyst" system, which they are currently implementing and for which they had to modify some of their processes to accommodate the system. This is a pure example of how users need to adapt to the system and thus they become the tools of "the system" (Chancellor, 2000). The synthesized design on the other hand is more adapted to their needs and the needs of all people affected with the outcomes of the system.

Sixth, the MPDP methodology is the first methodology that produces multiple distinct designs. This allows the stakeholders to have a great degree of choice among different 
alternatives. Other design theories focus only on one design, which may result in a system based on incomplete understanding of the decision process.

\section{Limitations and Suggestions for Future Research}

Most of the limitations of this study are a natural outcome of action research. Since I was actively involved in applying the MPDP methodology there is a possibility that the outcome might have been biased by my own views and interpretations of the interviews. My role as developer gave me special insights into the whole process. To minimize these biases, I ensured a standard interviewing technique throughout all interviews. I stuck to the interview guides as much as possible except when there was a need to probe further. Additionally, during the interview analysis phase, whenever a quote was not clear or I feel that there are contradictions in the information provided, I tried to contact the subject either via email and phone to clarify the issue in question or refer to my notes and observations to resolve the ambiguity. Furthermore, during the first stages of the methodology when I was still acquainting myself with the zoning decision process, I had contacts with staff members other than then three subjects interviewed. I also kept memos and logs about these contacts as references. Although the majority of the stakeholders confirmed the findings another developer may have seen and experienced other events that I was blind to. This lack of impartiality is an inherent limitation of action research.

External validity is also a weakness in this study. The results must be carefully generalized. Future action research studies of the MPDP methodology must be carried out in different organizations, for different type decisions and with different developers. Another 
weakness of this research is that the methodology was implemented by its developer. Future research must focus on having others use the methodology thus demonstrating its transferability.

Another weakness of this study is the lack of direct dialogue between the different stakeholders' groups as depicted in the MPDP methodology. The dialogue step of the MPDP methodology could not be operationalized as described because of the multiplicity of the stakeholders and their conflicting schedules. In an organizational setting, it would be easier to invite all stakeholders to a dialogue meeting where both designs are presented and discussed.

Future research can also include comparing MPDP to other ISD methodologies using action research. Two designer teams each using a different methodology to develop a DSS for the same decision process and comparing the results of the two methodologies might yield some interesting findings. Although the MPDP methodology was originally developed for DSS, the approach can certainly be applied to other IS as well.

\section{Conclusion}

MPDP represents a societal system development approach which recognizes the social nature of system development and provides an opportunity to build systems that takes into consideration both technical and social objectives of stakeholder groups. It goes beyond just the users of the system; it extends to include all stakeholders that have a direct or indirect relation to the decision. Given the class of problems for which MPDP was developed, limiting the participants in the design to only users would only increase resistance to the decision and hence create more conflict and unhappy stakeholders. MPDP also treats all stakeholders at the same level thus reducing the asymmetrical power that exists between the different stakeholder groups. 
The intention in this dissertation has been to develop a design theory for decision support systems in contentious situations and to illustrate it by describing an account of its use. This dissertation is but a first step in the continuous development of the MPDP methodology. 


\section{APPENDIX A: PILOT STUDY}


A pilot study has been conducted to make sure that the methodology proposed is practical and achieves the hypothesized result. Additionally, it allowed for the refinement of methodology before actual testing begins.

Each semester the College of Business Administration departments are faced with an important decision: the allocation of classrooms to the different classes and sections offered by that particular department. Most departments use the schedule and allocations from the same semester of the previous year as the starting point for the decision process. By default, each department is allocated two classrooms (almost exclusively) in Business Building. Six months (approximately) before each semester, a meeting is schedule for all departments where the decision makers from each department get together to determine classroom availability. They decide who gets which rooms and the times the rooms are available. At the end of the meeting, where considerable negotiation takes place, each decision maker gets a list of the rooms and times that were allocated to him/her (in addition to the two rooms already allocated to them). Armed with this information, the decision makers then have to decide who is teaching which section, where and what time the classes are offered. There are two types of classes: graduate classes and undergraduate classes. Most graduate classes are offered at night and most undergraduate classes are offered during the day. Class category is only one of the many factors that decision makers have to take into consideration.

Subjects in the study consisted of graduate students enrolled in a DSS class. To increase the students' motivation and to minimize threats to internal validity, the study was assigned as their term project. There were forty four students in the class. To assure a balance in the group members' knowledge, a survey was conducted inquiring about their knowledge of programming and their level of expertise in using packages such as Excel. Based on the results, six groups were formed.

\section{Procedure}


Three groups were assigned the MPDP methodology and the other three were assigned the prototyping methodology. Methods and department assignments were done randomly. The responsibility for each group was to design a DSS to help departments in their classroom allocations and class scheduling decisions. The two sets of groups were given presentations explaining the methodology to be used. Subjects were instructed that they should not share their knowledge with other groups. Groups were then introduced to the chair of their assigned department and were given five weeks to accomplish the project. To assess their progress, the groups were required to submit progress reports every week. Since the MPDP methodology requires intensive discourse between the stakeholders and the designers, a discussion session was organized where all groups, those who used MPDP, presented their prototypes to the users followed by a dialogue session. During the dialogue sessions the department chairs expressed their opinions on the presentations and discussed the most feasible features in each of the designs presented. Armed with this feedback, the groups were to create the synthesized design. Given the short period of time for the whole project, only one debate session was organized. At the end of the project period, all subjects were asked to fill out a questionnaire. The survey included a manipulation check and asked their feedback on the methodology they used.

\section{Results of the Pilot Study}

Results of the pilot revealed that MPDP does provide better insight in the understanding of the problem to be solved. Many of the subjects appreciated the conflict driven approach of the MPDP and indicated that it "promotes more alternative ideas," and gives "the ability to see other points of view."

In this pilot study the one session debate was not enough to achieve better results. Furthermore, the dialogue component of the methodology could have been enhanced by adding tools such as discussion forum and bulletin boards to allow for more discussion between different stakeholders groups. These tools will be used in the actual study. 


\section{APPENDIX B: STAKEHOLDER GROUPS INTERVIEW GUIDES}


I am part of a research team from University of Central Florida. We are conducting research on how zoning decisions are made and on the kinds of information that can facilitate this decision making process. This research is not designed as an evaluation of Orange County decision making process. It is a way for us to begin to understand how these complex decisions are made in a large metropolitan area. We would like to talk to you about how people in positions like yours participate in this process. Today, I am specifically interested in finding out how zoning fits into your overall agenda as a (position) and what kinds of information you use and prefer to help you with these decisions. I am also interested in hearing about specific cases that can be used to illustrate zoning decision making in Orange County.

Your identity will remain anonymous, and any and all information obtained in the course of this interview will be held confidential. I would like to ask your permission to tape-record this interview. This would allow me to focus more on what you are saying rather than note-taking. It will also enable me to be more efficient and accurate in reviewing the information you give me. You can choose to discontinue the tape-recording at any time during this interview.

Respondent's Title Organization

Respondent's Title and Position

How long have you been (present position)?

Have you held a position in Orange County? If so, in what capacity?

1. What role do you play in zoning decisions?

2. Who are the primary stakeholders of the zoning decision?

a. How influential would you say each of the stakeholder groups is for the zoning decision making process?

b. Of these stakeholder groups, identify the ones that directly influence the decision process.

c. Who are the ones that are affected the most by the decision?

\begin{tabular}{|l|l|}
\hline Stakeholder group & Influence \\
\hline$\square$ Planning Division & \\
\hline$\square$ Elected Officials & \\
\hline$\square$ P\&Z Commissioners & \\
\hline$\square$ Citizens & \\
\hline$\square$ Applicants & \\
\hline$\square$ Interest Groups & \\
\hline$\square$ Neighborhood Associations & \\
\hline$\square$ Developers/Contractors & \\
\hline
\end{tabular}

3. What would you say are the main zoning problems?

Which of these problems are receiving the most attention?

Who develops plans for solving these problems?

4. Who was responsible for developing the current decision process?

a. Are you satisfied or unsatisfied with the current process?

b. What suggestions do you have to improve the current process?

5. a. How would you say zoning is viewed by elected officials? as an issue of interest to the electorate as an issue that has public policy ramifications 
as an issue of constituent satisfaction

as an economic development issue

as a safety issue

as a quality of life issue

as an issue of professional standards

b. How would you say zoning is viewed by city agencies such as Planning Department?

as an issue of interest to the electorate

as an issue that has public policy ramifications

as an issue of constituent satisfaction

as an economic development issue

as a safety issue

as a quality of life issue

as an issue of professional standards

The following questions are designed to get at 1)how decisions are made, 2)who is involved in decision making, how information is used in decision making, what factors or criteria are used in making the decisions, what other positions, groups, and/or departments are conferred with, and what the relationships are among groups.

Now I would like to talk about two related issues: first, the kinds of information that is exchanged on zoning second, the relationships among the stakeholder groups that are involved in exchanging this information.

6. What criteria would you say the County uses for evaluating a zoning decision?

7. What kinds of information or data you currently use when preparing for a zoning application, who provides them to you, and what form they take.

\begin{tabular}{|l|l|l|l|l|}
\hline Type & Source & Form & Frequency & Usefulness \\
\hline & & & & \\
\hline & & & & \\
\hline & & & & \\
\hline & & & & \\
\hline
\end{tabular}

8. Are there other kinds of information you would find useful in helping you better prepare your application?

a. What form should this information be in to be of most use to you?

b. In your opinion, who or what department would be the best source for this kind of information?

Now, let's consider specific factors or criteria you use to make decisions or judgments using data or information. We are interested in what criteria you use to determine whether or not a zoning application is acceptable. 
9. To what extent do you think Orange County considers political factors such as demands currently being made by voters, elections, election issues or political officials in reaching its zoning decisions?
a. What kinds of factors does it consider?
b. What role do these factors play in its decisions? Could you give examples?
c. How important would you say these considerations are?
Very Important Important Not Very Important Not Important at All

10. Does the County ever consider quality of life factors such as neighborhood attractiveness or livability in reaching its decisions?
a. What kinds of factors does it consider?
b. What role do these factors play in its decisions? Could you give examples?
c. How important would you say these considerations are?
Very Important Important Not Very Important Not Important at All

14. Are there economic issues that play a part in the decisions the County makes about zoning [Note, give an example]?
a. (If yes,) What kinds of factors does it consider?
b. What role do these economic factors play in its decisions? Could you give examples?
c. How important would you say these considerations are?
_ Very Important
Important
Not Very Important
Not Important at All

15. Are there ethical issues that play a part in the decisions the County makes about zoning [Note, give an example]?
a. (If yes,) What kinds of factors do you consider?
b. What role do these ethical issues play in its decisions? Could you give examples?
c. How important would you say these considerations are?

_Very Important _ _ Important _ _ Not Very Important _ _ Not Important at All

16. Does the County ever consider interest group preferences play when it makes zoning recommendations? For example, does it ever take into consideration preferences or concerns expressed by neighborhood associations, environmental organizations, or historical associations in reaching its recommendations?

a. (If yes), what kinds of factors do you consider?

b. What role do these interest group factors play? Can you give some examples?

\section{Now we would like to talk about how different groups in the county communicate about zoning issues.}

17. Do you ever communicate directly with any of the groups involved in zoning issues?
$\square$ Planning $\square$ Elected Officials

a. (If so), which ones?

b. Is there anyone else in the County you talk to about zoning?

c. Do you ever talk to contractors, developers, or consultants about zoning issues?

d. How do you communicate with these groups? (meetings, public hearings, email, news paper...)

18. (For each of the communication links mentioned in question 17, )
a. How would you describe this relationship?
b. How important is this relationship to your role in the zoning decision making process? 
19. What types of zoning information and measures do you think are useful for communicating zoning issues to the public?

20. What kinds of contacts would be more beneficial to your ability to make good decisions about zoning? (who else should be involved in the making of zoning decisions?)

21. How much discretion do you think agency staff (such as Planning) have in identifying alternatives, setting priorities, presenting information to other stakeholders?

22. Are there any other things you would like to discuss or comments you would like to add? 


\section{APPENDIX C: STAKEHOLDER GROUPS COGNITIVE MAPS}




\section{Applicant Group Map}

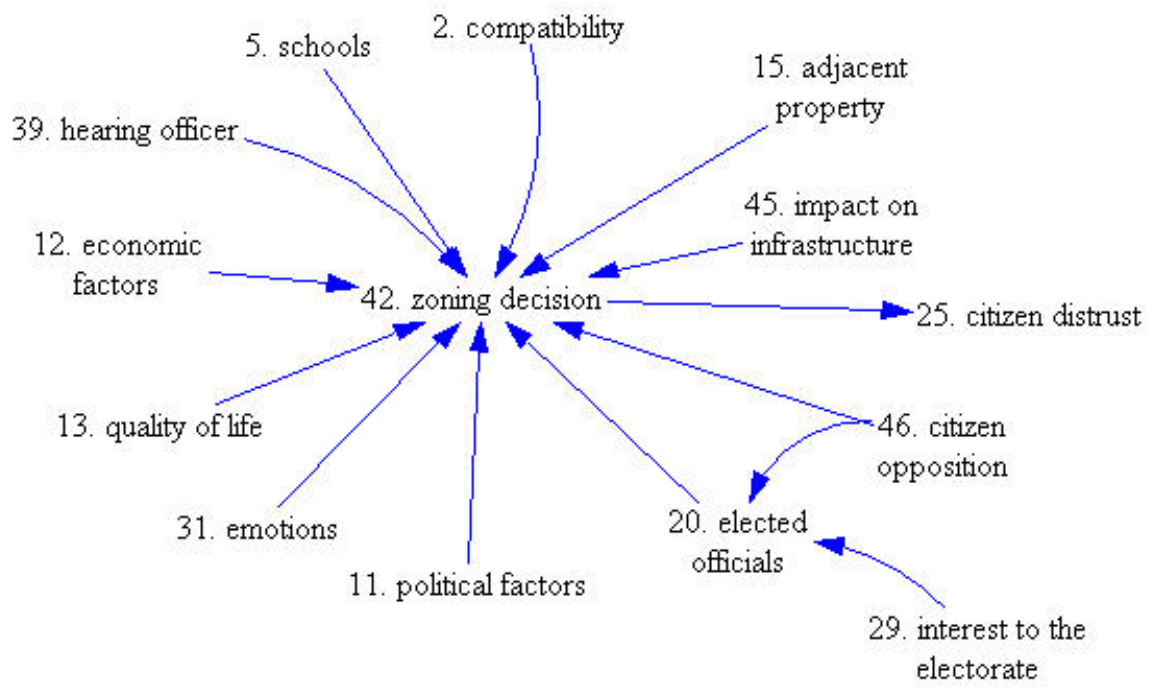

Interest Group Map

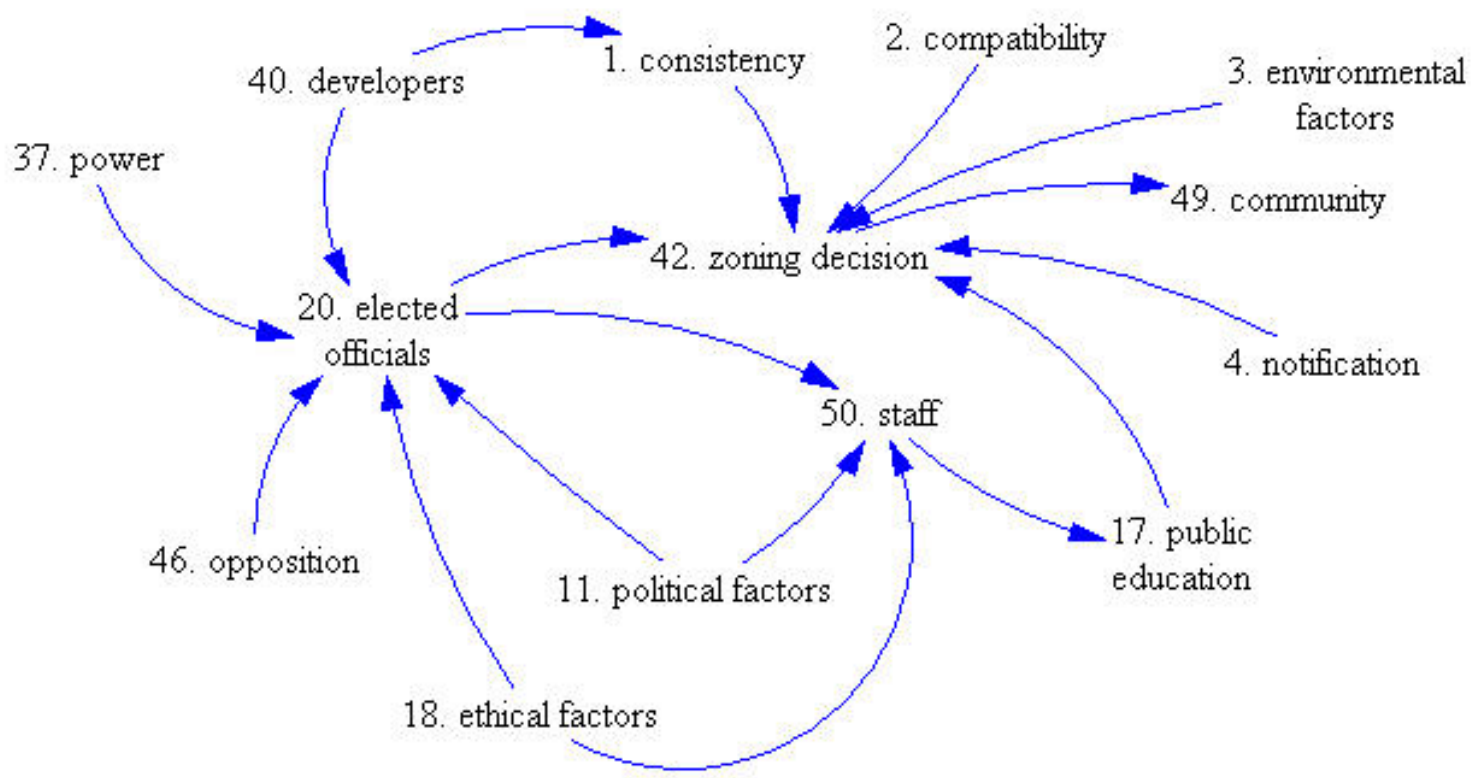

Elected Official Group Map 


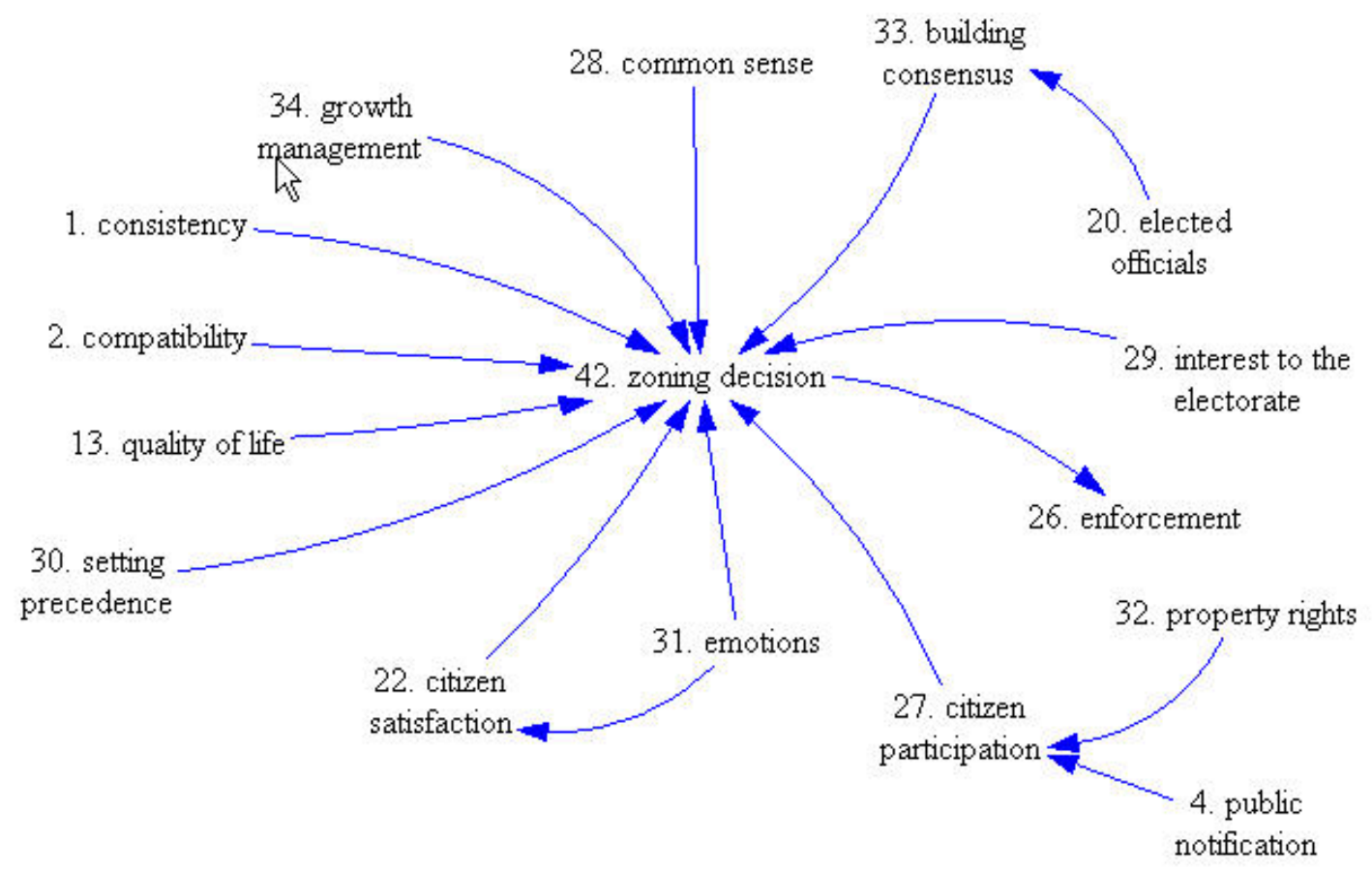

\section{Neighborhood Association Group Map}

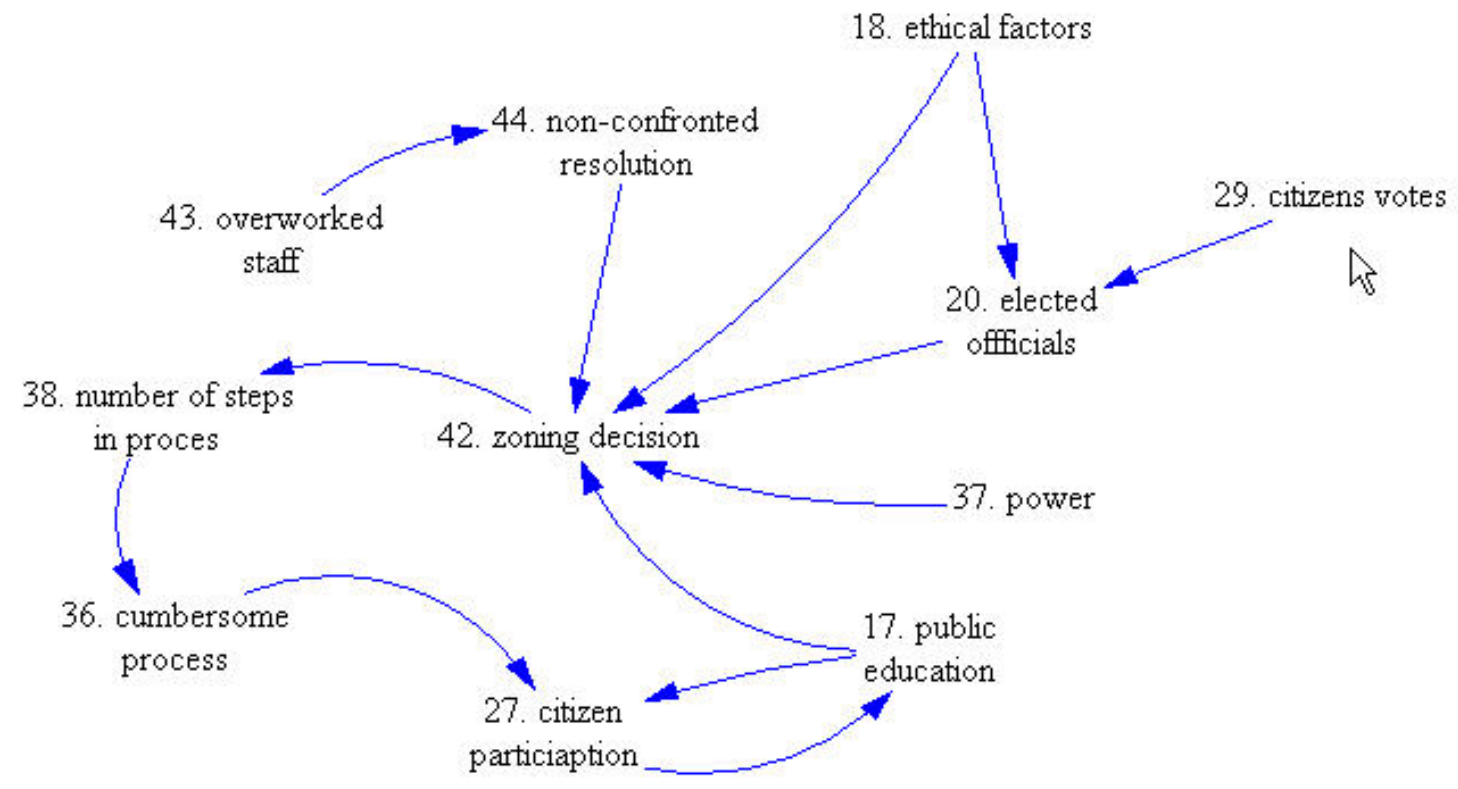




\section{Staff Group Map}

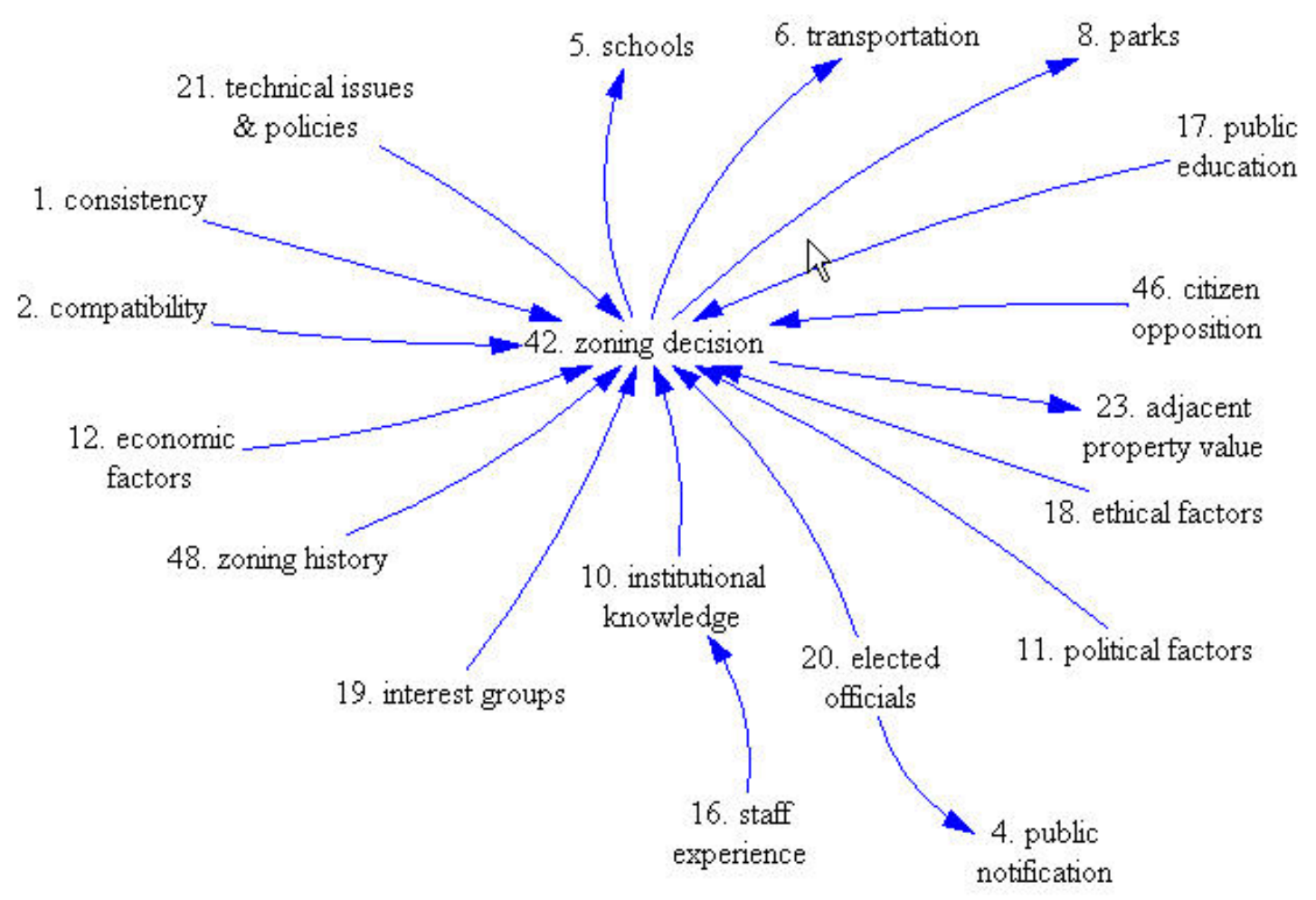




\section{APPENDIX D: EXAMPLE OF DISTANCE RATIO CALCULATIONS}


In order to show how the distance ratio is calculated consider the following two maps A and B (both maps shown for illustration purposes only). Both A and B are 10 by 10 matrices.

Map A:

\begin{tabular}{l|l|l|l|l|l|l} 
& $\mathbf{1}$ & $\mathbf{2}$ & $\mathbf{3}$ & $\mathbf{8}$ & $\mathbf{9}$ & $\mathbf{1 0}$ \\
\hline $\mathbf{1}$ & 0 & 1 & 0 & 1 & 0 & 0 \\
\hline $\mathbf{2}$ & 0 & 0 & 0 & 1 & 0 & 0 \\
\hline $\mathbf{3}$ & 0 & 0 & 0 & 0 & 0 & 0 \\
\hline $\mathbf{8}$ & 0 & 0 & 1 & 0 & 0 & 1 \\
\hline $\mathbf{9}$ & 0 & 0 & 0 & 1 & 0 & 0 \\
\hline $\mathbf{1 0}$ & 0 & 0 & 0 & 1 & 0 & 0
\end{tabular}

Map B:

\begin{tabular}{l|l|l|l|l|l} 
& $\mathbf{1}$ & $\mathbf{2}$ & $\mathbf{5}$ & $\mathbf{6}$ & $\mathbf{8}$ \\
\hline $\mathbf{1}$ & 0 & 1 & 0 & 0 & 1 \\
\hline $\mathbf{2}$ & 1 & 0 & 0 & 0 & 1 \\
\hline $\mathbf{5}$ & 0 & 0 & 0 & 0 & 1 \\
\hline $\mathbf{6}$ & 0 & 0 & 1 & 0 & 0 \\
\hline $\mathbf{8}$ & 0 & 0 & 0 & 1 & 0
\end{tabular}

The distance ratio formula applies to extended matrices, which means in our example to the whole 10x10 matrices. In applying the formula let's first calculate the denominator which is:

$$
6 p_{C}^{2}+2 p_{C}\left(p_{u_{A}}+p_{u_{B}}\right)+p_{u_{A}}^{2}+p_{u_{B}}^{2}-\left(6 p_{C}+\left(p_{u_{A}}+p_{u_{B}}\right)\right.
$$

$p_{c}$ is the number of nodes common to both maps. In our example, nodes 1,2 and 8 are common to both maps, therefore $p_{c}=3$

$p_{u A}$ is the number of nodes unique to map A. In our example, those nodes are nodes 3, 9 and 10, therefore $p_{u A}=3$ 
$p_{u B}$ is the number of nodes unique to map B. In our example, those nodes are nodes 5 and 6 , therefore $p_{u B}=2$

Given the values of $p_{c}, p_{u A}$, and $p_{u B}$ the denominator is equal to $\mathbf{7 9}$

The numerator formula consists of the sum of the sum of difference between all 100 cells (10x10), which is:

$$
\sum_{i=1}^{p} \sum_{j=1}^{p} \operatorname{diff}(i, j)
$$

First let's consider the different cases of $\operatorname{diff}(i, j)$ as presented by the formula:

$\operatorname{diff}(i, j)= \begin{cases}0 & \text { if } \mathrm{i}=\mathrm{j} ; \\ 1 & \text { if } \mathrm{i} \text { or } \mathrm{j} \notin \mathrm{P}_{\mathrm{c}} \text { And } \mathrm{i}, \mathrm{j} \in \mathrm{N}_{\mathrm{A}} \text { or } \mathrm{i}, \mathrm{j} \in \mathrm{N}_{\mathrm{B}} ; \\ \left|a_{i j}-b_{i j}\right| \text { otherwise. }\end{cases}$

Case \#1: $\mathrm{i}=\mathrm{j}$ which means the cells on the diagonal of both maps. By looking at the maps each cell on the diagonal on both A and B are zeros and therefore the $\operatorname{diff}(\mathrm{i}, \mathrm{j})=0$

Case \#2: if $i$ or $j \notin P_{c}$ And $i, j \in N_{A}$ or $i, j \in N_{B}$

$\mathrm{N}_{\mathrm{A}}$ and $\mathrm{N}_{\mathrm{B}}$ are the set of nodes of maps A and B respectively: $\mathrm{N}_{\mathrm{A}}=\{1,2,3,8,9,10\}$ and $\mathrm{N}_{\mathrm{B}}=\{1,2,5,6,8\}$

This means that one map has both $\mathrm{i}$ and $\mathrm{j}$ but the other map has either $\mathrm{i}$ or $\mathrm{j}$ (that is missing one of them). This would concern nodes 3, 9 and 10 in map A and nodes 5 and 6 in map B. These cells include $(8,3),(8,10),(2,9),(6,1)$ and $(8,6)$. Since the $\operatorname{diff}(\mathrm{i}, \mathrm{j})=1$ according the formula then the total is equal to 5 , since we have 5 such cells. 
Case \#3: the remaining cases are the case where both maps have both nodes and the case where neither map has both nodes. The first case include the following cells; $(1,2),(2,8)$ and $(1,8)$. The value of each if these cells is 1 so $\operatorname{diff}(1,2)=\left|a_{12}-b_{12}\right|=|1-1|=0$. The same is for $(2,8)$ and $(1,8)$. For the second case, this will cover all rows and columns of nodes 4 and 7 and the following cells $(8,1)$ and $(8,2)$. These cells all contain zero and therefore and the sum of the differences is equal to zero

Finally, by summing all the differences from all the cases the value of the distance ratio is $5 / 79=0.063$ 


\section{APPENDIX E: STAKEHOLDER GROUPS ASSOCIATION MATRICES}


The rows in each of the following matrices represent the same constructs on the columns in the same order. There is a total of 50 constructs in all matrices. Only the association matrices are shown not the extended matrices.

\section{Association Matrix for Applicant Group Cognitive Map}

Map id: Applicant

14 I

$\begin{array}{lllllllllllllll}2 & 5 & 11 & 12 & 13 & 15 & 20 & 25 & 29 & 31 & 39 & 42 & 45 & 46\end{array}$

$0 \begin{array}{llllllllllllll}0 & 0 & 0 & 0 & 0 & 0 & 0 & 0 & 0 & 0 & 0 & 1 & 0 & 0\end{array}$

$\begin{array}{llllllllllllll}0 & 0 & 0 & 0 & 0 & 0 & 0 & 0 & 0 & 0 & 0 & 1 & 0 & 0 \\ 0 & 0 & 0 & 0 & 0 & 0 & 0 & 0 & 0 & 0 & 0 & 1 & 0 & 0\end{array}$

$\begin{array}{llllllllllllllllllll}0 & 0 & 0 & 0 & 0 & 0 & 0 & 0 & 0 & 0 & 0 & 1 & 0 & 0\end{array}$

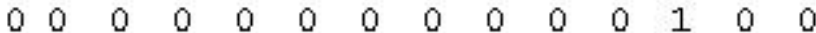

$\begin{array}{llllllllllllll}0 & 0 & 0 & 0 & 0 & 0 & 0 & 0 & 0 & 0 & 0 & 1 & 0 & 0\end{array}$

$0 \begin{array}{llllllllllllll}0 & 0 & 0 & 0 & 0 & 0 & 0 & 0 & 0 & 0 & 0 & 1 & 0 & 0\end{array}$

$\begin{array}{lllllllllllllll}0 & 0 & 0 & 0 & 0 & 0 & 0 & 0 & 0 & 0 & 0 & 0 & 0 & 0\end{array}$

$\begin{array}{llllllllllllll}0 & 0 & 0 & 0 & 0 & 0 & 1 & 0 & 0 & 0 & 0 & 0 & 0 & 0 \\ 0 & 0 & 0 & 0 & 0 & 0 & 0 & 0 & 0 & 0 & 0 & 1 & 0 & 0\end{array}$

$\begin{array}{llllllllllllll}0 & 0 & 0 & 0 & 0 & 0 & 0 & 0 & 0 & 0 & 0 & 1 & 0 & 0\end{array}$

$\begin{array}{llllllllllllll}0 & 0 & 0 & 0 & 0 & 0 & 0 & 1 & 0 & 0 & 0 & 0 & 0 & 0\end{array}$

$\begin{array}{llllllllllllll}0 & 0 & 0 & 0 & 0 & 0 & 0 & 0 & 0 & 0 & 0 & 1 & 0 & 0\end{array}$

\section{Association Matrix for Interest Group Cognitive Map}

Map id: Env

$\begin{array}{llllllllllllll}1 & 2 & 3 & 4 & 11 & 17 & 18 & 20 & 37 & 40 & 42 & 46 & 49 & 50\end{array}$

$\begin{array}{llllllllllllll}1 & 0 & 0 & 0 & 0 & 0 & 0 & 0 & 0 & 0 & 1 & 0 & 0 & 0\end{array}$

$\begin{array}{llllllllllllll}0 & 0 & 0 & 0 & 0 & 0 & 0 & 0 & 0 & 0 & 1 & 0 & 0 & 0\end{array}$

$\begin{array}{llllllllllllll}0 & 0 & 0 & 0 & 0 & 0 & 0 & 0 & 0 & 0 & 1 & 0 & 0 & 0 \\ 0 & 0 & 0 & 0 & 0 & 0 & 0 & 0 & 0 & 0 & 1 & 0 & 0 & 0\end{array}$

$\begin{array}{llllllllllllll}0 & 0 & 0 & 0 & 0 & 0 & 0 & 1 & 0 & 0 & 0 & 0 & 0 & 1\end{array}$

$\begin{array}{llllllllllllll}0 & 0 & 0 & 0 & 0 & 0 & 0 & 0 & 0 & 0 & 1 & 0 & 0 & 0\end{array}$

$\begin{array}{llllllllllllll}0 & 0 & 0 & 0 & 0 & 0 & 0 & 1 & 0 & 0 & 0 & 0 & 0 & 1\end{array}$

$\begin{array}{llllllllllllll}0 & 0 & 0 & 0 & 0 & 0 & 0 & 0 & 0 & 0 & 1 & 0 & 0 & 1\end{array}$

$\begin{array}{llllllllllllll}0 & 0 & 0 & 0 & 0 & 0 & 0 & 1 & 0 & 0 & 0 & 0 & 0 & 0\end{array}$

$\begin{array}{llllllllllllll}0 & 0 & 0 & 0 & 0 & 0 & 0 & 1 & 0 & 0 & 0 & 0 & 0 & 0\end{array}$

$\begin{array}{llllllllllllll}0 & 0 & 0 & 0 & 0 & 0 & 0 & 0 & 0 & 0 & 0 & 0 & 1 & 0\end{array}$

$\begin{array}{llllllllllllll}0 & 0 & 0 & 0 & 0 & 0 & 0 & 1 & 0 & 0 & 0 & 0 & 0 & 0\end{array}$

$\begin{array}{llllllllllllll}0 & 0 & 0 & 0 & 0 & 0 & 0 & 0 & 0 & 0 & 0 & 0 & 0 & 0 \\ 0 & 0 & 0 & 0 & 0 & 0 & 0 & 0 & 0 & 0 & 0 & 0 & 0 & 0\end{array}$ 


\section{Association Matrix for Elected Officials Group Cognitive Map}

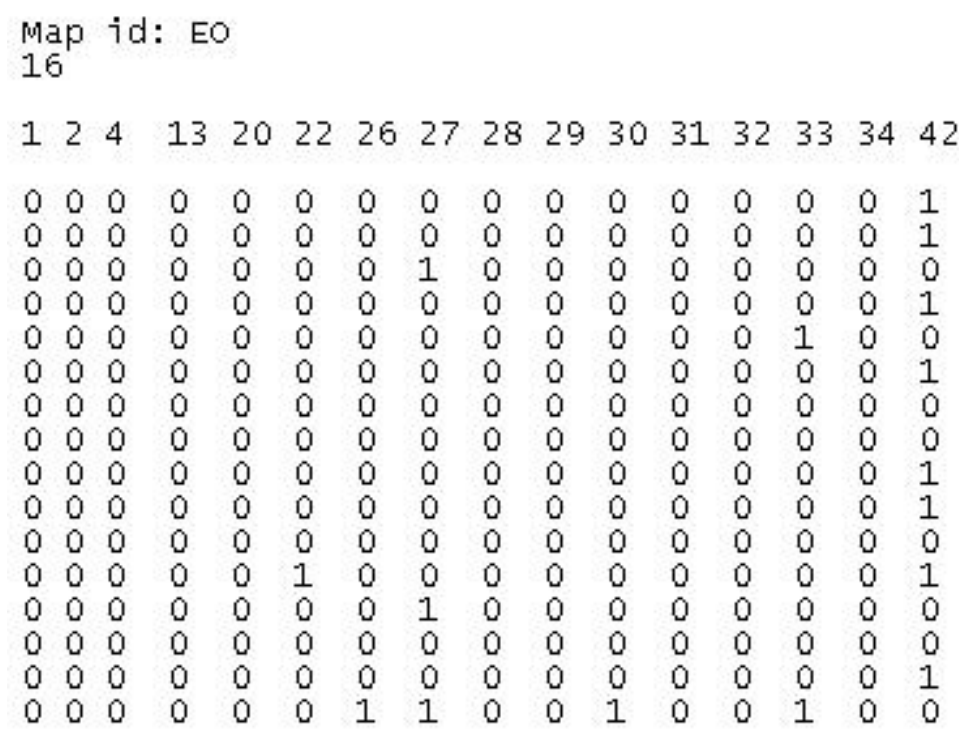

\section{Association Matrix for Neighborhood Associations Group Cognitive Map}

Map id: NAsso

11

$\begin{array}{lllllllllll}17 & 18 & 20 & 27 & 29 & 36 & 37 & 38 & 42 & 43 & 44\end{array}$

$\begin{array}{lllllllllll}0 & 0 & 0 & 0 & 0 & 0 & 0 & 0 & 1 & 0 & 0 \\ 0 & 0 & 0 & 0 & 0 & 0 & 0 & 0 & 1 & 0 & 0 \\ 0 & 0 & 0 & 0 & 0 & 0 & 0 & 0 & 1 & 0 & 0 \\ 0 & 0 & 0 & 0 & 0 & 0 & 0 & 0 & 0 & 0 & 0 \\ 0 & 0 & 1 & 0 & 0 & 0 & 0 & 0 & 0 & 0 & 0 \\ 0 & 0 & 0 & 1 & 0 & 0 & 0 & 0 & 0 & 0 & 0 \\ 0 & 0 & 0 & 0 & 0 & 0 & 0 & 0 & 1 & 0 & 0 \\ 0 & 0 & 0 & 0 & 0 & 1 & 0 & 0 & 0 & 0 & 0 \\ 0 & 0 & 0 & 0 & 0 & 0 & 0 & 1 & 0 & 0 & 0 \\ 0 & 0 & 0 & 0 & 0 & 0 & 0 & 0 & 0 & 0 & 1 \\ 0 & 0 & 0 & 0 & 0 & 0 & 0 & 0 & 1 & 0 & 0\end{array}$




\section{Association Matrix for Staff Group Cognitive Map}

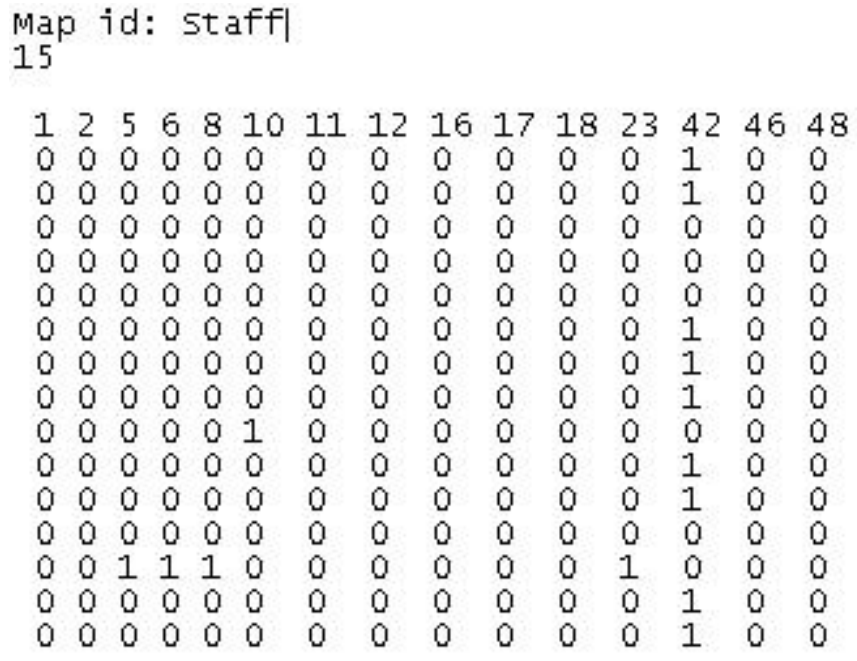


APPENDIX F: PROTOTYPE EVALUATION INTERVIEW GUIDE 
- Please indicate your decision for each of these zoning cases

a. What kinds of factors/information did you consider in making your decision?

b. How important would you say each of these factors to a zoning decision? All

Very Important $\quad \square$ Important $\quad \square$ Not Very Important $\quad \square$ Not Important at

- Is the information applicable and helpful for the decisions?

$\square$ Yes $\quad \square$ No

a. If No, probe why?

- Is the information of sufficient breath, depth, and scope for the decision?

$\square$ Yes $\quad \square$ No

a. If No, probe why?

- Is the information missing any critical data?
Yes
$\square$ No

a. If Yes, what is the missing information?

b. Do you find it difficult to make a decision effectively because the data you mentioned is not available to you?

- What portion of the information presented is essential for or instrumental in completing a zoning decision.

- What portion of the information presented is irrelevant in completing a zoning decision.

- Do you think the information presented is easy to understand and that the exact meaning of data elements is obvious and easy to find?

$\square$ Yes $\quad \square$ No

a. If No, which information do you find difficult to understand?

b. What suggestions do you have to make it more understandable?

- Do you think the information presented contains a substantial amount of bias?

$\square$ Yes $\quad \square$ No

a. If Yes, what part of the information do you think has bias?

b. What suggestions do you have to overcome this bias?

- Do you think the information provided is consistent with your views?

$\square$ Yes $\quad \square$ No 
a. If No, please describe the best way to represent your views in the current information?

b. If Yes, which parts of the information presented you think represents your views?

- How confident would you say you are in this information (provided by the planning department)?

$\square$ Very Confident $\square$ Confident $\quad \square$ Not Very Confident

$\square$ Not Confident at All

(if not very or not all then probe why and what needs to be done) 


\section{APPENDIX G: PROTOTYPE 1 AND 2 SCENARIOS}




\section{Prototype 1 - Scenario \#1}

Mr. Jason Smith owns 6 acres which are currently zoned as R-CE (country estate residential district). He would like to re-zone his property from R-CE to A-1 (Citrus rural). The A-1 zoning district would allow Mr. Smith to operate a horseback riding business and stable. Currently, the property has a barn and a house on it.

\section{GENERAL INFORMATION}

APPLICANT

REQUEST

LOCATION
Mr. Jason Smith

R-CE (Country Estate Residential District) (1957) to A-1 (Citrus rural).

(14001) Main Road generally described as located on the north side of Seagul Road, east of US 92.

PARCEL ID NUMBER(S) 39-21-27-0000-00-003

$39-21-27-0000-00-016$

39-21-27-0000-00-025

$\sim 6$ Acres.

Horseback riding business and stable

\section{IMPACT ANALYSIS}

Land Use Compatibility

The proposed A-1 (Citrus Rural) zoning would allow land uses that are compatible with the existing development in the area.

Comprehensive Policy Plan (CPP) Consistency

The CPP Future Land Use Map designation requested for this location is Rural Settlement 1/1. The A-1 zoning district is consistent with this land use designation.

\section{SITE DATA}


Existing Use

Adjacent Zoning

Adjacent Land Uses
House \& Barn

$$
\begin{array}{ll}
\text { N: } & \text { R-CE (Country Estate District (1981) } \\
\text { E: } & \text { R-CE (Country Estate District (1981) } \\
\text { W: } & \text { A-1 (Citrus Rural) (1957) } \\
\text { S: } & \text { R-1 (Single Family Dwelling District) (1957) }
\end{array}
$$

N: Single family dwellings

E: Single family dwellings, nursery

W: Large lot single family dwellings

S: $\quad$ Large single family dwellings

\section{ZONING DISTRICT STANDARDS (A-1)}

\section{District Summary}

$\begin{array}{lc}\text { Minimum Lot Area } & \\ \text { SFR: } & 1 / 2 \text { acre }(21,780 \text { square feet }) \\ \text { Mobile Home: } & 2 \text { acres } \\ \text { Minimum Lot Width: } & 100 \text { feet } \\ \text { Building Setbacks: } & \\ \text { Front Yard } & 35 \text { feet } \\ \text { Rear Yard } & 50 \text { feet } \\ \text { Side Yard } & 10 \text { feet } \\ \text { Side Street } & 15 \text { feet }\end{array}$

Permitted Use(s)

Single-family residence, agricultural production, plant nurseries, bee keeping, forestry services, logging, golf courses, religious organizations, raising and keeping of cows and horses etc.

\section{SPECIAL INFORMATION}

\section{Subject Property}

House and a Barn.

\section{Comprehensive Policy Plan Amendment - NA}

Rural Settlement - NA

Overlay District Ordinance - NA

\section{Environment/Soils}

(26) Ona fine sand, 0-2\% slopes, poorly drained 
(34) Pomelo fine sand, 0-5\% slopes, moderately well drained

Transportation/Access

Street

Main Road

Count:

Capacity:

\section{Functional Classification Comp-Plan}

2-lane local road

No improvement.

2003 Peak Directional Count for Main Road/CR415 from US 92 to Seagul Road is 241.

The capacity on Main Road/CR145 from US 92 to Seagul Road is 810. Remaining capacity is approximately 569 trips (3-84).

Water/Wastewater/Reclaim

Water:

Wastewater:

Reclaim water:
Existing service or provider Dream City Utilities Commission

8” VCP FM on Main Road (approx. 600’ away)

NA

\section{Schools}

Projected School Age Population - NA

The approved uses do not generate any school age population.

\section{Parks \& Recreation}

Name

Sunshine Park
Distance

$\sim 15.68$ miles

\section{Airport Noise Zone}

The subject property is not located in an Airport Land Use Zone. 


\section{Prototype 1 - Scenario \#2}

Mrs. Karen Brown owns a 4.57 acres that is currently zoned residential. She would like to rezone this property to R-T-2 (Combination Mobile Home and Single-Family Dwelling District). She would like to have the capability of placing mobile homes on the subject property. Currently, there are no other mobile homes in this area. The adjacent properties are mostly residential (single-family homes and duplexes).

\section{GENERAL INFORMATION}

APPLICANT

REQUEST

LOCATION
Karen Brown

R-2 (Residential District) (1985) to

R-T-2 (Combination Mobile Home and Single-Family Dwelling District)

Generally described as the west side of Central Park Avenue and north of W. Manhattan Avenue.

PARCEL ID NUMBER(S) 41-22-03-0000-00-64/65/66/68

TRACT SIZE

$\sim 4.57$ Acres.

PROPOSED USE Mobile homes.

\section{IMPACT ANALYSIS}

\section{Land Use Compatibility}

The proposed R-T-2 zoning would allow land uses that are incompatible with the existing development in the area.

\section{Comprehensive Policy Plan (CPP) Consistency}

The CPP Future Land Use Map designates this location as Low Density Residential (LDR). The R-T-2 zoning district is consistent with this land use designation.

\section{SITE DATA}

\section{Existing Use Vacant}

Adjacent Zoning

N: $\quad$ R-2 (Residential District) (1986)

R-1 (Single-Family Dwelling District) (1957) 
E: $\quad$ C-1 (Retail Commercial District) (1986)

W: Central Park Avenue and R-1 (Single-Family Dwelling District) (1957)

S: $\quad$ R-3 (Multiple-Family Dwelling District) (1957)

Adjacent Land Uses $\quad$ N: $\quad$ Single family residential unit

E: Vacant

W: Central Park Avenue and Single family residential unit

S: Duplex

ZONING DISTRICT STANDARDS (R-T-2)

District Summary

Min. Lot Area:

Min. Lot Width:

Max. Height:

Building Setbacks

Front:

Rear:

Side Yard:

Side Street:

$$
\begin{aligned}
& 1 / 2 \text { ac., }(21,760 \text { sq. ft. }) \\
& 100 \mathrm{ft} . \\
& 35 \mathrm{ft} . \\
& \\
& 35 \mathrm{ft} . \\
& 50 \mathrm{ft} . \\
& 10 \mathrm{ft} . \\
& 15 \mathrm{ft} .
\end{aligned}
$$

Permitted Use(s)

Mobile homes, family day care homes, non-store retailers, home occupations, accessory buildings and screened enclosures, single family and modular homes w/ customary accessory uses, etc.

\title{
SPECIAL INFORMATION
}

\section{Subject Property}

The property is currently zoned R-2 (Residential District) with a land use designation of Low Density Residential.

Comprehensive Policy Plan Amendment - NA

\author{
Rural Settlement - NA
}

Joint Planning Area - NA

Overlay District Ordinance - NA 


\section{Environment/Soils}

(34) Pomello fine sand, 0-5\% slopes, moderately well drained

(54) Zolfo fine sand, 0-2\% slopes, somewhat poorly drained

No potential conservation area exists on the site.

\section{Transportation/Access}

\begin{tabular}{|c|c|c|}
\hline Street & Functional Classification & Comp-Plan \\
\hline$\overline{\text { W. Manhattan Drive/ }}$ & 4-lane Urban/ & $\overline{\text { State Roadway-Programmed }}$ \\
\hline SR 75 & Principal Arterial & $\begin{array}{l}\text { improvement to widen to 6- } \\
\text { lanes from W. Madison } \\
\text { Highway to Clinton Highway. } \\
\text { Construction start date FY } \\
\text { 08/09 }\end{array}$ \\
\hline Count: & \multicolumn{2}{|c|}{$\begin{array}{l}2003 \text { Peak Directional Count for W. Mahattan Drive from } \\
\text { Alexis Road to Madison Highway is } 2000 \text {. }\end{array}$} \\
\hline Capacity: & \multicolumn{2}{|c|}{$\begin{array}{l}\text { The capacity on for W. Manhattan Drive from Alexis Road } \\
\text { to Madison Highway is } 2,110 \text {. }\end{array}$} \\
\hline
\end{tabular}

$\underline{\text { Remaining capacity is approximately } 110 \text { trips. }}$

Water/Wastewater/Reclaim

$\underline{\text { Existing service or provider }}$

Water: $\quad$ 16” DIP on W. Manhattan Drive (approximately 800’ away)

Wastewater: $\quad$ 18” DIP on W. Manhattan Drive (approximately 800’ away)

Reclaim water: NA

Schools

Projected School Aqe Population $\sim 10$

The net increase in the number of students generated from the change in zoning is not significant and will not negatively impact school capacity.

\begin{tabular}{|c|c|c|c|}
\hline Name & Distance & Capacity & Enrollment \\
\hline Courtney Elementary & $\sim 1.52$ miles & 407 & 774 \\
\hline Union Park Middle & $\sim 4.17$ miles & 1019 & 1369 \\
\hline Manhattan High & 2.62 miles & 2,619 & 2,459 \\
\hline
\end{tabular}




\section{Parks \& Recreation}
Name
Distance
Central Park
$\sim 0.63$ miles

\section{Airport Noise Zone}

The subject property is not located in an Airport Noise Zone 


\section{Prototype 1 - Scenario \#3}

Mr. Jim Courtney owns about 2 acres which are currently zoned as A-2 (Farmland Rural). He would like to rezone his property to R-2 (Medium density residential). He would like to build a second dwelling on this property. Currently, the property has an accessory building on it.

\section{GENERAL INFORMATION}

\section{Applicant Jim Courtney}

Request

A-2 (Farmland Rural) (1957) to R-2 (Residential District)

Location

North side of Burger Road and South Alligator Trail intersection or 6200 Burger Road

Tract Size 230.77 feet $x 378.52$ feet

Proposed Use Convert accessory building to a $2^{\text {nd }}$ dwelling at 6200 Burger Road.

\section{IMPACT ANALYSIS}

Land Use Compatibility

The proposed R-2 (Residential District) zoning would allow land uses that are incompatible with the existing development in the area.

Comprehensive Policy

Plan Consistency

The CPP Future Land Use Map designates this location as Low Density Residential (LD). The R-2 zoning district is inconsistent with this land use designation.

\section{SITE DATA}

Existing Use

(2) Single family dwellings, barn, and shed

Adjacent Zoning

N: A-2 (Farmland Rural) (1957)

E: $\quad$ R-2 (Residential District) (1981)

- $\quad$ Restricted to single family residences and/or duplexes

W: R-2 (Residential District) (1989)

S: $\quad$ R-2 (Residential District) (1981)

- $\quad$ Restricted to single family residences and/or duplexes

Adjacent Land Uses $\quad$ N: Single family dwelling

E: Single family dwelling 
W: Single family dwelling

S: $\quad$ Single family dwelling

\section{ZONING DISTRICT STANDARDS}

R-2 District Standards Two Dwelling Units

Permitted Uses

\author{
Minimum Lot Area: 8,000 square feet \\ Minimum Lot Width: 80 feet \\ Maximum Height: 35 feet \\ Minimum Setbacks \\ Front Yard: $\quad 25$ feet \\ Rear Yard: $\quad 25$ feet \\ Side Yard: $\quad 6$ feet
}

Single-family homes, fee-simple duplex and patio homes, home occupations (as defined in Sec. 38-1, O.C. Code), swimming pools, multifamily w/ customary accessory uses, etc.

\section{SPECIAL INFORMATION}

Subject Property

Single family dwelling and a shed.

\section{Comprehensive Policy Plan Amendment - NA}

Rural Settlement - NA

Overlay District Ordinance - NA

\section{Environment/Soils}

(35) Pomello-Urban land complex, 0-5\% slopes, moderately well drained;

(54) Zolfo fine sand, $0-2 \%$ slopes, somewhat poorly drained

Transportation/Access

Street/Thoroughfare

Brunner Road

Count:

Capacity:

Water/Wastewater $\underline{\text { Existing }}$

Principal Arterial, Urban

2001 Peak Directional Count for Brunner Rd. from Burger

Road to Coral reef Drive is 1,656.

The capacity for Brunner Road from Coral reef Drive to Burger Road is 1,850 .

Water: 10” PVC on Burger Rd (approx. 200’ away) Wastewater: 12” PVC on Pastel Dr. (approx. 350’ away) 


\section{Schools}

Name

Reagan Elementary School

Carnegie Middle School

Coral High School
Distance

$\sim 1.45$ miles

$\sim 3.54$ miles

$\sim 2.77$ miles
Capacity Enrollment

$580 \quad 689$

$1,217 \quad 1,387$

$2,825 \quad 2,364$

\section{$\underline{\text { Projected School Age Population } ~} 1$}

The net increase in the number of students generated from the change in zoning from A-2 to R-2 is insignificant and will not negatively impact school capacity.

\section{Parks \& Recreation}

Name

Alligator Trail Head

\section{Distance}

$\sim 1.95$ miles

\section{Airport Noise Zone}

The subject property is not located in an Airport Land Use Zone. 


\section{Prototype 2 - Scenario \#1}

Mr. Jason Smith owns 6 acres which are currently zoned as R-CE (country estate residential district). He would like to re-zone his property from R-CE to A-1 (Citrus rural). The A-1 zoning district would allow Mr. Smith to operate a horseback riding business and stable. Currently, the property has a barn and a house on it.

\section{GENERAL INFORMATION}
APPLICANT
Mr. Jason Smith
REQUEST
R-CE (Country Estate Residential District) (1957) to A-1 (Citrus rural).
LOCATION
(14001) Main Road generally described as located on the north side of Seagul Road, east of US 92.

PARCEL ID NUMBER(S) 39-21-27-0000-00-003

39-21-27-0000-00-016

39-21-27-0000-00-025

TRACT SIZE

$\sim 6$ Acres.

PROPOSED USE

Horseback riding business and stable

\section{IMPACT ANALYSIS}

\section{Land Use Compatibility}

The proposed A-1 (Citrus Rural) zoning would allow land uses that are compatible with the existing development in the area.

\section{Comprehensive Policy Plan (CPP) Consistency}

The CPP Future Land Use Map designation requested for this location is Rural Settlement 1/1. The A-1 zoning district is consistent with this land use designation.

\section{PUBLIC NOTIFICATION}

The notification area for this zoning request was 500 feet. 
- Number of notices mailed to property owners in the mailing area: 20

- Number of signatures appearing on a petition: No petition signed

- Number of responses opposing the request: 18

- Number of responses in favor of the request: 0 


\section{Prototype 2 - Scenario \#2}

Mrs. Karen Brown owns a 4.57 acres that is currently zoned residential. She would like to rezone this property to R-T-2 (Combination Mobile Home and Single-Family Dwelling District). She would like to place mobile homes on the subject property. There are no other mobile homes in this area. The adjacent properties are mostly residential (single-family homes and duplexes).

\section{GENERAL INFORMATION}
APPLICANT
Karen Brown
REQUEST
R-2 (Residential District) (1985) to
R-T-2 (Combination Mobile Home and Single-Family Dwelling District)
LOCATION
Generally described as the west side of Central Park Avenue and north of W. Manhattan Avenue.
PARCEL ID NUMBER(S)
TRACT SIZE
41-22-03-0000-00-64/65/66/68
PROPOSED USE
$\sim 4.57$ Ac.
Mobile homes.

\section{IMPACT ANALYSIS}

\section{Land Use Compatibility}

The proposed R-T-2 zoning would allow land uses that are incompatible with the existing development in the area.

\section{Comprehensive Policy Plan (CPP) Consistency}

The CPP Future Land Use Map designates this location as Low Density Residential (LDR). The R-T-2 zoning district is consistent with this land use designation.

\section{PUBLIC NOTIFICATION}

The notification area for this zoning request was 500 feet.

$>$ Number of notices mailed to property owners in the mailing area: 500

$>$ Number of signatures appearing on a petition against the proposed request: 345

$>$ Number of responses opposing the request: 250

$>$ Number of responses in favor of the request: 0 


\section{Prototype 2 - Scenario \#3}

Mr. Jim Courtney owns about 2 acres which are currently zoned as A-2 (Farmland Rural). He would like to rezone his property to R-2 (Medium density residential). He would like to build a second dwelling on this property. Currently, the property has an accessory building on it.

\section{GENERAL INFORMATION}

APPLICANT Jim Courtney

REQUEST A-2 (Farmland Rural) (1957) to R-2 (Residential District)

LOCATION North side of Burger Road and South Alligator Trail intersection or 6200 Burger Road

TRACT SIZE 230.77 feet $x 378.52$ feet

PROPOSED USE Convert accessory building to a $2^{\text {nd }}$ dwelling at 6200 Burger Road.

IMPACT ANALYSIS

Land Use Compatibility The proposed R-2 (Residential District) zoning would allow land uses that are incompatible with the existing development in the area.

Comprehensive Policy The CPP Future Land Use Map designates this location as Plan Consistency Low Density Residential (LD). The R-2 zoning district is inconsistent with this land use designation.

\section{PUBLIC NOTIFICATION}

The notification area for this zoning request was 500 feet.

$>$ Number of notices mailed to property owners in the mailing area: 39

$>$ Number of signatures appearing on a petition in favor of the proposed request: 25

$>$ Number of responses opposing the request: 0

$>$ Number of responses in favor of the request: 25 


\section{APPENDIX K: PROTOTYPE 3 SCENARIOS}




\section{Prototype 3 - Scenarios \#1}

Mr. Jason Smith owns 6 acres which are currently zoned as R-CE (country estate residential district). He would like to re-zone his property from R-CE to A-1 (Citrus rural). The A-1 zoning district would allow Mr. Smith to operate a horseback riding business and stable. Currently, the property has a barn and a house on it.

\section{GENERAL INFORMATION}

APPLICANT

REQUEST

LOCATION

PARCEL ID NUMBER(S)
Mr. Jason Smith

R-CE (Country Estate Residential District - Max 1du/ac) (1957) to A-1 (Citrus rural - Max 1du/10 ac).

Maximum density represents the number of units in zoning category as indicated in the FLUM.

(14001) Main Road generally described as located on the north side of Seagul Road, east of US 92.

39-21-27-0000-00-003

39-21-27-0000-00-016

39-21-27-0000-00-025

$\sim 6$ Acres.

Horseback riding business and stable.

\section{IMPACT ANALYSIS}

\section{Land Use Compatibility}

The proposed A-1 (Citrus Rural) zoning would allow land uses that are compatible with the existing development in the area.

\section{Comprehensive Policy Plan (CPP) Consistency}

The CPP Future Land Use Map designation requested for this location is Casablanca Rural Settlement 1/1. The A-1 zoning district is consistent with this land use designation.

\section{PUBLIC NOTIFICATION}

The notification area for this zoning request was 500 feet.

$>$ Number of notices mailed to property owners in the mailing area: 20

$>$ Number of signatures appearing on a petition: No petition signed

$>$ Number of responses opposing the request: 18 
$>$ Number of responses in favor of the request: 0

Concerns of the public:

$>$ Stallions may pose a danger to neighborhood children.

$>$ Selling the property with A-1 zoning might open the area up to adverse land uses.

$>\mathrm{A}-1$ is less restrictive than R-CE zoning.

$>$ Stables are not consistent with surrounding development.

$>$ Stables produce adverse sounds and smells

No Community meeting was held.

SITE DATA

Existing Use

Adjacent Zoning

Adjacent Land Uses
House \& Barn

$$
\begin{array}{ll}
\text { N: } & \text { R-CE (Country Estate District - 1981) } \\
\text { E: } & \text { R-CE (Country Estate District - 1981) } \\
\text { W: } & \text { A-1 (Citrus Rural - 1957) } \\
\text { S: } & \text { R-1 (Single Family Dwelling District - 1957) }
\end{array}
$$

$\mathrm{N}$ : $\quad$ Single family dwellings

E: Single family dwellings, nursery

W: Large lot single family dwellings

S: $\quad$ Large single family dwellings

\section{ZONING DISTRICT STANDARDS (A-1)}

\section{District Summary}

Minimum Lot Area

SFR:

Mobile Home:

Minimum Lot Width:

Building Setbacks:

Front Yard

Rear Yard

Side Yard

Side Street

Permitted Use(s)

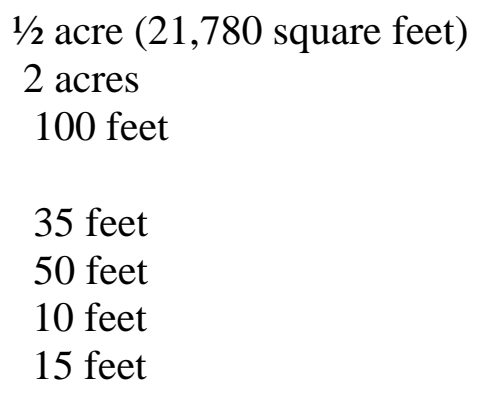

Single-family residence, agricultural production, plant nurseries, bee keeping, forestry services, logging, golf courses, religious organizations, raising and keeping of cows and horses etc. 


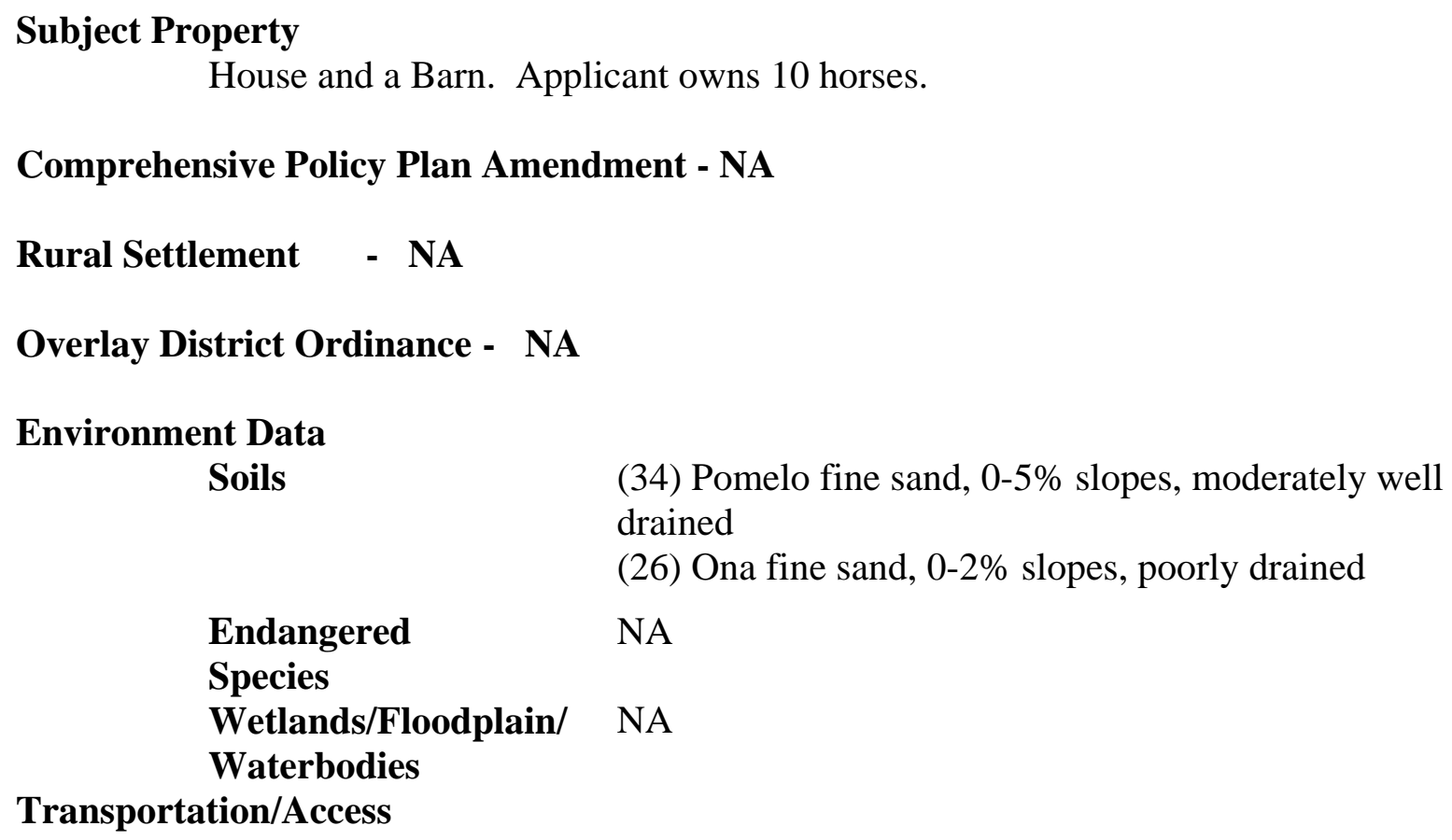

Count: $\quad 2003$ Peak Directional Count for Main Road/CR415 from US 92 to Seagul Road is 241.

Capacity: $\quad$ The capacity on Main Road/CR145 from US 92 to Seagul Road is 810.

Remaining capacity is approximately 569 trips (3-8-4). The Proposed request will not negatively affect transportation and access roads.

\section{Water/Wastewater/Reclaim}

Water:

Wastewater:

Reclaim water:

\section{Existing service or provider *}

Dream City Utilities Commission

8” VCP FM on Main Road (approx. 600' away)

$\mathrm{NA}$

*This is provided for information only, may not reflect the actual connection point. Connection point(s) will be determined at Final Construction Plan Review. 


\section{Schools}

Projected School Age Population - NA

The proposed uses do not generate any school age population.

\section{Parks \& Recreation}

Name

Distance

Sunshine Park

$\sim 15.68$ miles

\section{Airport Noise Zone}

The subject property is not located in an Airport Land Use Zone. 
ZONING MAP

Scenario \#1

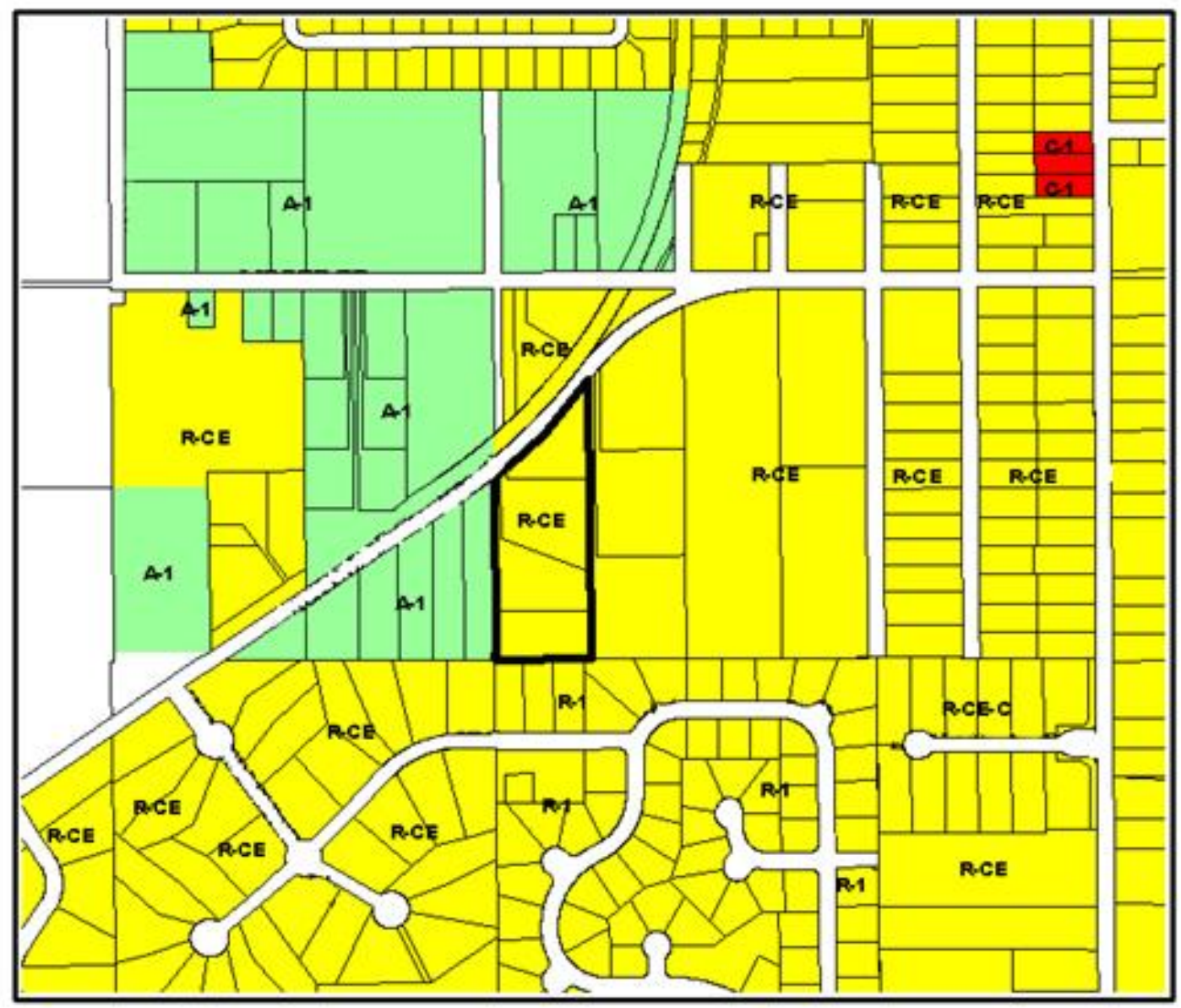

Request: R-CE to A-1

Applicant: Jason Smith Address: 14001 Main Road

Tract Size: $\sim 6$ Acres

\section{Legend:}

R-CE - Country estate district

R-1 - Single Family Dwelling District

A-1 - Citrus Rural

C-1- Retail Commercial District

Bold line : Subject property 


\section{FUTURE LAND USE MAP Scenario \#1}

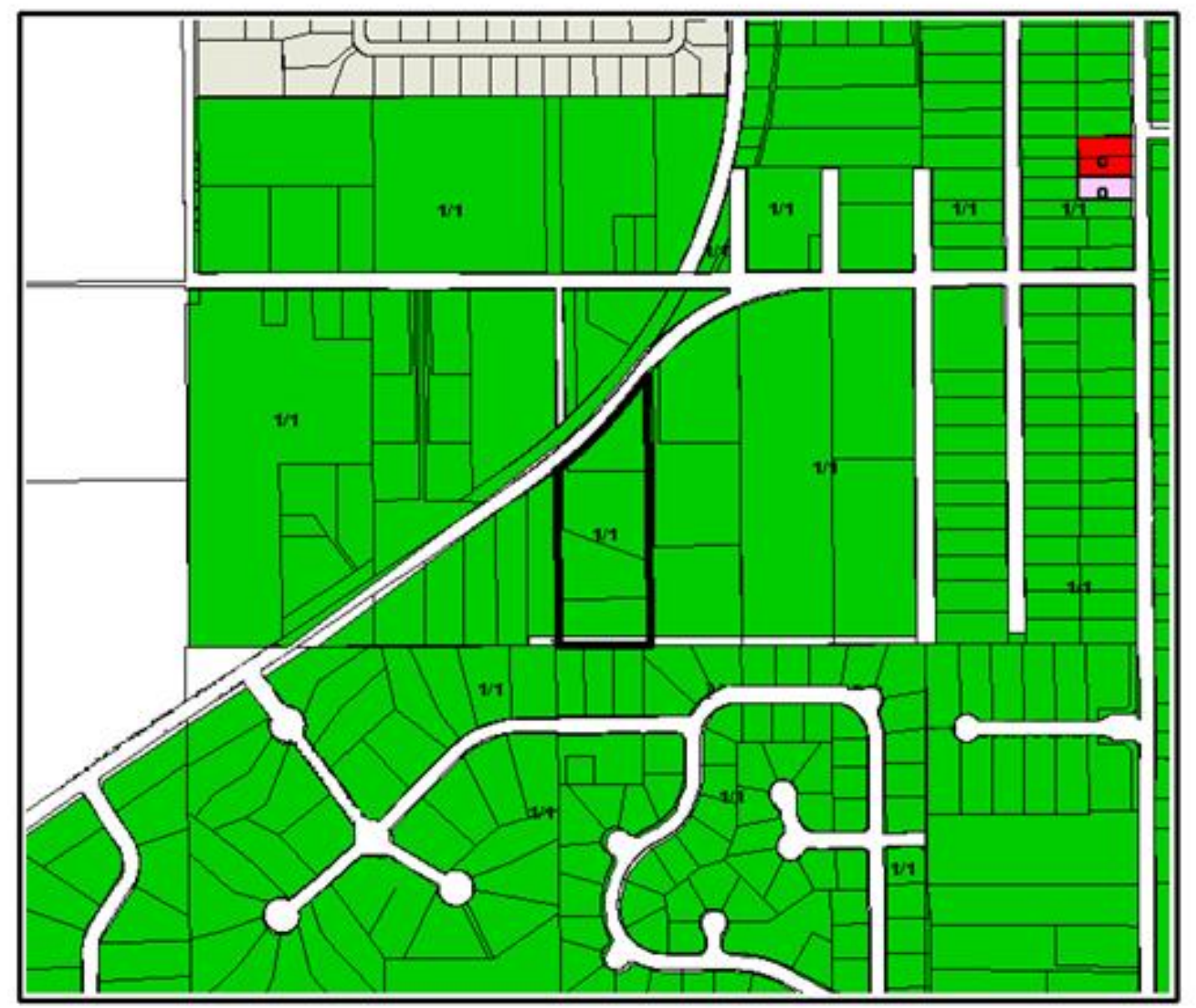

Request: R-CE to A-1 Applicant: Jason Smith Address: 14001 Main Road Tract Size: $\sim 6$ Acres

\section{Legend}

1/1 - Rural Settlement

C- Commercial

$\mathrm{O}$ - Office

Bold line : Subject property 


\section{Prototype 3 - Scenario \#2}

Mrs. Karen Brown owns 4.57 acres that is currently zoned residential. She would like to re-zone this property to R-T-2 (Combination Mobile Home and Single-Family Dwelling District). She would like to have the capability of placing mobile homes on the subject property. Currently, there are no other mobile homes in this area. The adjacent properties are mostly residential (single-family homes and duplexes).

\section{GENERAL INFORMATION}

APPLICANT

REQUEST
Karen Brown

R-2 (Residential District - Max 10du/ac) (1985) to

R-T-2 (Combination Mobile Home and Single-Family

Dwelling District - Max 4du/ac)

Maximum density represents the number of units in zoning category as indicated in the FLUM.

Generally described as the west side of Central Park Avenue and north of W. Manhattan Avenue.

PARCEL ID NUMBER(S) 41-22-03-0000-00-64/65/66/68

TRACT SIZE

$\sim 4.57$ Acres.

PROPOSED USE

Mobile homes. 18 units.

\section{IMPACT ANALYSIS}

\section{Land Use Compatibility}

The proposed R-T-2 zoning would allow land uses that are incompatible with the existing development in the area.

\section{Comprehensive Policy Plan (CPP) Consistency}

The CPP Future Land Use Map designates this location as Low Density Residential (LDR). The R-T-2 zoning district is consistent with this land use designation.

\section{PUBLIC NOTIFICATION}

The notification area for this zoning request was 500 feet. 
$>$ Number of notices mailed to property owners in the mailing area: 500

$>$ Number of signatures appearing on a petition against the proposed request: 345

$>$ Number of responses opposing the request: 250

$>$ Number of responses in favor of the request: 0

Concerns of the public:

$>$ Mobile homes are not compatible with the development of the area

$>$ Mobiles homes will decrease value of surrounding residential properties

$>$ They don't provide for stable neighborhood

$>$ They negatively affect the aesthetics of the area.

\section{SITE DATA}

Existing Use

Adjacent Zoning

Adjacent Land Uses
Vacant

N: $\quad$ R-2 (Residential District) (1986)

R-1 (Single-Family Dwelling District) (1957)

E: $\quad$ C-1 (Retail Commercial District) (1986)

W: Central Park Avenue and R-1 (Single-Family Dwelling District) (1957)

S: $\quad$ R-3 (Multiple-Family Dwelling District) (1957)

N: Single family residential unit

E: $\quad$ Vacant

W: Central Park Avenue and Single family residential unit

S: $\quad$ Duplex

\section{ZONING DISTRICT STANDARDS (R-T-2)}

\section{District Summary}

Min. Lot Area:

Min. Lot Width:

Max. Height:

Building Setbacks

Front:

Rear:

Side Yard:

Side Street:
$1 / 2$ ac., (21,760 sq. ft.)

$100 \mathrm{ft}$.

$35 \mathrm{ft}$.

$35 \mathrm{ft}$.

$50 \mathrm{ft}$.

$10 \mathrm{ft}$.

$15 \mathrm{ft}$.

\section{Permitted Use(s)}

Mobile homes, family day care homes, non-store retailers, home occupations, accessory buildings and screened enclosures, single family and modular homes 
w/ customary accessory uses, etc.

\title{
SPECIAL INFORMATION
}

\section{Subject Property}

The property is currently zoned R-2 (Residential District) with a land use designation of Low Density Residential.

Comprehensive Policy Plan Amendment - NA

\author{
Rural Settlement - NA \\ Joint Planning Area - NA \\ Overlay District Ordinance - NA
}

\section{Environment Data}

Soils

(35) Pomello fine sand, 0-5\% slopes, moderately well drained

(54) Zolfo fine sand, 0-2\% slopes, somewhat poorly drained.

Endangered Species - NA

Wetlands/Floodplain/Waterbodies - NA

\section{Transportation/Access}

$\underline{\text { Street }}$

W. Manhattan Drive/

SR 75

$\underline{\text { Count: }}$

Capacity:

\section{Functional Classification Comp-Plan}

State Roadway-Programmed improvement to widen to 6lanes from W. Madison Highway to Clinton Highway. Construction start date FY

08/09

4-lane Urban/

Principal Arterial
2003 Peak Directional Count for W. Mahattan Drive from Alexis Road to Madison Highway is 2000.

The capacity on for W. Manhattan Drive from Alexis Road to Madison Highway is 2,110.

Remaining capacity is approximately 110 trips. The Proposed request will not negatively affect transportation and access roads. 
Water/Wastewater/Reclaim

Existing service or provider

Water: $\quad 16$ ” DIP on W. Manhattan Drive (approximately 800' away)

Wastewater: $\quad$ 18” DIP on W. Manhattan Drive (approximately 800’ away)

Reclaim water: NA

Water Capacity

The Proposed request will not negatively affect water capacity.

Schools*

Projected School Aqe Population $\sim 10$

The net increase in the number of students generated from the change in zoning is not significant and will not negatively impact school capacity.

$\begin{array}{lccc}\text { Name } & \text { Distance } & \text { Capacity } & \text { Enrollment } \\ \text { Courtney Elementary } & \sim 1.52 \text { miles } & 407 & 774 \\ \text { Union Park Middle } & \sim 4.17 \text { miles } & 1019 & 1369 \\ \text { Manhattan High } & \sim 2.62 \text { miles } & 2,619 & 2,459 \\ & & & \\ \text { * Source Orange County Public School Enrollment Summary-dated 05/14/04 }\end{array}$

Parks \& Recreation

$\begin{array}{ll}\text { Name } & \frac{\text { Distance }}{\sim 0.63 \text { miles }}\end{array}$

Airport Noise Zone

The subject property is not located in an Airport Noise Zone 


\section{ZONING MAP}

Scenario \#2
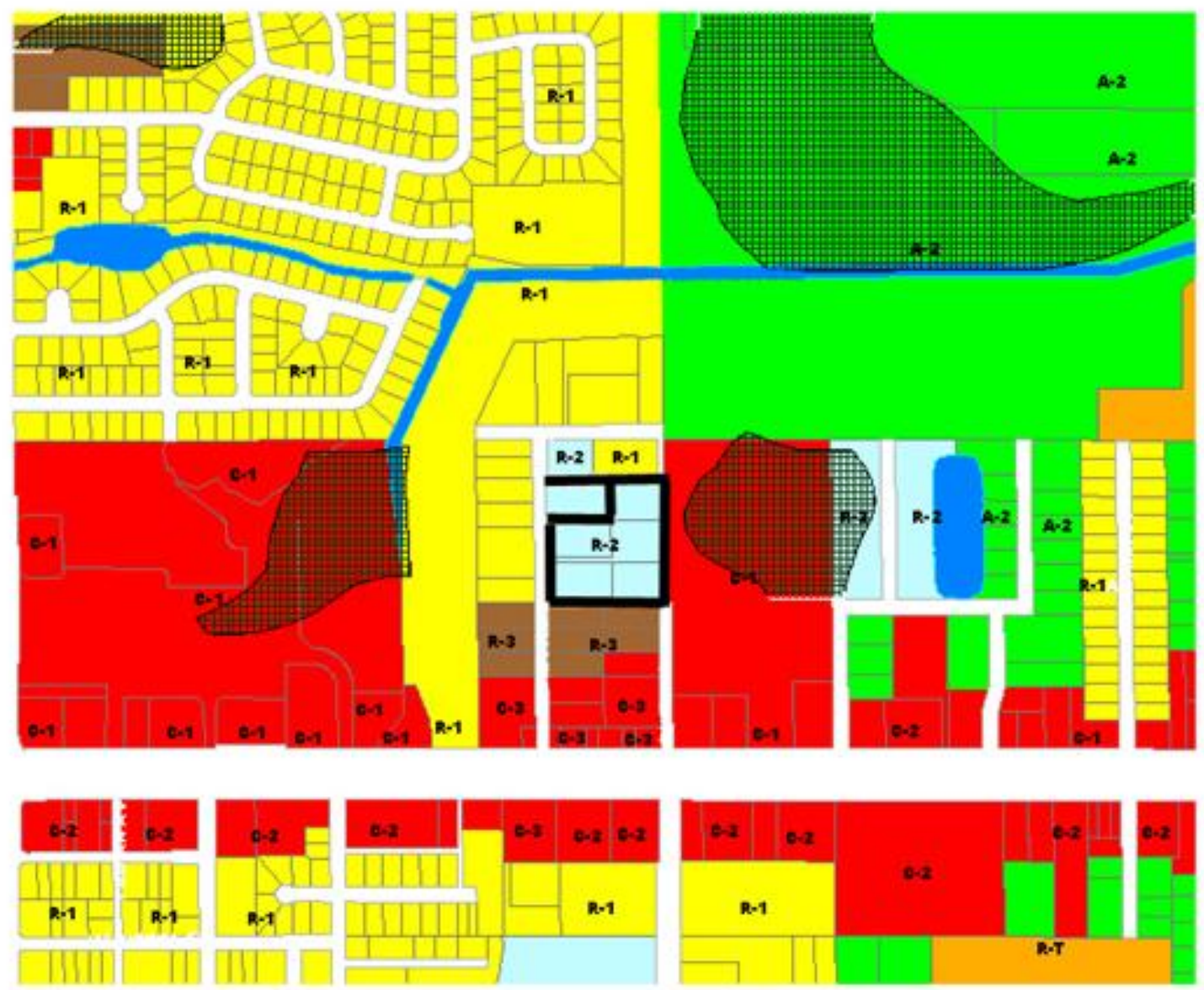

Request: R-2 to R-T-2
Applicant: Karen Brown
Address: East side of Central
Park AV., North of $W$
Manhattan
Tract Size: $\sim 4.57$ Acres

Legend:

C-1 - Retail Commercial District

C-2 - General Commercial district

C-3 - Wholesale Commercial district

R-1 - Single Family Dwelling District

R-2 - Residential District

R-T - Mobile Home Park District

Bold line : Subject property 


\section{FUTURE LAND USE MAP Scenario \#2}

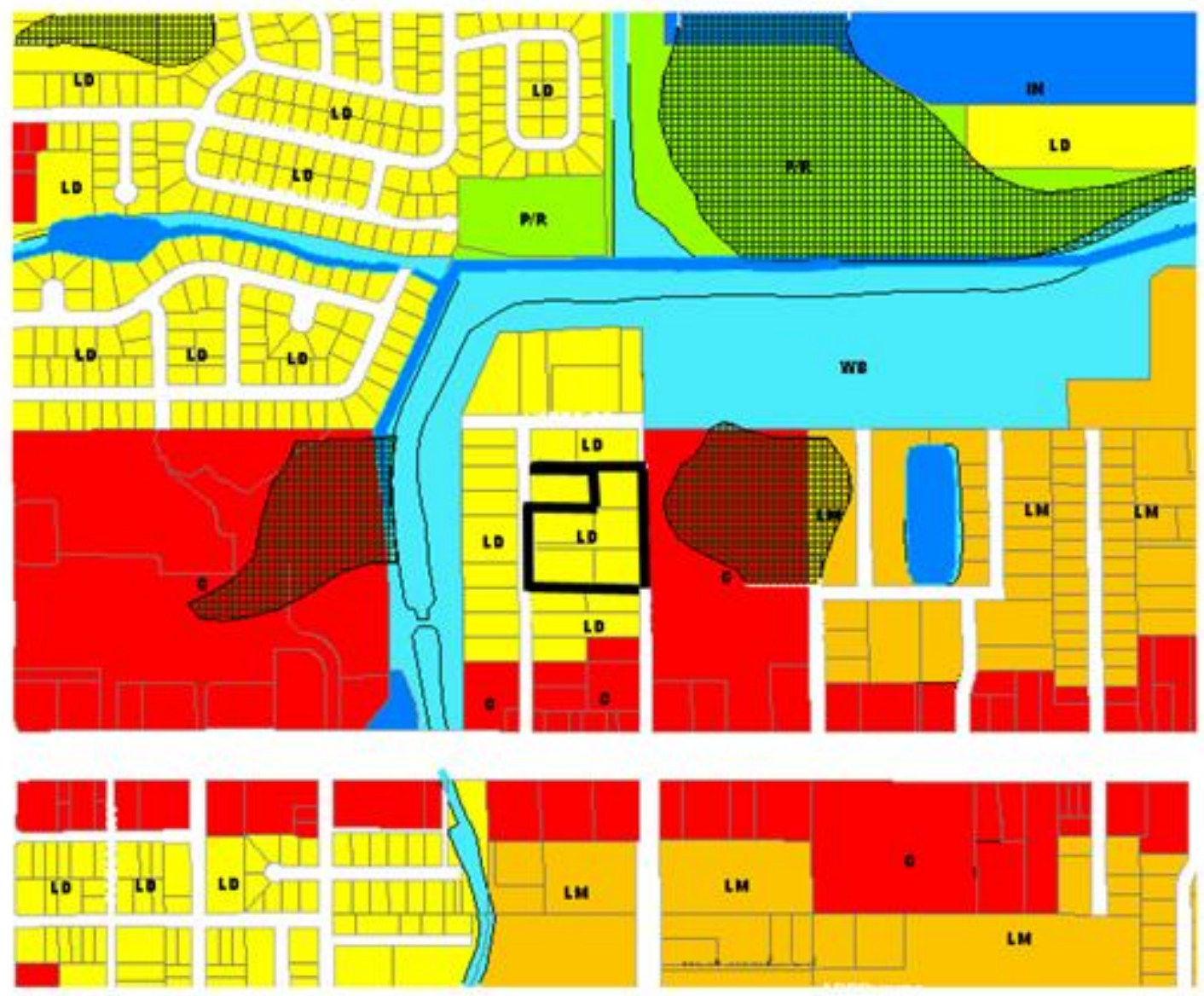

\begin{tabular}{|l} 
Request: \\
Applicant: Karen Brown \\
Address: East side of Central \\
Park Av., North of W \\
Manhattan \\
Tract Size: $\sim 4.57$ Acres
\end{tabular}

Legend.

LD - Low Density

LM - Low-Medium Density

IN - Industrial

$\mathrm{C}$ - Single Family Dwelling District

WB- Waterbodies

P/R - Park/Recreation

Bold line : Subject property 


\section{Prototype 3 - Scenario \#3}

Mr. Jim Courtney owns about 2 acres which are currently zoned as A-2 (Farmland Rural). He would like to rezone his property to R-2 (Medium density residential). He would like to build a second dwelling on this property. Currently, the property has an accessory building on it.

\section{GENERAL INFORMATION}

APPLICANT Jim Courtney

REQUEST A-2 (Farmland Rural - Max 1du/10ac) (1957) to R-2 (Residential District - Max 10du/ac)

Maximum density represents the number of units in zoning category as indicated in the FLUM.

LOCATION North side of Burger Road and South Alligator Trail intersection or 6200 Burger Road

PARCEL ID NUMBER(S) 21-22-03-0000-00-68/69

TRACT SIZE $\sim 2$ acres

PROPOSED USE Convert accessory building to a $2^{\text {nd }}$ dwelling at 6200 Burger Road.

IMPACT ANALYSIS

Land Use Compatibility The proposed R-2 (Residential District) zoning would allow land uses that are incompatible with the existing development in the area.

Comprehensive Policy Plan Consistency
The CPP Future Land Use Map designates this location as Low Density Residential (LD). The R-2 zoning district is inconsistent with this land use designation.

\section{PUBLIC NOTIFICATION}

The notification area for this zoning request was 500 feet.

$>$ Number of notices mailed to property owners in the mailing area: 39

$>$ Number of signatures appearing on a petition in favor of the proposed request: 25

$>$ Number of responses opposing the request: 0

$>$ Number of responses in favor of the request: 25

Concerns of the public: NA 


\section{SITE DATA}

Existing Use

Adjacent Zoning

Adjacent Land Uses
Single family dwelling, barn, and shed

N: A-2 (Farmland Rural) (1957)

E: R-2 (Residential District) (1981)

- $\quad$ Restricted to single family residences and/or duplexes

W: R-2 (Residential District) (1989)

S: $\quad$ R-2 (Residential District) (1981)

- $\quad$ Restricted to single family residences and/or duplexes

$\mathrm{N}$ : Single family dwelling

E: Single family dwelling

W: Single family dwelling

S: $\quad$ Single family dwelling

\section{ZONING DISTRICT STANDARDS (R-2)}

R-2 District Standards Two Dwelling Units

Permitted Uses
Minimum Lot Area: 8,000 square feet

Minimum Lot Width: 80 feet

Maximum Height: 35 feet

Minimum Setbacks

Front Yard:

Rear Yard:

Side Yard:
25 feet

25 feet

6 feet

Single-family homes, fee-simple duplex and patio homes, home occupations (as defined in Sec. 38-1, O.C. Code), swimming pools, multifamily w/ customary accessory uses, etc.

\section{SPECIAL INFORMATION}

\section{Subject Property}

Single family dwelling and a shed.

Comprehensive Policy Plan Amendment - NA

Rural Settlement - NA

Overlay District Ordinance - NA 


\section{Environment Data}

Soils

(35) Pomello fine sand, 0-5\% slopes, moderately well drained

(54) Zolfo fine sand, 0-2\% slopes, somewhat poorly drained.

\section{Endangered Species - NA}

Wetlands/Floodplain/Waterbodies - NA

\section{Transportation/Access}

Street/Thoroughfare Existing

Brunner Road

Principal Arterial, Urban

\section{$\frac{\text { Proposed }}{\text { N/A }} \quad \frac{\text { CIP }}{\text { N/A }}$}

Count: $\quad 2001$ Peak Directional Count for Brunner Rd. from Burger Road to Coral reef Drive is 1,656 .

Capacity: $\quad$ The capacity for Brunner Road from Coral reef Drive to Burger Road is 1,850 .

Remaining capacity is approximately 194 trips (3-8-4).

The Proposed request will not negatively affect transportation and access roads.

Water/Wastewater/Reclaim

Water: $\quad$ 10” PVC on Burger Rd (approx. 200’ away)

Wastewater: $\quad$ 12” PVC on Pastel Dr. (approx. 350’ away)

Reclaim: N/A

Water Capacity

The Proposed request will not negatively affect water capacity.

Schools*

Projected School Age Population $\sim 8$

The net increase in the number of students generated from the change in zoning from A-2 to R-2 is insignificant and will not negatively impact school capacity.

Name

Reagan Elementary School

Carnegie Middle School
Distance

$\sim 1.45$ miles

$\sim 3.54$ miles

- 183 -
Capacity Enrollment

580

689

$1,217 \quad 1,387$ 
Coral High School

$\sim 2.77$ miles

2,825

2,364

* Source Orange County Public School Enrollment Summary-dated 05/14/04

\section{Parks \& Recreation}

Name

\section{Distance}

Alligator Trail Head

$\sim 1.95$ miles

Airport Noise Zone

The subject property is not located in an Airport Land Use Zone. 


\section{ZONING MAP}

Scenario \#3

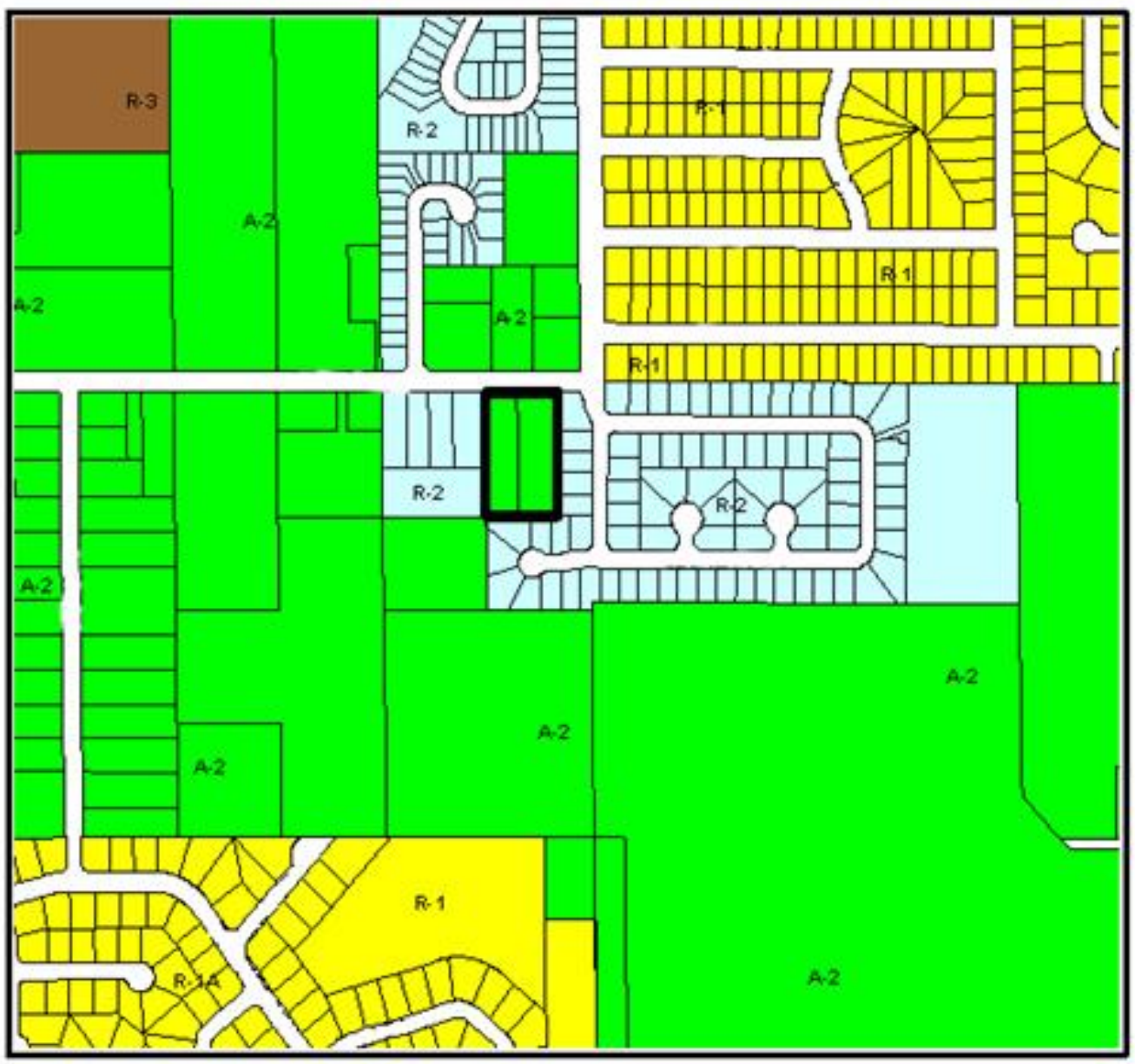

Request: A-2 to R-2

Applicant: Jim Courtney Address: 8020 Bates Road

Tract Size: $\sim 2$ Acres
Legend:

A-1 - Citrus Rural - 1du/10ac

A-2 - Farmland Rural - 1du/10ac

R-1, R-1A - Single Family Dwelling District 4dulac

R-2 - Residential District - 10du/ac

Bold line : Subject property 
FUTURE LAND USE MAP Scenario \#3

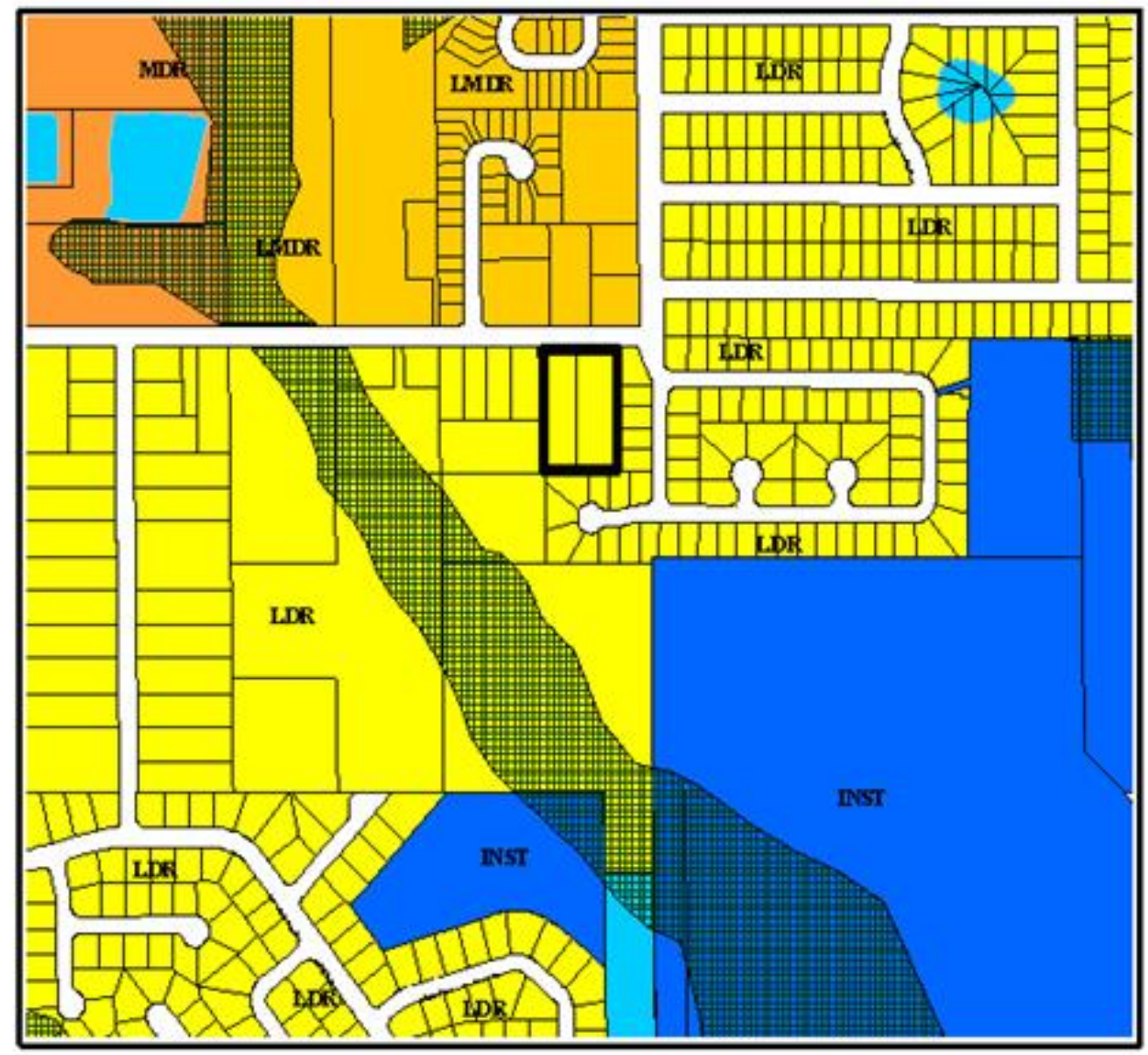

Request: A-2 to R-2

Applicant: Jim Courtney Address: 8020 Bates Road

Tract Size: $\sim 2$ Acres
Legend:

LDR - Low Density Residential INST - Institutional LMDR - Low-Medium Density Residential MDR - Medium Density Residential 曲 - Conservation

Bold line : Subject property 


\section{APPENDIX L: PROCESS EVALUATION INTERVIEW QUESTIONS}


1. What is your reaction to this type of design process? What the strengths and weakness of this process?

2. Do you think it would be useful for Orange county staff to use this type of design process in the future? If so for what type of problems do you think it is appropriate? Inappropriate?

3. Would you suggest any modifications or improvements for this design process?

These questions were adapted from Mason (1968). 


\section{APPENDIX M: IRB APPROVAL FORM}




\section{IRB COMMITTEE APPROVAL FORM FOR UCF/OOR/IRB USE ONLY}

PI(s) Name: Duafaa Elgarah

Title: A Dialectical Methodology for Decision Support Systems Design: Theory and Application in an E-government Context.

Check as applicable (optional):

L ]Yes [ ]No

[ ]Yes [ ]No

[ ]Yes I jNo

[ ]Yes [ ]No
Have sufticient assurances been given to the committee to establish that the potential value of this research excecds the risks involved?

Written and oral presentations must be given to participating subjects (parents or guardians, if minors) informing them of the protocol, possible risks involved, the value of the researeh, and the right to withdraw at any time.

A signed written consent must be obtained for each human subject participant.

Are cooperating institutions involved? If yes, was there a sheet attached providing the name of the institutions, the number and status of participants, name of the involved official of the institution, telephone, and other pertinent information?

\section{Committee Members:}

Dr. Theodore Angelopoulos:

Ms. Sandra Browdy:

[ ] Contingent Approval Dated:

Dr. Ratna Chakrabarti:

Dr. Karen Dennis:

De. Barbara Fritzsche:

Dr. Robert Kennedy:

Dr. Gene Lee:

Ms. Gail McKinney:

Dr. Debra Reinhar:

Dr. Valerie Sims:

[x] Expedited Dated: 13 Nov 2003

[ ] Exempt Dated:

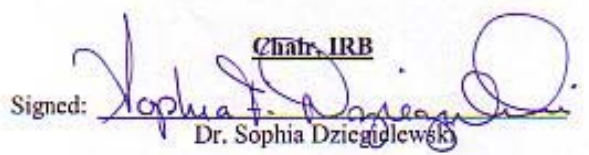




\section{LIST OF REFERENCES}

References denoted with * represent the studies shown in Table 10.

Ackoff, R. L., The Art of Problem Solving. Accompanied by Ackoff's Fables, New York, John Wiley \& Sons, 1978.

Alter, S.L., Decision Support Systems: Current Practice and Continuing Challenge. Reading, MA: Addison-Wesley, 1980.

* Ahituv, N. "A systematic approach toward assessing the value of an information system,” MIS Quarterly, 1980, pp. 61-75.

Ata, M., A Knowledge-Based Decision Support System for Managerial Problem Recognition and Diagnosis, Unpublished Ph.D. dissertation, Texas Tech University, Information Systems \& Quantitative Sciences Department, Lubbock, TX, 1985.

Ata, M., Courtney, J.F., and Paradice, D.B., "A Prototype DSS for structuring and Diagnosing Managerial Problems," IEEE Transactions on Systems, Man, and Cybernetics 18, 6, Nov/Dec, 1988, pp. 899-907.

Avison, D.E., Francis L., Myers, M., and Nielson, P.A. "Action Research," Communications of the ACM, (42:1), January 1999, pp. 94-97.

Avison, D.E. \& Fitzgerald, G., "Information Systems Practice, Education and Research," Journal of Information Systems January, (1:1), 1991, pp. 5-17.

Avison, D. E. and Wood-Harper, A.T. Multiview: an Exploration in Information Systems Development. McGraw-Hill, Maidenhead. 1990.

Avison, D. E. and Fitzgerald, G., Information systems development: methodologies, techniques and tools. McGraw-Hill Book Company Europe, $2^{\text {nd }}$ edition, Berkshire, England, 1995.

Avison, D.E., Baskerville, R. and Myers, M.D. "Controlling action research projects," Information Technology \& People, (14:1), 2001, pp. 28-45.

* Bailey, J. E. and Pearson, S. W., "Development of a Tool for Measuring and Analyzing User Satisfaction,” Management Science, (29:5), 1983, pp. 530-545.

Baldwin, D., “Applying multiple views to information systems: A preliminary framework,” Data Base, (24:4), 1993, pp. 15-30.

Ball, N.L., "Design Science II: The Impact of Design Science on E-commerce Practice and Research," Communications of the AIS, (7:2), July 2001. Retrieved July 26, 2005 from Communications of the AIS web site: http://cais.aisnet.org/articles/7-

2/default.asp?View=html\&x=57\&y=14. 
* Baroudi, J.J. and Orlikowski, W.J. "A short-form measure of user information satisfaction: A psychometric evaluation and notes on use," Journal of Management Information Systems, (4:4), Spring 1988, pp. 44-58.

Baskerville, R. L. "Investigating information systems with action Research,” Communications of AIS, (2:19), 1999.

Baskerville, R., Wood-Harper, T., "A critical perspective on action research as a method for information systems research,” Journal of Information Technology, (11:3), July 1996, pp. $235-246$

Baskerville, R.L. and Wood-Harper, A.T. "Diversity in information systems action research methods," European Journal of Information Systems (7:2), 1998, pp. 90-107.

Benbasat, I., and Zmud, R "Empirical Research in Information Systems: The Practice of Relevance," MIS Quarterly (32:1), March 1999, pp. 3-16.

Bjerknes, G., Ehn, P., and Kyng, M., Eds. Computers and Democracy. Avebury, Aldershot, U.K., 1987.

* Blaylock, B.K. and Rees, L.P. “Cognitive style and the usefulness of information,” Decision Sciences, (15:1), Winter 1984, pp. 74-91.

Burstein, F. and Gregor, S. "The Systems Development or Engineering Approach to Research in Information Systems: An Action Research Perspective," Proceedings of the Australian Conference on Information Systems, 1999, Victoria University, Wellington, NZ, pp. 122-134.

Carlsson, C., "Some Features of a Methodology for Dealing with Multiple-Criteria Problems," Theory and Practice of Multiple Criteria Decision Making, Carlsoon, C. and Kochetkov, Y., 1983, North-Holland Publishing Company, Amerterdam.

Chae, B., Courtney, J. F. "Hegelian Inquiring Organizations: Design Guidelines, Guiding Principles, and IT Support," Proceedings of the AMCIS Conference, 2000, pp. 1497-1502.

Checkland, P. B., Systems Thinking, Systems Practice. Wiley, Chichester, 1981.

Checkland, P. B. "Soft Systems Methodology," Human Systems Management, (8), 1989, pp. 273-289.

Churchman, C. W. The Design of Inquiring Systems, Basic Books, Inc., New York, 1971.

Cosier, R.A, "Methods for improving the strategic decision: Dialectic versus the devil's advocate," Strategic Management Journal, (3), 1982, pp. 173-374.

Courtney, J. F. "Decision-Making and Knowledge Management in Inquiring Organizations: A New Decision-Making Paradigm for DSS," Decision Support Systems: Special Issue on Knowledge Management, (31), 2001, pp. 17-38. 
Courtney, J.F., Richardson, S. and Paradice, D.B. "Decision Support Systems for Ecosystems Management: A Singerian Approach to Urban Infrastructure Decision Making" A Handbook of Sustainable Development Planning: Studies in Modeling and Decision Support, M. Quaddus and A. Siddique (Eds), Northamton, MA: Edward Elgar Publishers, forthcoming.

Courtney, Jr., J.F. and Paradice, D.B. "Studies in Managerial Problem Formulation Systems," Decision Support Systems, (9:4), June, 1993, pp. 413-423.

Davis, F., "Perceived Usefulness, Perceived Ease of Use, and User Acceptance of Information Technology,” MIS Quarterly, (13:3), 1989, pp. 319-340.

DeLone, W. H. and McLean, E. R. "Information Systems Success: The Quest for the Dependent Variable," Information Systems Research, (3:1), March 1992, pp. 60-95.

DeLone, W. H. and McLean, E. R. "Information Systems Success: A Ten-Year Update," Journal of Management Information Systems (19:4), Spring 2003, pp. 9-30.

DeSanctis, G., Poole, M.S., “Capturing the complexity in advanced technology use: adaptive structuration theory,” Organization Science, 1994, (5:2), pp. 121-145.

Doll, W.J., and Torkzadeh, G. “The Measurement of End-user Computing Satisfaction,” MIS Quarterly, (12:2), June 1988, pp. 259-274.

Eom, S., Decision Support Systems Research (1970-1999): A Cumulative Research Tradition and Reference Disciplines, published in June 2002 by Edwin Mellen Press of Lewiston, New York.

Epstein, B.J. and King, W.R. “An experimental study of the value of information,” Omega, (10:3), 1982, pp. 249-258.

Fielden, G.D.R., Engineering Design, 1975.

Ford, J. D. and Ford, L. W. "Logics of Identity, Contradictions, and Attraction in Change," Academy of Management Review, (19:4), October 1994, pp. 756.

Freeman, R.E., Strategic Management: A Stakeholder Approach. 1984, Cambridge, Mass.: Ballinger.

* Gallagher, C.A., "Perceptions of the value of a management information system,” Academy of Management Journal, March 1974, pp. 46-55.

Galliers, R.D. and Land, F.F., "Choosing Appropriate Information Systems Research Methodologies," Communications of the ACM, (30:11), 1987, pp. 900-902.

Gant, J.P. and Gant, D.B. "Web Portals and Their Role in E-Government,” Proceedings of the AMCIS Conference, 2001, pp 1617-1623.

Garrity, E.J. and G. L. Sanders (Eds.), Information Systems Success Measurement, Idea Group Publishing, Hershey, PA, (1998). 
Gregg, D.G., Kulkarni, U.R., and Vinze, A.S., "Understanding the Philosophical Underpinnings of Software Engineering Research in Information Systems," Information Systems Frontiers, (3:2), 2000, pp.169-183.

* Goodhue, D.L., "Development and measurement validity of a Task-Technology Fit Instrument for User Evaluations of Information System,” Decision Sciences, (29:1), Winter 1998, pp. 105-138.

Gorry, A. and Morton, S., “A framework for management information systems,” Sloan Management Review, 13(1), 1971, pp. 55-70.

Haynes, J.D., "Calculative Thinking and Essential Thinking in Heidegger's Phenomenology," AMCIS Proceedings, 2001, Dallas.

Haynes, J.D. Perspectival Thinking : For Inquiring Organisations, published by This One and Company Ltd., New Zealand, 2000.

Hirschheim, R. and Klein, H.K., "Four Paradigms of Information Systems Development," Communications of the ACM, (32:10), October 1989, pp. 1199-1216.

Hirschheim, R. and Klein, H.K., "Realizing Emancipatory Principles in Information Systems Development: The Case for ETHICS," MIS Quarterly, (18:1), March 1994, pp. 83-109.

Hirschheim, R., Iivari, J. and Klein, H.K., "A Comparison of Five Alternative Approaches to Information Systems Development," AJIS, (15:1), September 1997, pp.1-27.

Hult, M. and Lennung, S-A. "Towards a Definition of Action Research: A Note and Bibliography," Journal of Management Studies, (17:2), May 1980, pp. 241-250.

Iivari, J., Hirschheim, R. and Klein, H.K., "A Dynamic Framework for Classifying Information Systems Development Methodologies and Approaches," Journal of Management Information Systems, (17:3), Winter 2000/2001, pp. 179-218.

Iivari, J., Hirschheim, R. and Klein, H.K., "A Paradigmatic Analysis Contrasting Information Systems Development Approaches and Methodologies," Information Systems Research, (9:2), June 1998, pp. 164-193.

* Iivari, J, and Koskela, E."The PIOCO model for information systems design,” MIS Quarterly, September 1987, pp.401-419.

* Ives B., Olson M.H.J. and Baroudi J.J., "The measurement of user information satisfaction," Management Science, (26:10), 1983, pp. 785-793.

Jennex, M., Olfman, L, Panthawi, P., and Park, Y. "An Organizational Memory Information Systems Success Model: An Extension of DeLone and McLean's I/S Success Model,” HICSS (1) 1998: 157-165.

* Jones, J. W., \& McLeod, R., "The structure of executive information systems: An exploratory analysis,” Decision Sciences, (17:2), 1986, pp. 220-249. 
Karsak, E.E.,” Distance-based fuzzy MCDM approach for evaluating flexible manufacturing system alternatives,” International Journal of Production Research, (10:13), 2002, pp. 31673181.

Keen, P. G. W. "MIS Research: Reference Disciplines and a Cumulative Tradition," Proceedings of the First International Conference on Information Systems, 1980, pp. 9-18.

Keen, P.G.W. 1980. "Adaptive Design for Decision Support Systems," Data Base, (12), Fall 1980, pp.15-25.

Keen, P.G.W., "Let.s focus on action not info,” online, http://www2.computerworld.com/ home/cwlaunch.nsf/launch?RealForm\&/home/print9497.nsf/ November 17, 1997.

Keen, P. G. W. and M. S. Scott Morton, Decision Support Systems: An Organizational Perspective. Reading, MA: Addison-Wesley, Inc., 1978.

Kelly, K. New Rules for the New Economy, New York, Penguin Books. 1998.

* King, W.R. and Epstein, B.J. “Assessing information system value: An experimental study,” Decision Sciences, 14, 1983, pp. 34-45.

Kuhn, Thomas, S., The Structure of Scientific Revolutions, The University of Chicago Press, Chicago, 1962.

* Larcker D.F. and Lessig V.P., "Perceived usefulness of information: a psychometric examination," Decision Sciences, (11:1), 1980, pp. 121-134.

Lau, F. "A Review on the Use of Action Research in Information Systems Studies," in Information Systems and Qualitative Research, A.S. Lee, J. Liebenau and J.I. DeGross (eds.), Chapman and Hall, London, 1997, pp. 31-68.

* Lee, Y., Strong, D., Kahn, B. and Wang, R. “AIMQ: A Methodology for Information Quality Assessment,” Information \& Management, (40), 2002, pp. 133-146.

Linstone, H. A. Decision Making for Technology Executives, Artech House, Boston, London, 1999.

Little, J. D. C., "Models and Managers: The Concept of a Decision Calculus," Management Science, (16:8), April 1970, pp. B466-485.

Loy, S.L., An Experimental Investigation of a Graphical Problem-Structuring Aid and the Nominal Group Technique for Group Decision Support Systems, Unpublished Ph.D. Dissertation, Texas Tech University, Information Systems \& Quantitative Sciences Department, Lubbock, TX, 1986.

* Mahmood, M, A and Medewitz, J.N. "Impact of design methods on decisions support systems success: An empirical assessment,” Information \& Management, (9), 1985, pp. 137-151. 
* Mahmood, M.A. “System development methods: A comparative investigation,” MIS Quarterly, (11:3), September 1987, pp. 293-311.

Malhotra, Y. "Knowledge Management in Inquiring Organizations," Proceedings of 3rd Americas Conference on Information Systems, Indianapolis, August 1997, pp. 293-295.

Marakas, G.M., System Analysis and Design: An Active Approach, Prentice Hall, New Jersey, 2001.

March, S.T. and Smith, G.F., "Design and natural science research on information technology," Decision Support Systems, (15), 1995, pp. 251-266.

Markoczy, L., and Goldberg, J., “A method for eliciting and comparing causal maps,” Journal of Management, (21:2), 1995, pp 305-333.

Markus, M.L., Majchrzak, A., and Gasser, L., "A Design Theory for Systems That Support Emergent Knowledge Processes,” MIS Quarterly, (26:3), September 2002, pp. 179-212.

Mason, R. O. (1968). Dialectics in Decision Making: A Study in the Use of Counterplanning and Structured Debate in Management Information Systems. (Doctoral Dissertation, University of California, Berkeley, 1968).

Mason, R. O., "A dialectical approach to strategic planning," Management Science, (15), 1969, pp. 403-414.

Mason, R. O. and Mitroff, I. I. "A Program for Research on Management Information Systems," Management Science, (19:5), 1973, pp. 475-487.

Mason, R.O. and Mitroff, I.I., Challenging Strategic Planning Assumptions. 1981. WileyInterscience, New York.

McKinney, R.H. "The Origins of Modern Dialectics," Journal of The History of Ideas, (44), 1983, pp. 179-192.

Miles, M. and Huberman, A. An expanded sourcebook qualitative data analysis, $2^{\text {nd }}$ edition, Sage, Thousand Oaks, CA, 1994.

* Miller, J. and B. A. Doyle. "Measuring the Effectiveness of Computer-Based Information System in the Financial Services Sector,” MIS Quarterly, (11:1), 1987, pp.107-124.

Mitroff, I. I. and Linstone, H. A. The Unbounded Mind: Breaking the Chains of Traditional Business Thinking, Oxford University Press, New York, 1993.

Mitroff, I.I., Emshoff, J.R., and Lawler, E.E., "Assumptional analysis: A methodology for strategic problem solving," Management Science, (25), 1979, pp. 583-593.

Moore, J.H. and Chang, M.G., “Design of Decision Support Systems,” Database,(12:1), 1980, pp. 8-14. 
Mumford, E.,Designing Human Systems: The EHTICS Method, Manchester Business School, Manchester, United Kingdom, 1983.

Mumford, E. Job satisfaction: A method of analysis. In Designing Organizations for Satisfaction and Efficiency, K. Legge and E. Mumford, Eds. Gower Press, Teakfield, U.K., 1978, pp.1835 .

Mumford, E. and Henshall, D., A participative approach to computer systems design, Associated Business Press, London, 1979.

NPR, 1993, Report of the National Performance Review, Washington, DC: Government Printing Office, p.v.

Nunamaker, J.F. and Chen, M., "Systems Development in Information Systems Research," IEEE, 1990, 631-639.

Nunamaker, J.F., Chen, M., and Purdin, T.D., "Systems Development in Information Systems Research," Journal of Management Information Systems, (7:3), Winter 1991, pp. 89-106.

Olle, T.W., Sol, H.G., and Verrijn-Stuart, A.A., Information Systems Design Methodologies: A Comparative Review, Amesterdam Noeth-Holland, 1986.

Orlikowski, W.J. \& Baroudi, J.J. "Studying Information Technology in Organizations: Research Approaches and Assumptions," Information Systems Research, (2) 1991, pp. 1-28.

Orlikowski, W. J., "CASE Tools as Organizational Change: Investigation Incremental and Radical Changes in Systems Development,” MIS Quarterly, (17:3), September 1993, pp. 309-340.

Orlikowski, W.J. and C.S. Iacono, "Desperately seeking the 'IT' in IT research- a call to theorizing the IT artifact," Information Systems Research, (12:2), 2001, pp. 121-134.

Paradice, D.B. and Courtney, J.F., "Controlling Bias in User Assertion in Expert Decision Support Systems for Problem Formulation," Journal of Management Information Systems, (3:1), Summer 1986, pp. 52-64.

Paradice, D.B. and Courtney, J.F., "Causal and Non-Causal Relationshis and Dynamic Model Construction in a Managerial Advisory System," Journal of Management Information Systems, (3:4), Summer 1987, pp. 39-53.

Paradice, D.B. and Davis, R.A., "Modeling multiple perspectives in complex decision-making environments,” January 2003.

Parkan, C. and Wu, M., "Comparison of three modern multicriteria decision-making tools," International Journal of Systems Science, (31:4), April 2000, pp.497-517.

Parker, C.,Wafula, E.,Swatman, P. and Swatman, P. "Information systems research methods: The technology transfer problem," Proceedings of the 5th Australian Conference on 
Information System, 1994, Caulfield, Vic., Monash University, Department of Information Systems, 197-208.

Porat, A., \& Hass, J., “Information effects on decision making,” Behavioral Science, (14), 1969, pp. 98-104.

Pracht, W.E., "GISMO: A Visual Problem Structuring and Knowledge Organization Tool," IEEE Transactions on Systems, Man, and Cybernetics, (16), 1986, pp. 265-270.

Pracht, W.E. and Courtney, J.F., "The Effects of an Interactive, Graphic-Based DSS to Support Problem Structuring," Decision Sciences, (19:3), Summer 1988, pp. 598-621.

* Rainer, R. K., and Watson, H. J., "The Keys to Executive Information Systems Success," Journal of Management Information Systems (12:2), 1995, pp. 83-98.

Rapoport, R.N. "Three Dilemmas in Action Research," Human Relations, (23:4), 1970, pp. 499513.

Redman, T.C., "The impact of poor data quality on the typical enterprise," Communications of the ACM, (41:2), 1998, pp. 79-82.

Robey, D. and Markus, M.L. "Beyond Rigor and Relevance: Producing Consumable Research about Information Systems," Information Resources Management Journal, (11:1), Winter 1998, pp.7-15.

Rittel, H. W. J., and Webber, M. M. "Dilemmas in a General Theory of Planning," Policy Sciences, (4), 1973, 155-169.

Rivard, S. and Huff, S.L., "User developed applications: evaluation of success from the DP department perspective,” MIS Quarterly, (8:1), March 1984, pp. 533-542.

Saaty, T.L. (1995), Decision Making for Leaders, RWS Publications, Pittsburgh

Salzman, H., and Rosenthal, S.R. Software by Design, Oxford University Press, New York, 1994.

Sanders , G.L., and Courtney, J.F. "A Field Study of Organization Factors Influencing DSS Success," MIS Quarterly, (9:1), 1985, pp. 77-93.

Saunders, C. "The Role of Business in IT Research," Information Resources Management Journal, (11:1), 1998, pp. 4-6.

Schweiger, D. M., Sandberg, W. R., \& Ragan, J. W., "Group approaches for improving strategic decision making: A comparative analysis of dialectical inquiry, devil's advocacy, and consensus," Academy of Management Journal, (29), 1986, pp. 51-71.

Seddon, P.B. "A Respecification and Extension of the DeLone and McLean Model of IS Success," Information Systems Research, (8:3), 1997, pp.240-253. 
Shim, J.P., Warkentin, M., Courtney, J.F., Power, D.J., Sharda, R., and Carlsson, C., "Past, present, and future of decision support technology,” Decision Support Systems, (33), 2002, pp. 111-126.

Smith, H.H., "The citizen's Guide to Planning," American Planning Association, Planners Press, Chicago, IL, 1979.

Snavely, H.J. “Accounting Information Criteria,” The Accounting Review, (42:2), April 1967, pp. 223-232.

Simon, H.A. The Sciences of the Artificial, 1969, Massachusetts Institute of Technology.

Singer, P. Hegel, Oxford University Press, Oxford, 1983.

Singleton, R. A., \& Straits, B. C. 1999. Approaches to Social Research. (3rd ed.). New York: Oxford University Press.

Susman, G.I. "Action Research: A Sociotechnical systems perspective," in Beyond Method: Strategies for Social Science Research, G. Morgan (ed.), Sage Publications, London, 1983.

Susman, G.I. and Evered, R.D. "An Assessment of the Scientific Merits of Action Research," Administrative Science Quarterly, (23), 1978, pp. 582-603.

Sprague, R, H., Jr., "A Framework for the Development of Decision Support Systems," Management Information Systems Quarterly, (4:4), December 1980, pp. 1-26.

* Srinivasan, A. “Alternative measures of systems effectiveness: Associations and Implications," MIS Quarterly, (9:3), September 1985, pp. 243-253.

Streufert, S., "Effects of information relevance on decision making in complex environments" Memory and Cognition, (1), 1973, pp. 224-228.

* Swanson, E.B.,’Management information systems: Appreciation and involvement," Management Science, (21:2), October, 1974, pp.178-188.

* Teo, S. T. and P. K. Wong, “An Empirical Study of the Performance Impact of Computerization in the Retail Industry," Omega International Journal of Management Science, (26), 1998, pp. 611-621.

Turban, E. and Aronson, J., Decision Support Systems and Intelligent Systems. Prentice-Hall, USA, 1998.

Van de Ven, A. H., and Poole, M. S. "Explaining Development and Change in Organizations," Academy of Management. The Academy of Management Review; Mississippi State; Jul 1995.

Von Bulow, I., "The bounding of a problem situation and the concept of a system's boundary in soft system methodology," Journal of Applied Systems Analysis, (16), 1989, pp. 35-41.

Walls, J.G., Widmeyer, G. R., and El Sawy, O.A. "Building an Information System Design Theory for Vigilant EIS," Information Systems Research, (3:1), 1992, pp. 36-59. 
Weber, R., "Toward a Theory of Artifacts: A Paradigmatic Basis for Information Systems Research,” The Journal of Information Systems (1:2), 1987, pp. 3-19.

Whetten, D.A. “What constitutes a theoretical contribution?” Academy of Management Review, 14(4), 1989, pp. 490-495.

* Wixom, B. H., Watson, H.J. "An Empirical Investigation of the Factors Affecting Data Warehousing Success,” MIS Quarterly, (25:1), March 2001, pp. 17-41.

Wood-Harper, T. "Comparison of Information Systems Definition Methodologies: An Action Research Multiview Perspective,” University of East Anglia Ph.D. Thesis, 1989.

* Zmud R.W., "An empirical investigation of the dimensionality of the concept of information," Decision Sciences, (9:2), 1978, pp. 187-195. 